\title{
Assessing the feasibility of home administration of misoprostol in the prevention of postpartum hemorrhage in rural Pakistan
}

\author{
Ali M. Mir \\ Population Council \\ Abdul Wajid \\ Population Council \\ Sadaf Gull \\ Population Council
}

Follow this and additional works at: https://knowledgecommons.popcouncil.org/departments_sbsr-rh

Part of the Community-Based Research Commons, Family, Life Course, and Society Commons, International Public Health Commons, Maternal and Child Health Commons, Obstetrics and Gynecology Commons, and the Women's Health Commons How does access to this work benefit you? Let us know!

\section{Recommended Citation}

Mir, Ali M., Abdul Wajid, and Sadaf Gull. 2010. "Assessing the feasibility of home administration of misoprostol in the prevention of postpartum hemorrhage in rural Pakistan." Islamabad: The PAIMAN Project, JSI Research and Training Institute. 


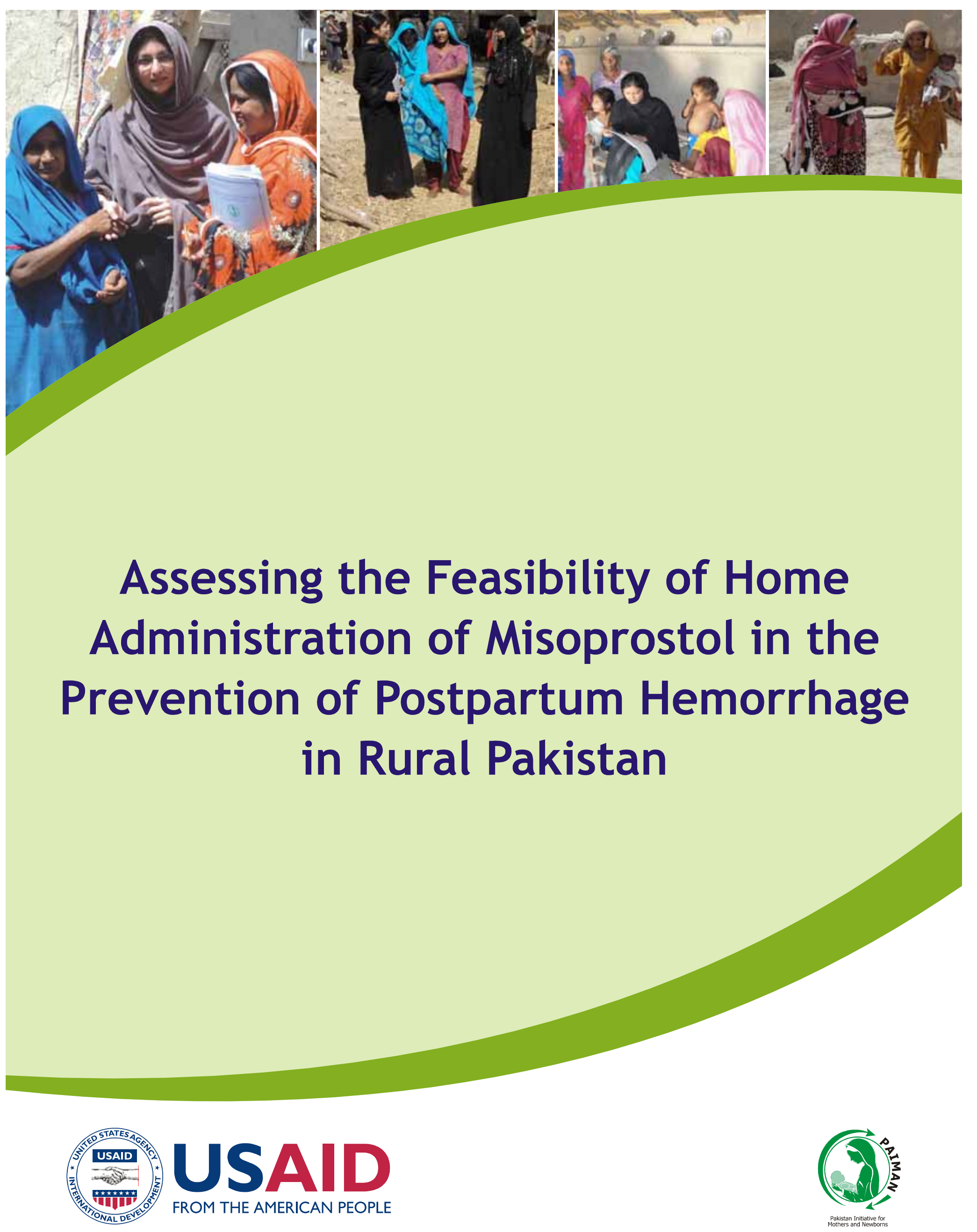



Assessing the Feasibility of Home
Administration of Misoprostol in
the Prevention of Postpartum
Hemorrhage in Rural Pakistan

Ali Mohammad Mir

Abdul Wajid Sadaf Gull 
Copyright (C 2010 by The PAIMAN Project, JSI Research and Training Institute, Inc.- All Rights Reserved Any part of this publication may be reproduced or translated by duly acknowledging the source.

The PAIMAN Project is funded by the United States Agency for International Development and implemented by JSI Research \& Training Institute, Inc. in conjunction with Aga Khan University, Contech International, Save the Children, US, The Population Council, and Johns Hopkins University/CCP

This report was prepared by the Population Council, an international, non-profit, non-governmental organization established in 1952, seeks to improve the well-being and reproductive health of current and future generations around the world and to help achieve a humane, equitable, and sustainable balance between people and resources.

The Council analyzes population issues and trends; conducts research in the reproductive sciences; develops new contraceptives; works with public and private agencies to improve the quality and outreach of family planning and reproductive health services; helps governments design and implement effective population policies; communicates the results of research in the population field to diverse audiences; and helps strengthen professional resources in developing countries through collaborative research and programs, technical exchange, awards, and fellowships.

\section{For inquiries, please contact:}

Population Council

\# 7, Street 62, F-6/3, Islamabad, Pakistan

Tel: 92518445566

Fax: 92512821401

Email:pcpak@popcouncil.org

Web: http://www.popcouncil.org

http://www.paiman.org.pk

Published: October 2010

\section{Disclaimer}

"This study/report is made possible by the generous support of the American people through the United States Agency for International Development (USAID). The contents are the responsibility of JSI Research \& Training Institute, Inc and do not necessarily reflect the views of USAID or the United States Government." 


\section{TABLE OF CONTENTS}

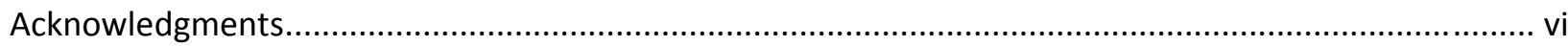

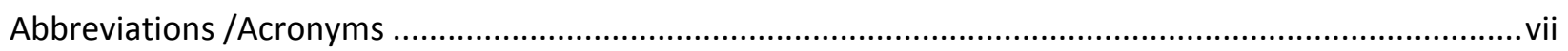

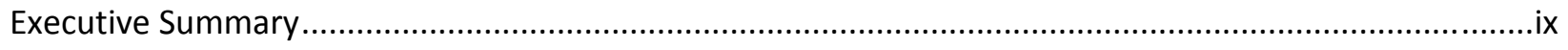

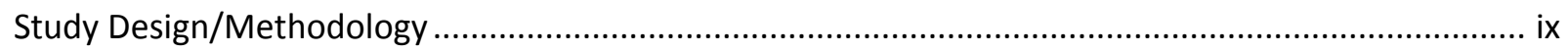

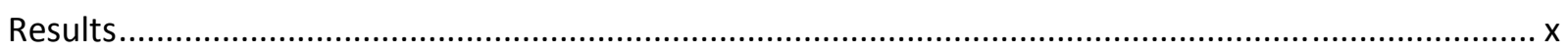

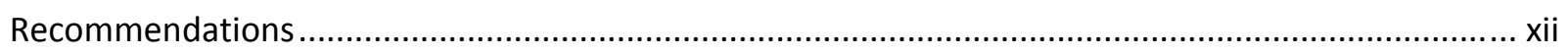

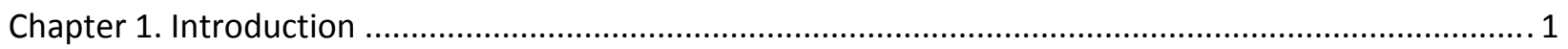

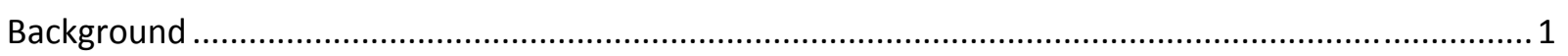

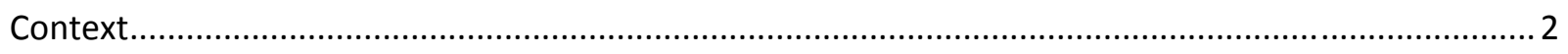

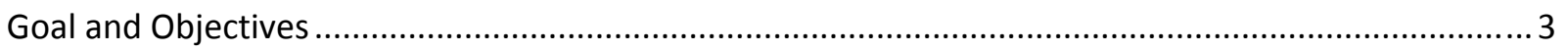

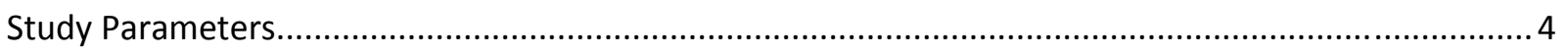

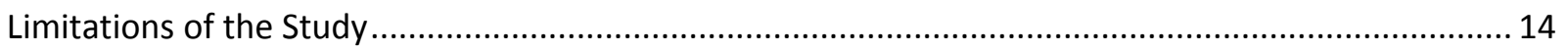

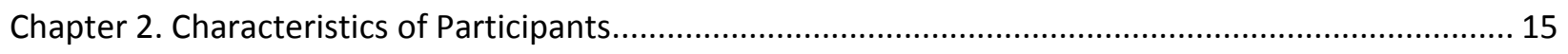

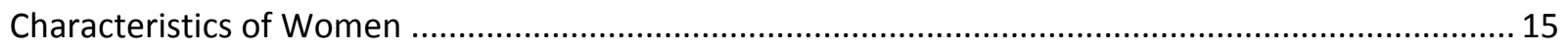

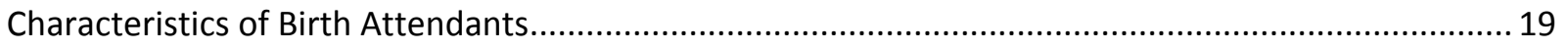

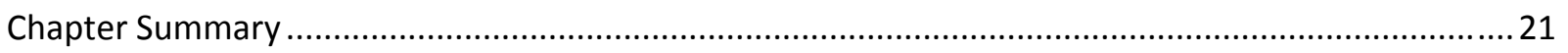

Chapter 3. Knowledge: Postpartum Hemorrhage and Misoprostol ..................................................... 23

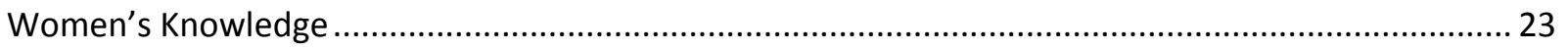

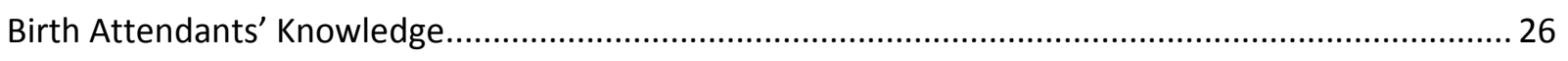

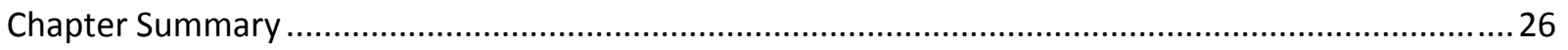

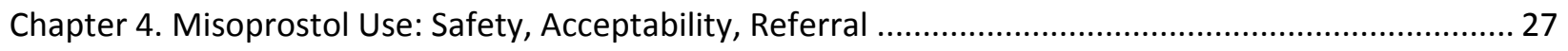

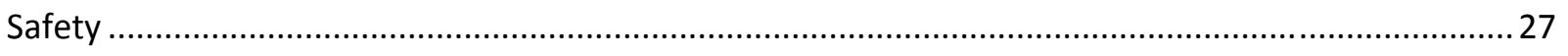

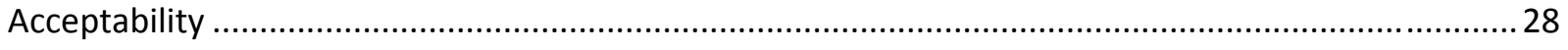

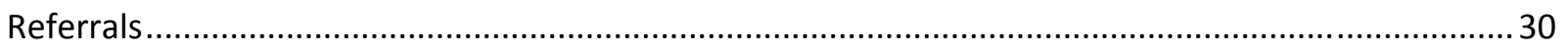

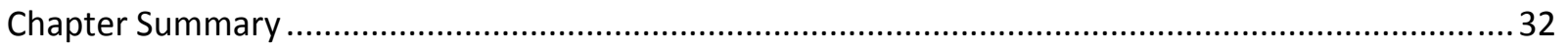

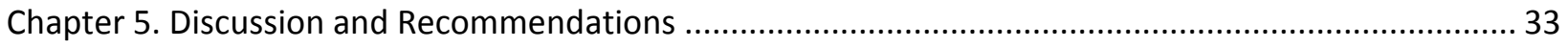

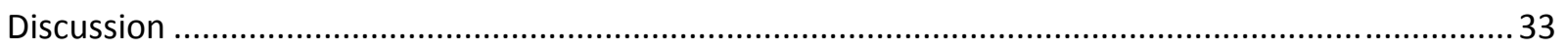

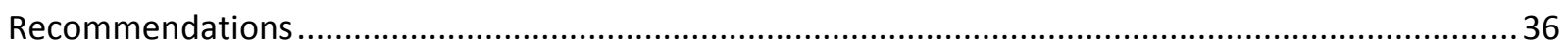

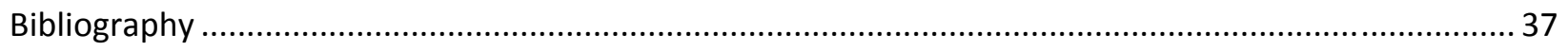

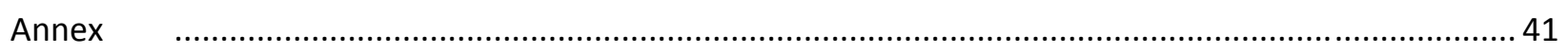

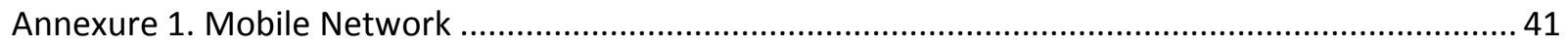

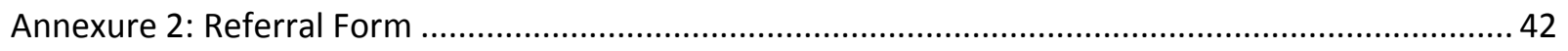

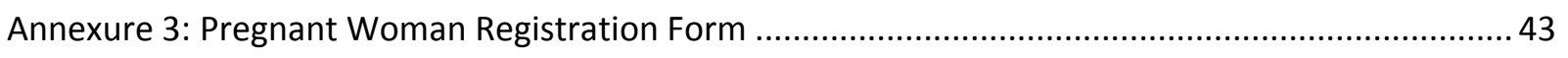

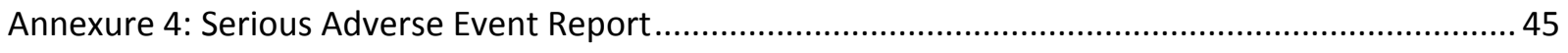

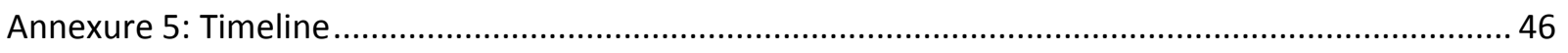

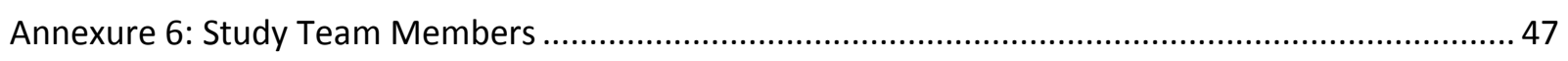

Annexure 7: Characteristics of Dadu and Khanewal districts .......................................................... 48

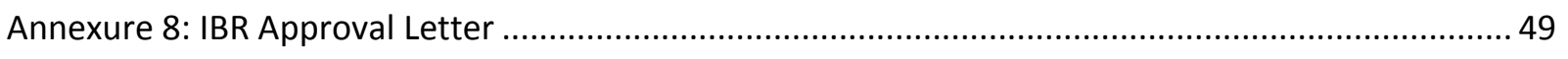

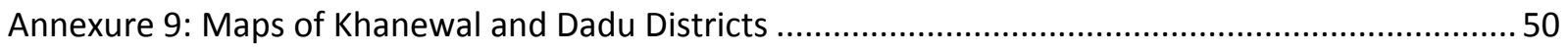

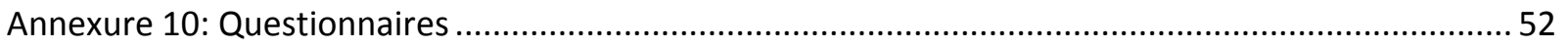




\section{List of Tables}

Table 1.1: Number of study participants who completed specified questionnaires/forms, according to areas

Table 2.1: Percentage distribution of husbands, by areas, according to occupation

Table 2.2: Percentage distribution of women, by areas, according to live births, stillbirths, abortions and antenatal care visits

Table 2.3: Percentage distribution of women, by areas, according to who provided their antenatal

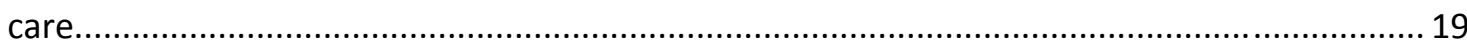

Table 2.4: Percentage distribution of women, by areas, according to checkup components ................... 19

Table 2.5: Percentage distribution of birth attendants, by areas, according to type............................... 20

Table 2.6: Percentage distribution of birth attendants, by areas, according to sociodemographic

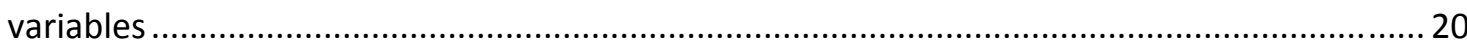

Table 3.1: Percentage distribution of women, by areas, according to perceptions and knowledge about postpartum hemorrhage

Table 3.2: Percentage distribution of women, by areas, according to knowledge about causes of $\mathrm{PPH}^{*}$

Table 3.3: Percent distribution of women in intervention areas, according to knowledge about misoprostol

Table 3.4: Percentage distribution of birth attendants, by areas, according to knowledge about PPH

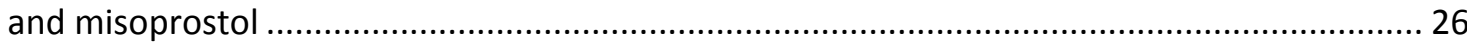

Table 4.1: Distribution of women according to misoprostol use and other variables .............................. 27

Table 4.2: Distribution of women who used misoprostol, according to variables of use ......................... 28

Table 4.3: Distribution of women who used misoprostol and delivered at home, according to

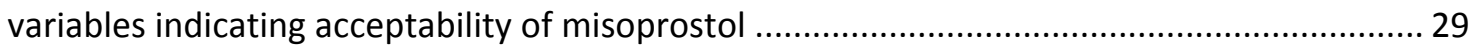

Table 4.4: Distribution of women, according to the main reason for not taking misoprostol................... 29

Table 4.5: Distribution of women, according to the amount (in Pakistan rupees) they would be

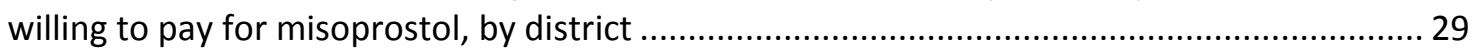

Table 4.6: Distribution of PPH referrals and deaths (as percents of all referrals and all deaths), by areas.....

Table 4.7: Distribution of women who had home deliveries, by areas, according to perception of excessive postpartum vaginal bleeding, by areas.

Table 4.8: Distribution of women who had home deliveries, by correct intake, incorrect intake and no intake of misoprostol tablets, according to perception of excessive postpartum vaginal bleeding.

Table 4.9: Distribution of all referrals in intervention and comparison areas, by cause. 


\section{List of Figures}

Figure 1.1: Study profile of pregnant women in Dadu and Khanewal districts ........................................ 6

Figure 1.2: Pictorial booklet/Pictorial instructional leaflet enclosed with CDKs ..................................... 11

Figure 2.1: Percentage distribution of women, by areas, according to age groups ................................ 15

Figure 2.2: Percentage distribution of women, by areas, according to education .................................. 16

Figure 2.3: Percentage distribution of husbands, by areas, according to education .............................. 17

Figure 2.4: Percentage distribution of birth attendants, by areas, according years of work experience .. 21 


\section{ACKNOWLEDGMENTS}

This operations research on assessing the feasibility of home administration of misoprostol in the prevention of postpartum hemorrhage in rural Pakistan was funded by the United States Agency for International Development (USAID) under the PAIMAN project.

A large number of individuals and institutions were involved in the various stages of project implementation and it is simply not possible to acknowledge by name everyone who made this study possible. We are very grateful to VSI Venture Strategies Innovations for donating 6,000 misoprostol tablets used in this research. We are also grateful for the support and help of all members of the Technical Advisory Group (TAG) who gave advice and guidance during all phases of this study. At the inception stage and during the initial review of the report we benefited from the suggestions and insights of international experts, including Dr. John Townsend, Vice President, Reproductive Health Program, Population Council, New York, and Dr. Anrudh Jain, Distinguished Scholar, Population Council, New York.

We would like to express our deep appreciation to colleagues at the Population Council. Dr. Zeba A. Sathar, Country Director, was the overall supervisor for the study and provided invaluable guidance and support. Dr. Arshad Mehmood, Director, Research, provided assistance with the study design and sampling procedures. We acknowledge with gratitude the contribution of the Mr. Maqsood Sadiq in data analysis. Dr. Saleem Shaikh also provided inputs for which we are thankful. Dr. Zubaida Rashid and Mr. Mansoor Qaisar provided assistance with a number of assignments throughout the study. We must acknowledge with gratitude the role of Dr. Rizwana Chaudhry and Dr. Nasira Tasneem, who reviewed the verbal autopsies.

Mr. Imran Ahmed, Director, Finance and Administration, Population Council, Islamabad, and his team, which included Mr. Abdul Kashif, Mr. Zaheer Bhati and Mr. Asim Abbasi, expertly handled all financial matters. Mr. Irfan Masood and the data entry team worked very hard and often late hours to complete the data entry and analysis on time. Computer support was made available by Mr. Muhammad Khalil, Program Manager (IT). Mr. Ahmad Hassan and Mr. Amir Naseem played important roles in managing the logistical arrangements of this study. Mr. Waqas Abrar handled secretariat and administrative assignments in a most efficient and cheerful manner, often beyond the call of duty.

We are most grateful to Pamela Ledbetter for her meticulous review of the report and her editorial inputs. We appreciate Mr. Ali Ammad for his hard work on the layout and design of the report.

Finally, we want to thank the social interviewers and logistics supervisors who undertook a very challenging assignment, often in very difficult circumstances. We are indeed thankful to Dr. Sonia Memon, District Supervisor Study Team Dadu and Dr. Samreen Afzal, District Supervisor Study Team Khanewal for managing the field role. We also owe a debt of gratitude to all of the study respondents who willingly gave their time to participate in the study. 


\section{ABBREVIATIONS /ACRONYMS}

\begin{tabular}{|c|c|c|c|}
\hline AMTSL & $\begin{array}{l}\text { Active Management of the Third } \\
\text { Stage of Labor }\end{array}$ & PDHS & $\begin{array}{l}\text { Pakistan Demographic and Health } \\
\text { Survey }\end{array}$ \\
\hline $\mathrm{APH}$ & Antepartum Hemorrhage & PKR & Pakistan Rupees \\
\hline BHU & Basic Health Unit & $\mathrm{PPH}$ & Postpartum Hemorrhage \\
\hline CBI & Community-Based Intervention & PSLM & $\begin{array}{l}\text { Pakistan Social \& Living Standards } \\
\text { Measurement Survey }\end{array}$ \\
\hline CDK & Clean Delivery Kit & $\mathrm{RH}$ & Reproductive Health \\
\hline CMW & Community Midwife & SAE & Serious Adverse Event \\
\hline $\mathrm{DHQ}$ & District Headquarter & SBA & Skilled Birth Attendant \\
\hline EmONC & $\begin{array}{l}\text { Emergency Obstetric and Neonatal } \\
\text { Care }\end{array}$ & SMART & $\begin{array}{l}\text { Safe Motherhood Applied } \\
\text { Research and Training }\end{array}$ \\
\hline GoP & Government of Pakistan & SPSS & $\begin{array}{l}\text { Statistical Package for Social } \\
\text { Sciences }\end{array}$ \\
\hline IEC & $\begin{array}{l}\text { Information, Education and } \\
\text { Communication }\end{array}$ & TAG & Technical Advisory Group \\
\hline IRB & Institutional Review Board & TBA & Traditional Birth Attendant \\
\hline IV Drip & Intravenous Drip & THQ & Tehsil Headquarter \\
\hline KAB & Knowledge, Attitude and Behavior & TT & Tetanus Toxoid Vaccination \\
\hline LHV & Lady Health Visitor & UC & Union Council \\
\hline LHW & Lady Health Worker & UNFPA & United Nation Population Fund \\
\hline $\mathrm{MNCH}$ & $\begin{array}{l}\text { Maternal, Neonatal and Child } \\
\text { Health }\end{array}$ & UNICEF & United Nation Children's Fund \\
\hline $\mathrm{MNH}$ & Maternal and Neonatal Health & USAID & $\begin{array}{l}\text { United States Agency for } \\
\text { International Development }\end{array}$ \\
\hline MMR & Maternal Mortality Ratio & USP & United States Pharmacopoeia \\
\hline $\mathrm{MOH}$ & Ministry of Health & VSI & Venture Strategies Innovations \\
\hline NPFP\&PHC & $\begin{array}{l}\text { National Program for Family } \\
\text { Planning and Primary Health Care }\end{array}$ & WHO & World Health Organization \\
\hline OR & Operations Research & WMO & Woman Medical Officer \\
\hline PAIMAN & $\begin{array}{l}\text { Pakistan Initiative for Mothers and } \\
\text { Newborns }\end{array}$ & & \\
\hline
\end{tabular}





\section{EXECUTIVE SUMMARY}

According to the Pakistan Demographic and Health Survey (PDHS) 2006-07, the maternal mortality ratio for Pakistan is reported at 276 per 100,000 live births (NIPS and Macro International, 2008). In rural areas, this figure is 319 per 100,000 live births. The PDHS 2006-07 also showed that postpartum hemorrhage was the most common cause of maternal deaths (27.2 percent). Around two-thirds of all births in Pakistan take place at home, where a traditional birth attendant (TBA or dai) or a family member usually attends the delivery (NIPS and Macro International, 2008). In Pakistan, owing to limited access to health facilities, about 61 percent of deliveries are conducted by unskilled birth attendants within home settings.

This operations research project was carried out by the Population Council as part of the Pakistan Initiative for Mothers and Newborns (PAIMAN) project funded by the United States Agency for International Development (USAID). The overall goal of the project was to test the feasibility of administering misoprostol for the prevention of PPH in a home setting through community-based healthcare providers, including traditional birth attendants (dais), or family members, in two districts of Pakistan.

The study was conducted to document the feasibility of distribution of misoprostol by community health workers in a home setting and to assess the acceptability and use of the drug by pregnant women for the prevention of PPH when administered at home. Besides this, to identify the common side effects of misoprostol and determine the reduction in demand for referral due to PPH after oral ingestion of misoprostol.

\section{Study Design/Methodology}

This operations research (OR) was conducted in Dadu district, Sindh province, and Khanewal district, Punjab province. The quasi-experimental design used for this study comprised of intervention and comparison areas. Data collection was carried out from November 2009 to June 2010 using a number of data collection tools.

The study consisted of two phases: the first phase involved community awareness and community education, through counseling, and the second involved data collection. During community awareness and registration of the women, each identified pregnant woman and her family members, in the comparison and intervention areas, were given a briefing about birth preparedness and danger signs during pregnancy, delivery and the postpartum period. For women in the intervention areas, the briefing also included information about misoprostol. For all identified pregnant women, these initial briefings were designed to help them make a well-informed decision about whether to participate in the study or not.

Later, two counseling sessions were held with the eligible pregnant women from the intervention and comparison areas who participated in the study. The first session was conducted one month before each 
woman's expected delivery date and the second was 15 days before delivery. Information on the same topics that had been touched on in the initial briefings was presented during each of the counseling sessions/visits. During the second visit, clean delivery kits were given to the women in both areas. The clean delivery kits for the women in the intervention areas contained three tablets of 200 micrograms of misoprostol each, along with a pictorial instructional leaflet. For this research, VSI Venture Strategies Innovations donated 6,000 misoprostol tablets. The clean delivery kits given to the women in the comparison areas did not include misoprostol tablets.

The 566 birth attendants identified by the pregnant women as the people expected to carry out their deliveries were given a one-day interactive training. Each person identified as an expected birth attendant, whether a TBA or a family member, was also given a clean delivery kit (with misoprostol in the intervention areas and without misoprostol in the comparison areas).

\section{Results}

\section{Characteristics of the Women}

Out of a sample of 872 women in the intervention areas and 826 women in the comparison areas who had initially agreed to participate in the study, the mean age in both areas was 28 years. Mean education in the intervention areas was 1.7 years; it was 1.3 years in the comparison areas. The mean number of live births was 3.0 in the intervention areas and 2.8 in the comparison areas. Nearly half of the respondents in both areas had made at least one antenatal visit. More than two-fifths of the husbands, in both intervention and comparison areas, were uneducated (41 and 47 percent respectively).

\section{Characteristics of the Birth Attendants}

About 80 percent of the birth attendants in both the intervention and comparison areas were traditional birth attendants/dais. MBBS doctors made up the second largest group of attendants: 6 percent in the intervention areas and 10 percent in the comparison areas. More than half of the birth attendants in both areas were 45-64 years of age, fairly evenly split between 45-54 and 55-64. Just over 70 percent of the birth attendants in both areas were uneducated, as most were traditional birth attendants (TBAs). A major proportion of birth attendants were currently married: 65 percent - intervention areas; 58

percent - comparison areas. Widows were the second most common group in both areas; very few birth attendants were single or separated.

\section{Knowledge of Respondents}

Women in the intervention areas were provided a briefing on misoprostol's advantages and use during the initial community awareness and registration session. When the study participants were interviewed one month before their expected delivery date to ascertain how much of the information they had retained, 95 percent of the women in the intervention areas mentioned that tablets taken orally could prevent PPH. About 52 percent of these women were able to recall that the name of the drug was misoprostol. Among those who knew about misoprostol, 92 percent knew how to use it correctly. 


\section{Knowledge of Birth Attendants}

Almost all of the birth attendants in both intervention and comparison areas (around 95 percent) knew how to recognize postpartum hemorrhage. Over half of the birth attendants (60 percent) could recall the name of the tablets (misoprostol). Almost all (98 percent) of the birth attendants knew, correctly, that misoprostol should be administered immediately after delivery of the baby and before delivery of the placenta. About 78 percent of the birth attendants knew that shivering is one of the side effects of misoprostol and 67 percent knew about fever, while smaller percentages knew about other side effects.

\section{Misoprostol Use: Safety, Acceptability and Referral}

\section{Safety}

Out of the 890 women identified in the intervention areas as pregnant, 872 agreed to participate in the study, while 18 refused. Out of 872 who agreed to participate, 770 delivered at home and were eligible for misoprostol. Among the remaining, 55 were ineligible because a cesarean section delivery was indicated, and 47 were excluded due to referral to facility before delivery for obstetric complications. Among the eligible women in the intervention areas, 678 women ( 88 percent) took the misoprostol tablets provided to them in the clean delivery kits, while 92 women (12 percent) did not.

In the comparison areas, 826 agreed to participate and 720 with home deliveries were included. Out of the other 106 women, 77 with a history of C-sections were deemed ineligible for inclusion in the study, and 29 were referred to a facility for other obstetric complications and were also excluded from the analysis.

The recommended time and dosage of misoprostol administration is three tablets to be ingested after the birth of the baby but prior to the delivery of the placenta. Of the women who delivered at home in the intervention areas, 647 (84 percent) took the tablets correctly (at the correct time and according to the correct dose).

The 647 women who took misoprostol tablets correctly (correct dose and correct time) were asked about the side effects and 40 percent reported that they had experienced side effects (Table 4.2). The majority reported suffering shivering/chills (69 percent), followed by fever ( 27 percent) and nausea (17 percent). However, in all of these cases, the symptoms were transient and did not require referral for specialized care.

\section{Acceptability}

Women who used misoprostol. Among the women who delivered at home and used misoprostol, 91 percent said that they would use the tablets in future. When these women were asked if they would also be willing to purchase the tablets in the future, 93 percent expressed their willingness to do so. Almost all of these women also said they would recommend misoprostol to others (only 2 were not willing to recommend misoprostol).

Birth attendants. Of those birth attendants in the intervention areas who had administered misoprostol tablets and knew of its name (nearly 60 percent), almost all (98 percent) said that they would recommend the tablets to other clients. 


\section{Referral}

In the intervention areas, 3 women ( 0.38 percent) suffered from postpartum hemorrhage that required referral to a higher-level facility. Out of these, 2 had ingested misoprostol; the 1 who had not ingested misoprostol later died upon reaching a facility. In the comparison areas, 5 (0.64 percent) required referral for the management of PPH; out of these cases, two women died.

\section{Recommendations}

- Train community based providers in the use of misoprostol in resource constrained settings

The results from our study further substantiate the already available empirical evidence that recommends the use of misoprostol in resource-constrained settings by community providers. For this purpose training needs to be imparted to LHW'S and community midwives in the use of misoprostol including its dosage, side effects and their management.

- Empower families to make pregnancies safer through information

Raising community awareness regarding the need for birth spacing, antenatal checkups, proper nutrition during pregnancy, use of supplements, immunization, use of clean delivery kits at the time of delivery, and postpartum use of misoprostol must be carried out, especially in rural communities. In this regard LHWs through their support group meetings can especially raise awareness regarding use of misoprostol by delivering women and their birth attendants. 


\section{CHAPTER 1. INTRODUCTION}

\section{Background}

Globally, about 500,000 women die annually from complications during pregnancy or childbirth (WHO, 2004). The most common cause of maternal mortality is postpartum hemorrhage, accounting for onethird of maternal deaths. Ninety-nine percent of these deaths occur in developing countries to women who rarely receive appropriate care because they give birth outside of a hospital setting (Abou Zhar and Royston, 1991).

Postpartum hemorrhage (PPH) is widely defined as excessive blood loss of $500 \mathrm{ml}$ or more from the genital tract in the first 24 hours following delivery of a baby. In the majority of cases, PPH occurs in the early postpartum period. Vaginal tears, retained products of placenta, and delayed delivery of placenta and uterine atony (which delays placental detachment and eventually its delivery) are the major factors that contribute to the incidence of PPH. Three effective uterotonic drugs are available for use in the active management of the third stage of labor.

As a routine, the injectable oxytocin is recommended at the time of delivery of a baby to prevent PPH. It acts as a uterotonic and facilitates the process of placenta detachment as well as contraction of the uterus. Oxytocin has minor adverse effects, including nausea, vomiting and diarrhea. It requires storage in a cool temperature $\left(5-25^{\circ} \mathrm{C}\right)$, although it can be kept outside these temperatures for short durations. The other drug is methergin. Adverse effects with methergin are more common; it is also less stable in warm temperatures, requires dark storage, and cannot be used in the 10 to 15 percent of women who have hypertension in pregnancy. Both of these drugs require a skilled provider trained in safe injection practices and they require the availability of sterile syringes and needles (Sanghvi et al., 2010).

Misoprostol, a prostaglandin E1, acts as an alternative uterotonic to the injectable drug oxytocin and is available in tablet form. It has been found to be effective in controlling as well as preventing PPH (Prata, Mbaruku, Campbell, Potts, Vahidnia, 2005; Derman et al., 2006). It is inexpensive, comparatively easy to use, and does not require any special conditions for its storage. Moreover, its tablet form provides a community health care provider, a traditional birth attendant, and even the just-delivered woman herself, with the opportunity to easily administer it. Misoprostol causes occasional side effects, which include shivering and fever (Derman et al., 2006; Zuberi et al., 2008; Blum, Alfirevenic, Walraven, Weck, Winikoff, 2007; Sultana and Khatun, 2007). The use of misoprostol has been recommended by the United States Pharmacopoeia (USP) Expert Committee for the Prevention of PPH, especially in settings where injectable uterotonic drugs are not available (Carpenter, 2001).

According to the Pakistan Demographic and Health Survey (PDHS) 2006-07, the maternal mortality ratio (MMR) for Pakistan is reported at 276 per 100,000 live births (NIPS and Macro International, 2008). In rural areas, this figure is 319 per 100,000 live births. The PDHS 2006-07 also showed that postpartum hemorrhage was the most common cause of maternal deaths (27.2 percent). 
The purpose of the present study was to test the feasibility of lowering maternal mortality using community education about PPH prevention along with the distribution of misoprostol tablets directly to women and their birth attendants for postpartum home administration. According to the PDHS, around two-thirds of all births in Pakistan take place at home, where a traditional birth attendant (TBA or dai) or a family member usually attends the delivery (NIPS and Macro International, 2008). In these circumstances, providing women with 600 micrograms of misoprostol, taken orally, is a potentially safe and easy way to prevent the development of PPH in resource-constrained settings without appropriate storage facilities or highly trained providers (Derman et al., 2006).

\section{Context}

Before commencing this study, an extensive review of international and national literature was carried out to inform the study design. Some of the main findings relevant to the study are summarized below.

The leading cause of postpartum hemorrhage is uterine atony, most often preventable by conventional uterotonics, among which oxytocin is usually preferred (Gülmezoglu et al., 2001; Langenbach, 2006; Ng et al., 2001). However, the use of oxytocin is not yet feasible in much of the developing world, where deliveries still take place in rural areas with untrained birth attendants (Langenbach, 2006; Selo-Ojeme, 2002; Kodkany et al., 2004; Walraven et al., 2005).

The role of misoprostol in preventing PPH, particularly in areas where the routine management of the third stage of labor cannot be practiced, has been very well established. Research on misoprostol has been carried out either as randomized controlled trials or operations research in some developing countries with promising results for the management of PPH (Derman et al., 2006; Prata, Hamza, Gypson and Nada, 2006; Prata et al., 2005). Evidence from many developing countries is now available regarding the successful distribution of misoprostol, its acceptability in the community after proper creation of awareness, and compliance by pregnant women and support from their families.

A review carried out by Goldberg, Greenberg and Darney (2001) found consistent evidence to support the use of misoprostol for preventing PPH in circumstances where oxytocin is not available. A study of education and home-based distribution of misoprostol for prevention of PPH carried out in neighboring Afghanistan showed that the distribution of misoprostol by community health workers was safe, acceptable, feasible and effective (Sanghvi et al., 2010). Derman et al. (2006) conducted a placebocontrolled trial in India that utilized the services of nurses and midwives to give 600 micrograms of misoprostol orally. This study documented a significant decrease in PPH in the intervention group as compared to the comparison group. Prata et al. (2005) conducted a field intervention trial in Tanzania with TBAs where they gave 1000 micrograms of misoprostol rectally at the onset of PPH. The study found this resulted in lower referrals for PPH to higher-level health facilities as compared to the nonintervention areas. The same researchers carried out another study in a hospital setting in Egypt where a significantly higher proportion of women in the non-intervention group required PPH management as compared to the intervention group that received misoprostol (Prata et al., 2006). In a study carried out in Nigeria oral misoprostol was seen to be as effective and safe as intramuscular oxytocin (Afolabi, Kuti, Orji and Ogunniyi, 2010). 
JHPIEGO conducted a community-based study in collaboration with the Ministry of Health of Indonesia and the Obstetrical and Gynaecological Society of Indonesia in 2004. The study was developed to demonstrate that community-based distribution of 600 micrograms of misoprostol before delivery of a baby and the self-administration of the drug by the mother immediately after a home birth could lower the incidence of PPH among women living in areas where skilled providers do not attend a high proportion of births. In the intervention areas, 93.7 percent of 1,282 women used the drug after delivery. Nearly 4 percent of the women in the comparison areas were referred for PPH compared to only 2.1 percent of women in the intervention areas. The authors used statistical models in the data analysis to conclude that women in the intervention areas were 25 percent less likely to experience excessive bleeding, 30 percent less likely to need an emergency referral to a health facility, and 45 percent less likely to need an emergency referral for PPH (Wiknjosastro and Sanghvi, 2004).

In Pakistan, two research studies on misoprostol use, conducted in hospital and community settings, have been documented. Both were carried out by Aga Khan University. The first study was a hospitalbased treatment-placebo-control trial in which 600 micrograms of misoprostol were given sublingually with the routine management of PPH treatment (Zuberi et al., 2008). The results were modestly in support of misoprostol use, but there were no statistically significant differences between the intervention (oxytocin and misoprostol) and comparison (oxytocin only) groups. However, the trial had to be terminated as the PPH rate was low. Another community-based placebo-controlled trial was conducted in Chitral in the Northern Areas where TBAs were utilized to provide 600 micrograms of misoprostol orally to women shortly after they gave birth. The results showed that oral misoprostol reduced the rate of PPH by 24 percent compared with the placebo. Referrals for higher-level care during the immediate postpartum period were similar following administration of misoprostol (2.4 percent) or placebo (1.8 percent) (Gynuity Health Projects, Aga Khan University and Family Care International, 2009).

WHO recommends the use of misoprostol only in circumstances where use of injectables, including oxytocin, is not possible and health workers are properly trained in the correct use of misoprostol as well as identification and management of side effects (WHO, 2009).

The Population Council, as a consortium partner of the USAID-sponsored Pakistan Initiative for Mothers and Newborns (PAIMAN), undertook an operations research project in two districts of Pakistan to assess the feasibility of home administration of misoprostol in the prevention of PPH in rural Pakistan. The purpose of undertaking the study was based on the premise that such an intervention has the potential to significantly reduce the number of preventable maternal deaths and provide a powerful model for more effective safe motherhood interventions in rural areas. This study was conducted with the approval of the Ministry of Health ( $\mathrm{MOH}$ ) and the National Maternal, Neonatal and Child Health (MNCH) program.

\section{Goal and Objectives}

\section{Goal}

The overall goal of this operations research project was to assess the feasibility of administering 
misoprostol for the prevention of $\mathrm{PPH}$ in a home setting through community-based healthcare providers, including traditional birth attendants (dais), community midwives (CMWs) and family members, in two districts of Pakistan.

\section{Objectives}

The following were the objectives for this study:

- To document the feasibility of distribution of misoprostol by community health workers, including traditional birth attendants (dais), in a home setting;

- To assess the acceptability and use of the drug by pregnant women for the prevention of PPH when administered at home;

- To identify the common side effects of misoprostol; and

- To determine the reduction in demand for referral due to PPH after oral ingestion of misoprostol.

\section{Study Parameters}

A quasi-experimental design was used to document the coverage and process of distribution and the acceptability of providing misoprostol to prevent postpartum hemorrhage in community settings in Pakistan. The study documented the use of misoprostol by community-based birth attendants, including traditional birth attendants (dais); the acceptability and compliance by delivering women; and the incidence of side effects and need for referral with the use of 600 micrograms (3 tablets) of oral misoprostol.

\section{Location and Duration}

This was a one-year project; it started on 27 October 2009 and ended on 30 September 2010. This study was conducted in two districts, Dadu district in Sindh province and Khanewal district in Punjab province. Both districts were chosen because they were focus districts of the Pakistan Initiative for Mothers and Newborns Health (PAIMAN) project and were approved by the Technical Advisory Group (TAG) constituted to advise on the study design. In addition, these two districts are fairly representative of the other districts of the provinces. The characteristics of both districts are provided in Annex.

In Khanewal district, seven union councils were selected, while in Dadu six union councils were selected. The union council selection was based on ensuring that women from both the intervention and comparison areas could reach a referral facility within two hours of travel time.

\section{Population}

\section{Sample Selection: Inclusion Criteria}

Pregnant women living in the selected union councils of Khanewal and Dadu districts who were 15-49 years of age and intended to deliver at home, were willing to participate in the study, and would be delivering during the study period were included in the study. During the initial registration, women who fit the criteria were included regardless of parity, past obstetric history or medical conditions. Also 
included were the birth attendants who were expected to be present at the time of delivery and to conduct the delivery (this included TBAs, relatives, etc.).

Selection criteria of eligible pregnant women varied in different villages depending on when registration occurred: where registration started in the beginning of the study, women in their second and third trimesters were included, while in villages where registration was done later in the study, women only in their third trimester were included. See Figure 1.1 and Table 1.1 for more details on study participants.

\section{Sample Selection: Exclusion Criteria}

Pregnant women in the selected union councils were excluded from the study for any of these reasons: if they intended to deliver at a health facility, were not within the age limit of 15-49 years, or were not willing to participate in the study. In the final analysis of study findings, women were also excluded if they had certain complications or previous history of complications, such as previous antepartum or postpartum hemorrhage or retained placenta, or if they had a previous or planned Cesarean section.

\section{Sampling Technique}

Six union councils in Dadu and seven in Khanewal closest to the selected health facilities (within two hours distance from the referral health facility) were included in the study to register the required number of eligible women. The selected health facilities were the Tehsil Headquarters Hospital of Mian Channu in Khanewal district and the District Headquarters Hospital of Dadu in Dadu district (both of which offered comprehensive EmONC services). Out of these union councils, 3 in each district were initially assigned for the intervention and 3 were assigned for the comparison. The selection of union councils was purposive so as to avoid diffusion among the intervention and comparison areas. An additional union council was included in the intervention areas in Khanewal district to register the required number of eligible pregnant women, bringing the intervention areas total of union councils to 4 in Khanewal and 3 in Dadu. Registration of women was done beyond sample size to compensate for subsequent ineligibility of some respondents.

Sample Size/Sample Size Estimation. Currently, the PPH rate is estimated to be in the range of 10-15 percent for rural settings in countries like Pakistan (WHO, 2004), and we expected that this rate could be reduced by half (5-7 percent) with the introduction of misoprostol. Based on these estimates, we calculated sample sizes on the assumption that half of the women with PPH ( 7 percent) would be referred to a health facility in the comparison areas, while in the intervention areas the referrals due to PPH would be reduced to a quarter (3.25 percent). For this purpose, a minimum of 554 deliveries in each of the two groups was required to test the difference of a reduction of 50 percent in reported PPH (Rosner, 1995).

The formula used for sample size estimation is:

$$
\begin{aligned}
& \left.n=(A+B)^{2 *} *\left(p_{1} *\left(1-p_{1}\right)\right)+\left(p_{2} *\left(1-p_{2}\right)\right)\right] /\left[p_{1-} p_{2}\right]^{2} \\
& \text { Where } \quad \begin{array}{l}
p_{1}=\text { proportion of referrals due to } P P H \text { in comparison group }=0.075 \\
p_{2}=\text { proportion of referrals due to } P P H \text { in intervention group }=0.035 \\
A=z_{\alpha / 2}=1.96 \text { (for } \alpha=0.05 \text { for } 95 \% \text { confidence interval) } \\
B=z_{1-6}=1.64 \text { (for } B=0.05 \text { for } 95 \% \text { power) }
\end{array}
\end{aligned}
$$


A minimum of 800 pregnant women in the intervention areas and an equal number in the comparison areas had to be enrolled in order to achieve the minimum required number of completed observations to detect differences with public health significance. By inflating the sample size by 25 percent in the intervention group and the comparison group, we hoped to compensate for non-compliance in the intervention group and hospital deliveries in both groups. Loss to follow-up was also estimated to be about 15 percent, thus increasing the minimum sample further. Out of 890 pregnant women initially contacted in the intervention areas, 18 ( 2 percent) refused to participate in the study. Of the 846 contacted in the comparison areas, 20 (2 percent) refused to participate. See Figure 1.1, which shows the profile of the pregnant women in the study, and Table 1.1, which shows the number completing specified questionnaires in the intervention and the comparison areas.

Figure 1.1: Study profile of pregnant women in Dadu and Khanewal districts

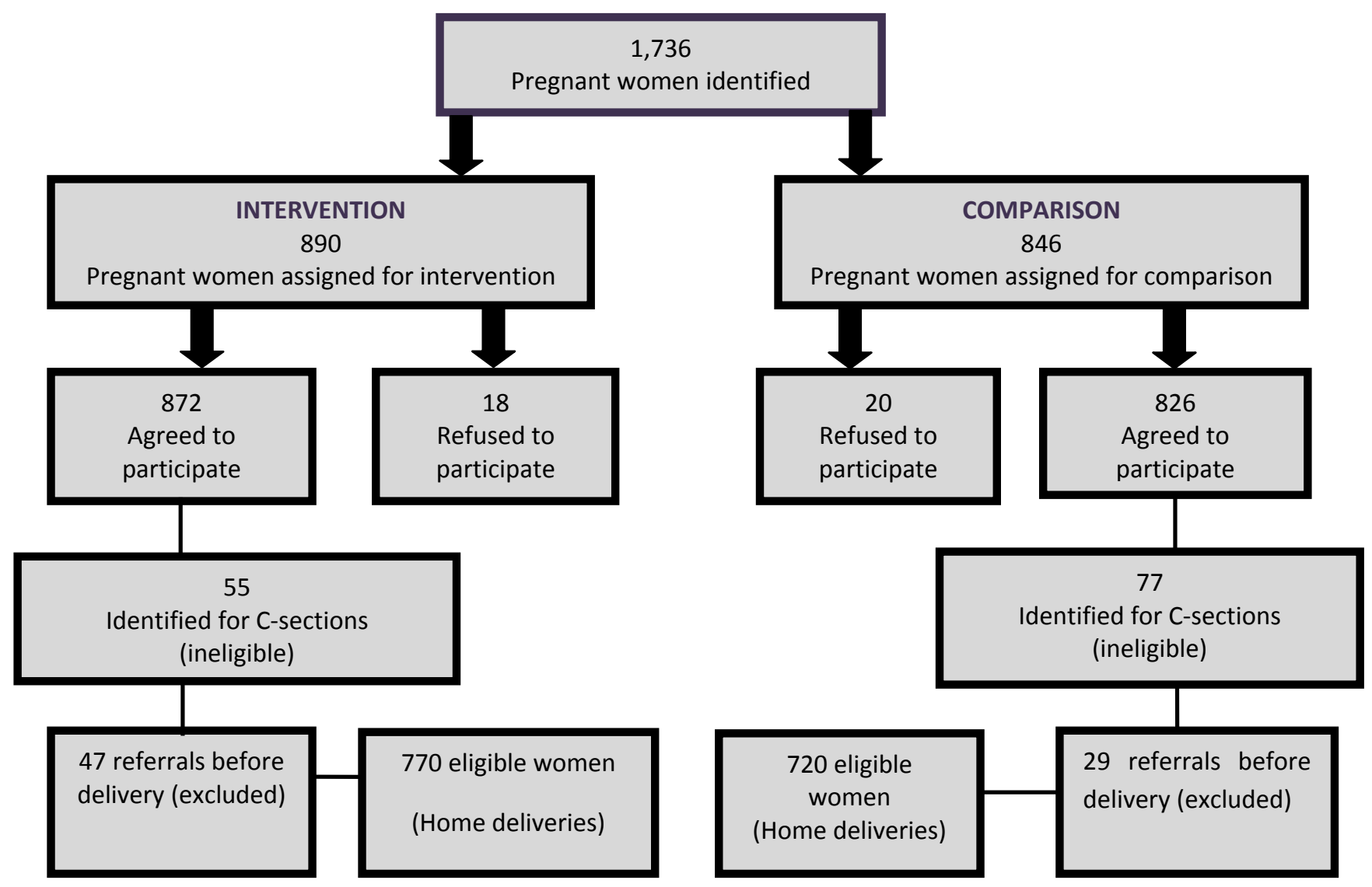




\section{Study Teams}

A total of eight teams were selected for fieldwork in Khanewal and Dadu districts: four teams worked in each of the two districts. In Khanewal, 2 teams covered the 4 intervention areas and 2 teams covered the 3 comparison areas. In Dadu, 2 teams covered the 3 intervention areas and 2 teams covered the 3 comparison areas. The study teams made three separate visits to the homes of eligible women in the areas they were responsible for and also organized trainings for the birth attendants. Each team comprised of one logistics supervisor and two social scientists. A female medical doctor was selected as a district supervisor for each of the two districts.

\section{Roles and Responsibilities}

Roles and responsibilities for each study member were identified and they were provided with a written list of responsibilities they were required to follow.

\section{Training}

A total of 16 social scientists, 8 logistics supervisors and 2 district supervisors from Khanewal and Dadu districts were trained in Islamabad in two training sessions. The first session lasted for 10 days, the second for 8 days.

During the first phase of the training, participants were trained on interviewing pregnant women and then registering those who met the criteria. The second phase of the training focused on interviews to be conducted in the postpartum period with the women, their birth attendants and relatives. During the training, the social scientists were trained to use a pictorial booklet that informed participants about how to identify high-risk conditions and manage the delivery, including when to refer and, finally, how to administer misoprostol tablets (this last was for those participants who were in the intervention areas only).

During the training, the 8 logistics supervisors were also trained on how to establish a mobile network for timely referral of emergency cases to the health facility.

\section{Supervision and Monitoring}

All of the teams for both districts carried out their field activities in continuous and close supervision by their respective district supervisors (the female doctor appointed to provide supervision in each district). The study coordinator regularly visited the study sites to ensure that sampling procedures and standard operating procedures were being followed.

\section{Quality Assurance}

A number of measures were instituted to ensure that the highest quality standards were maintained in all areas of the study, including data collection and data analysis. Quality assurance during the fieldwork is described above under supervision and monitoring of field teams. The highest standards were also maintained with regard to the protection of all study participants. These are described under ethical considerations below.

\section{Ethical Considerations}

Ethical approval was taken from the institutional review board at the Population Council's headquarters in New York (see Annex, IRB Approval Letter). In addition, a Technical Advisory Group was formed that 
was comprised of representatives of the Pakistan Ministry of Health, the National MNCH Program, academics, researchers and gynecologists. The National MNCH program, Government of Pakistan, also issued a letter in support of the use of misoprostol for operations research. Ethical issues were taken into considerations in all areas of the study. Specific areas for which ethical considerations were essential included:

1. Informed consent

Informed consent was taken from all study participants in both intervention and comparison areas after giving them information about the study (see Annex, Informed Consent Form). The possible side effects of oral ingestion of misoprostol were discussed with the participants in the intervention areas. Separate consent forms were used for each of the questionnaires. Women who were able to sign signed their own names on the consent forms; if a woman could not sign her own name, a witness present at the occasion signed the consent form on the woman's behalf.

2. Risks and benefits

Respondents were informed about the potential risks and benefits of participating in the study. The individual benefits of participating in the study were explained: namely, that any woman who developed complications at the time of delivery would be facilitated by the project team working in that area for transportation to the health facility. In addition, all of the pregnant women in the study, in intervention and comparison areas, were provided with clean delivery kits for safe delivery. The potential risks of participation in the study were also explained, these were linked to improper timing of taking the drug or not following the recommended dosage.

3. Confidentiality

The data collected from all of the study participants was kept confidential and anonymous. Before data collection, participants were assured by the social scientists that their names would not be disclosed and that information provided by them would be used collectively. Each questionnaire was coded and names were not used.

\section{Safety Measures}

\section{Safety Reporting}

1. Referral cards

All households with recruited women, in both the intervention and comparison areas, were issued referral cards with contact numbers for the logistics supervisor, drivers engaged for transportation, birth attendants and LHV working in that particular area so that the women could contact anyone in the network to report any side effects or complications. They were also provided information about the importance of the first 1-2 hours after delivery, when timely referral in case of postpartum hemorrhage can save a life. 
2. Serious adverse event report

Any serious adverse event experienced, regardless of causality, by any subject entered into this study, was to be reported to the Population Council's serious adverse event (SAE) desk (by the district supervisor) and to the Population Council's study coordinator using the SAE form provided. This report was to be submitted no more than 2 calendar days from the time the site staff was notified of the event.

\section{Safety Management}

1. LHVs for back-up support

LHVs in the study union councils were trained for back-up support to ensure timely referral to the health facility in case complications occurred at the time of delivery or after delivery.

2. Mobile network

A mobile phone and transportation network was established between households, logistics supervisors and drivers for timely transportation of recruited women to the referral health facility in case of complications at the time of delivery or after delivery.

3. Twenty-four hour emergency services at the referral health facility

Medical officers working in obstetrics and gynecology with trained paramedics were on call 24 hours at the referral health facility. The referral facility selected in Khanewal district was the THQ Mian Channu and in Dadu district it was the DHQ Dadu. These facilities were selected on the basis of availability of comprehensive EmONC services.

\section{Community A wareness and Community Education}

The first phase of the study involved community awareness and community education. Preliminary household listing was carried out in both the intervention and comparison areas, and 1,736 pregnant women were initially identified. The listing process was facilitated by local lady health workers who helped introduce the social scientists to household members. All pregnant women in the selected union councils who intended to deliver at home during the study period and were within the age limit of 15-49 years and were willing to participate were initially included in the study.

Once fully informed about the goal, procedures for follow-up, and risks and potential benefits of participation in the study, the women were requested to provide their consent to participate in the study and were than registered. A registration form was used for registering each of the eligible pregnant women in both the intervention and comparison areas (see Annex).

Community education was carried out for each group involved in some way with the study. A description of the education provided for each group follows. 


\section{Pregnant women in the study}

In both the intervention and comparison areas, each identified pregnant woman was provided with information about birth preparedness and danger signs during pregnancy, delivery and the postpartum period, specifically including information about when to transport a woman in case of complications. In the intervention areas, each identified pregnant woman was also provided with information about the safe dose of misoprostol and the method of administration, plus misoprostol's benefits and side effects. In the comparison areas, information on misoprostol tablets was not provided.

The counseling sessions with the pregnant women, both in intervention and comparison areas, were carried out using pictorial booklets and were completed in 2 sessions. The first session was conducted one month before the expected delivery date and the second 15 days before delivery. The same information was repeated during both visits. During the second visit, clean delivery kits that included misoprostol tablets were provided to the women in the intervention areas and clean delivery kits that did not include misoprostol tablets were provided to the women in the comparison areas.

The clean delivery kits for the women in the intervention areas contained three tablets of 200 micrograms of misoprostol each, along with a pictorial leaflet (Figure 1.2). These pictorial leaflets had specific information on the correct timing and use of misoprostol. The reason for giving CDKs with misoprostol to the women in the intervention areas was to ensure the availability of misoprostol at the time of delivery in case the birth attendant was unable to arrive in time for the birth.

Wrappers of the used misoprostol tablets and the tablets not consumed by the women were collected by the birth attendants and returned to the social scientist overseeing that area for the study. In total, 6,000 tablets of $200 \mathrm{mcg}$ of misoprostol, under the brand name Misotac, were donated by Venture Strategies Innovations (VSI) for this study, having been procured from Sigma Pharmaceutical Industries, Egypt.

\section{Female relatives of the pregnant women in the study}

The female relatives of the pregnant women in the study, in the intervention and comparison areas, were provided a briefing on birth preparedness and safe delivery, with an emphasis on the fact that all deliveries can develop complications. Relatives were informed about the referral system and the importance and need for making arrangements for shifting the woman to the health facility in a timely manner in case the woman developed complications. Female relatives in the intervention areas were also given information on misoprostol.

\section{Birth attendants who were expected to handle the deliveries of the women in the study}

All of the identified birth attendants (566) were given a one-day interactive training. These were conducted by the district supervisor in Khanewal and in Dadu, with the assistance of social scientists within the selected union councils. All of the birth attendants were trained using a pictorial booklet. Birth attendants who were unable to come on their particular training day were trained subsequently. 
Figure 1.2: Pictorial booklet/Pictorial instructional leaflet enclosed with CDKs
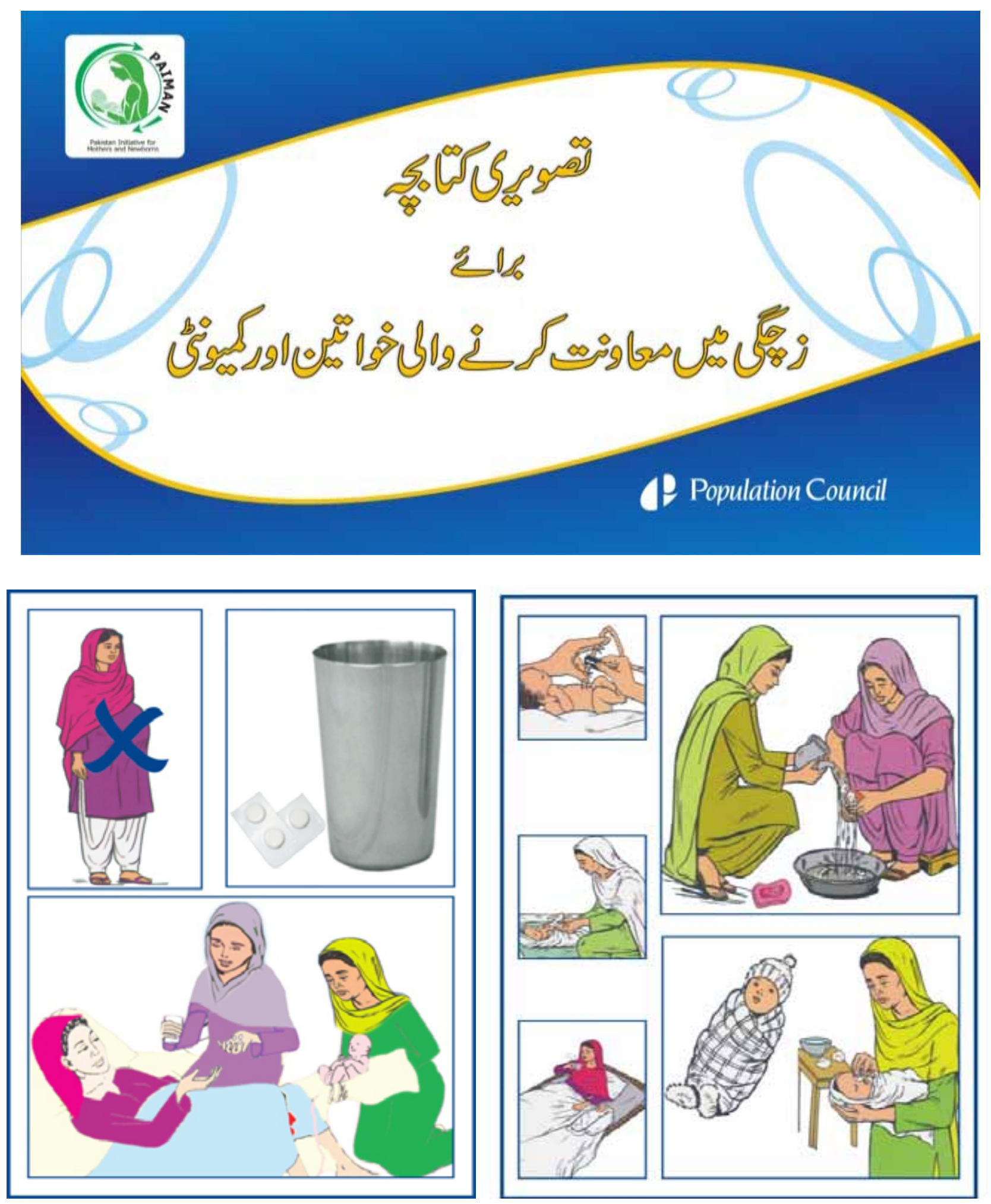
In the intervention areas, birth attendants were given information on danger signs during pregnancy, delivery and the postpartum period, safe delivery, birth preparedness, and when to transfer a women in case of complications. They were also informed about the availability of misoprostol for the prevention of PPH, its dose, method of administration, benefits and side effects. In the comparison areas, they were provided with the same information except they were not given any information on misoprostol.

Clean delivery kits were provided to the birth attendant identified by each woman as the person she would like to conduct her delivery. Though the majority of birth attendants were TBAs, there were other categories of attendants as well (see Table 2.5).

\section{Lady health visitors}

A one-day training was given to LHVs in the study areas in both districts. The district supervisors conducted these trainings using a specially prepared training manual. The training emphasized the LHV's role in providing back-up support in case of complications and in making timely referrals to the health facilities.

\section{Male family members of the pregnant women in the study, and community elders and influentials} Logistics supervisors were involved in counseling male family members of the recruited women in both the intervention and comparison areas. Sessions were carried out in groups, giving the men the information on timely referral in case of complications at the time of delivery and after the delivery. Included in these sessions were community elders and influentials who needed to be informed about the study. Male family members were given the same information as the women and female family members according to whether or not they were in intervention or comparison areas, including information on misoprostol (only if they were in an intervention area).

\section{Orientation meeting with referral health facility doctors}

Meetings were organized with obstetricians of the referral health facilities in both districts. These physicians were given a detailed briefing on the project and were provided with the referral forms they were asked to fill out if a case was referred to them from the study areas (both comparison and intervention).

\section{Data Collection}

The second phase of the study involved the data collection. The section on study parameters describes some aspects of data collection (e.g., quality control, safety measures, etc.). In this section, the questionnaires used for data collection are described, followed by a description of the data management and analysis.

Data collection was carried out from November 2009 to June 2010 using a number of data collection tools, which are described below. Table 1.1 shows the number of data collection tools completed for each group of study participants.

\section{Questionnaires}

Five sets of questionnaires were developed; these had been pretested and amended accordingly. Four types of questionnaires were used in both the intervention and comparison areas, while the fifth questionnaire was used only in the intervention areas. (See Table 1.1.) 
Questionnaires used in both the intervention and comparison areas:

1. Questionnaire for interviewing pregnant women

This was used to obtain sociodemographic and pregnancy-related data. This questionnaire was administered when study teams visited the registered women who agreed to participate in the study one month before their expected delivery date.

2. Questionnaire for interviewing women during the postpartum period

This was administered within 72 hours of delivery to study participants; information was obtained on the delivery process.

3. Questionnaire for interviewing women with complications who had been referred to the health facility.

This was used for interviewing only those women who had been referred to health facilities for the management of complications.

4. Questionnaire for interviewing birth attendants

All birth attendants who had been involved in the delivery were interviewed after the delivery.

Questionnaire used in the intervention areas only:

5. Questionnaire for interviewing female relatives present at the time of delivery

This questionnaire was administered only in the intervention areas to female relatives of the women who had recently delivered.

\section{Referral Form}

A referral form was also used to obtain detailed information about the cases with complications that were referred to a health facility. The form was completed by the doctor in-charge at the facilities where the referred case was treated in both the intervention and comparison areas. (See Annex.)

\section{Serious Adverse Event Form}

A serious adverse event form, developed by the Population Council (New York), was used to obtain information in case of any serious complication, regardless of cause, occurring in either the intervention or the comparison areas. When required, this form was completed by one of the project's district supervisors, who were medical doctors. (See Annex.)

\section{Verbal Autopsy}

Detailed information was obtained, through a verbal autopsy conducted by the district supervisor (a medical doctor) and reviewed by a nosologist, for any maternal death that occurred. 
Table 1.1: Number of study participants who completed specified questionnaires/forms, according to areas

\begin{tabular}{|c|c|c|c|}
\hline Variable & $\begin{array}{r}\text { Intervention } \\
\text { areas }\end{array}$ & $\begin{array}{r}\text { Comparison } \\
\text { areas }\end{array}$ & Total \\
\hline $\begin{array}{l}\text { Pregnant women 15-49 who met study criteria: completed } \\
\text { in-take questionnaire (including women with past C- } \\
\text { sections) }\end{array}$ & 872 & 826 & 1,698 \\
\hline $\begin{array}{l}\text { Study women interviewed after birth: completed } \\
\text { postpartum questionnaire (including women with } \\
\text { present C-sections) }\end{array}$ & 782 & 727 & 1,509 \\
\hline $\begin{array}{l}\text { Study women referred for complications: completed } \\
\text { referral questionnaire (including women with present C- } \\
\text { sections) }\end{array}$ & 87 & 94 & 181 \\
\hline $\begin{array}{l}\text { Birth attendants involved in deliveries: completed post- } \\
\text { delivery birth attendant questionnaire }\end{array}$ & 303 & 263 & 566 \\
\hline $\begin{array}{l}\text { Family members present at time of delivery: completed } \\
\text { post-delivery family questionnaire (intervention areas } \\
\text { only) }\end{array}$ & 872 & 0 & 872 \\
\hline $\begin{array}{l}\text { Doctors in-charge at referral medical facilities where } \\
\text { complications were referred: completed referral form }\end{array}$ & 87 & 94 & 181 \\
\hline Verbal autopsy & 3 & 5 & 8 \\
\hline
\end{tabular}

\section{Data Management/Data Analysis}

The team leaders sent the completed quantitative questionnaires to the Population Council office in Islamabad. Prior to commencing data entry, the questionnaires were edited. The data were entered, and range skip and filter checks were applied to minimize errors and omissions. The data were then coded and entered using CSPro (version 3.2) and SPSS (version 14). Results were summarized using frequency distributions and cross tabulations. All study data and forms were stored in locked cabinets at the Population Council office in Islamabad.

\section{Limitations of the Study}

The study design was quasi-experimental and the area selection was not randomized. In the absence of sufficient research on assessing the compliance of misoprostol ingestion within home settings, it is difficult to make comparisons across regions. Although not an identified objective, we did ask for women's experiences of postpartum bleeding within the intervention and comparison areas; this was based on perceptions rather than actual measurements. 


\section{ChAPTER 2. ChARACTERISTICS OF PARTICIPANTS}

\section{Characteristics of Women}

In the first section of this chapter, characteristics of the study women from the intervention and comparison areas are compared. One general characteristic was that the commonly spoken languages in both intervention and comparison areas were Punjabi, Sindhi and Saraiki.

\section{Age}

Out of a sample of 872 women in the intervention areas and 826 women in the comparison areas who had agreed to participate in the study, the largest age group, about a third of the women in both areas, was 25-29 years of age (Figure 2.1). The smallest age groups were 40-44 and 45-49 years, with 3 percent or less. About 7 percent in both the intervention and comparison areas were ages 15-19 years. The mean age was 28 years in both the intervention and comparison areas. [Note: SD=5.7 intervention areas; $\mathrm{SD}=6.0$ comparison areas.]

Figure 2.1: Percentage distribution of women, by areas, according to age groups

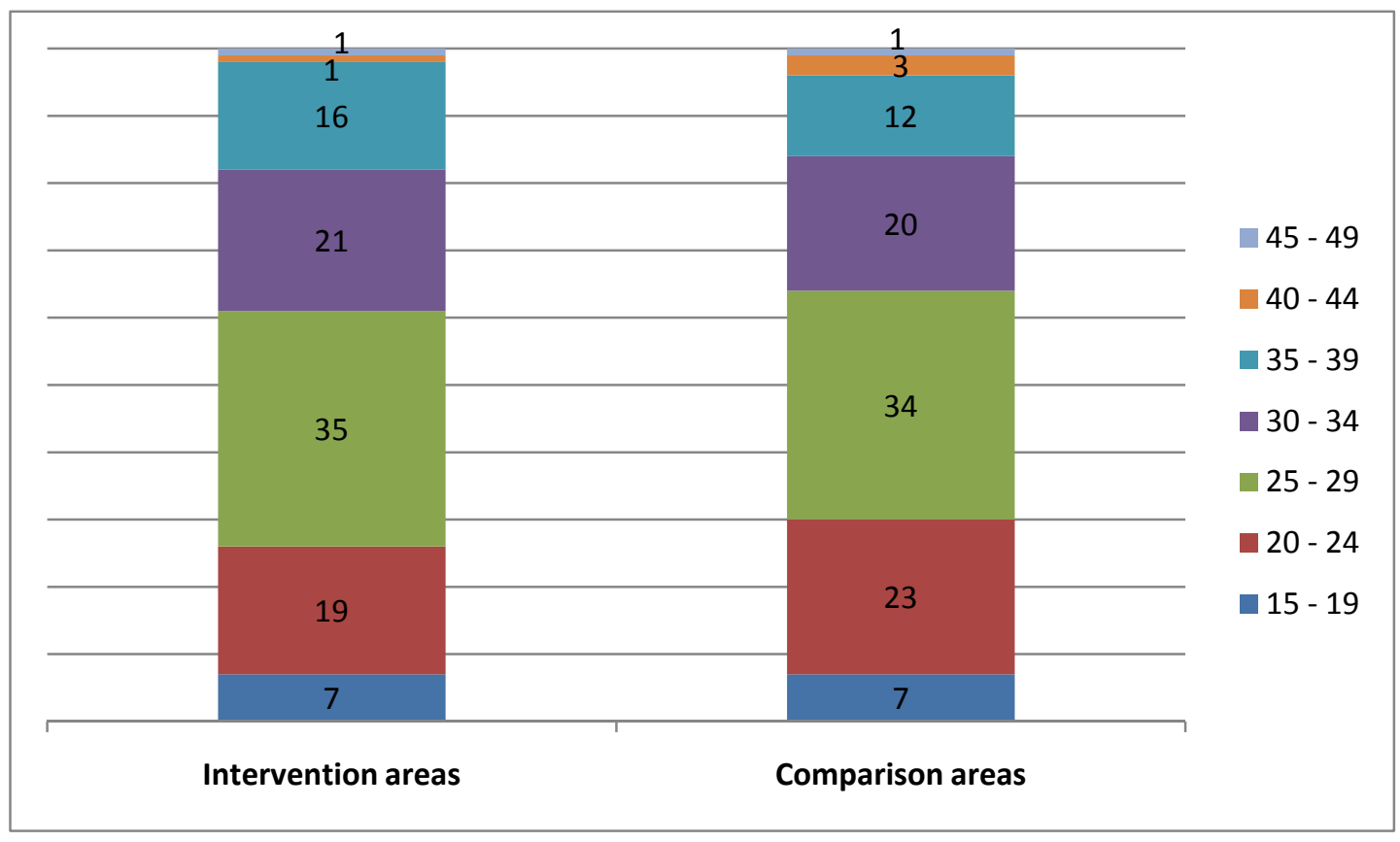




\section{Education}

As shown in Figure 2.2, a majority of the women in the intervention and comparison areas were not educated. A negligible proportion of women reported receiving education beyond the secondary level. Among the women who attended school, more were found in the primary education group. Mean education in the intervention areas was 1.7 years and 1.3 years in the comparison areas. [Note: $\mathrm{SD}=3.1$ intervention areas; $\mathrm{SD}=2.8$ comparison areas.]

Figure 2.2: Percentage distribution of women, by areas, according to education

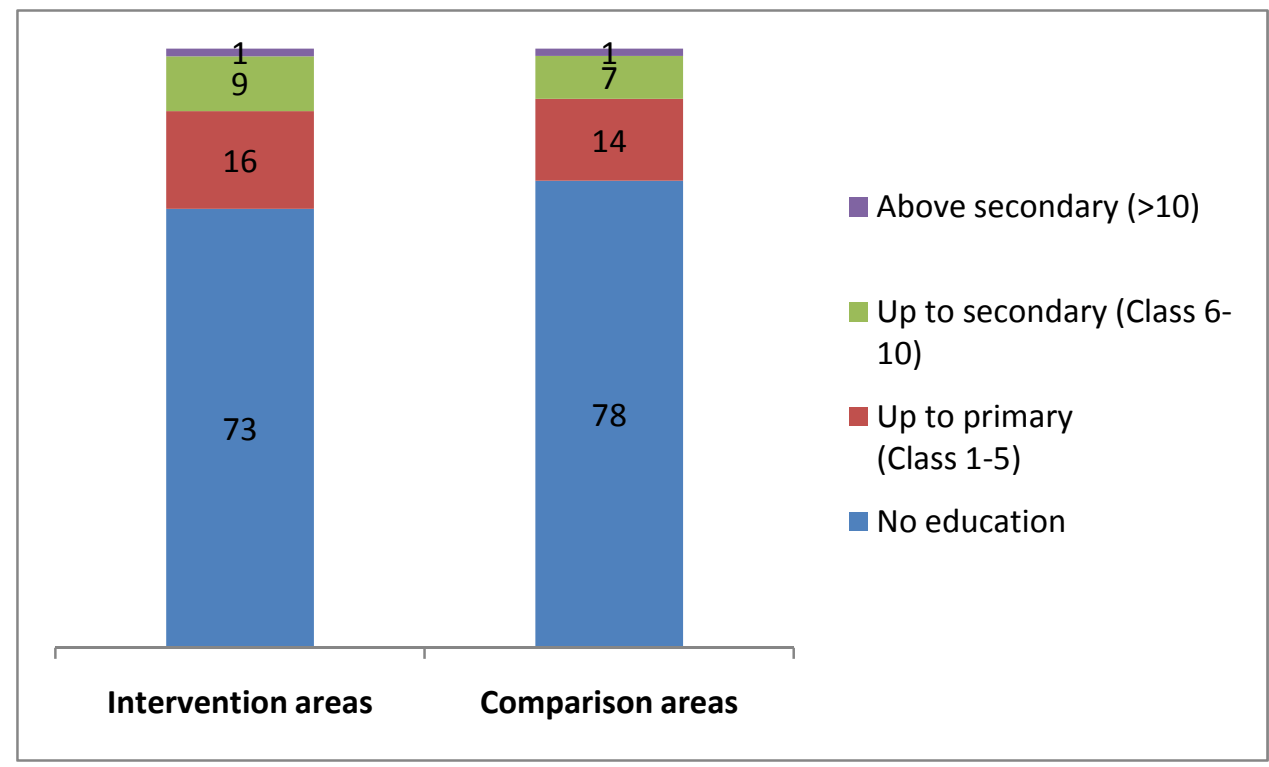

\section{Women's Husbands}

\section{Education}

As shown in Figure 2.3, more than two-fifths of the husbands, in both intervention and comparison areas, were uneducated: 41 percent - intervention areas; 47 percent - comparison areas. However, slightly more than a quarter had attained an education at or beyond class 6 . Those who were educated above secondary school made up only a small percentage. The mean number of years of schooling in the intervention areas was 4.8 and in the comparison areas it was 4.1. [Note: SD=4.7 intervention areas; $\mathrm{SD}=4.4$ comparison areas.] 
Figure 2.3: Percentage distribution of husbands, by areas, according to education

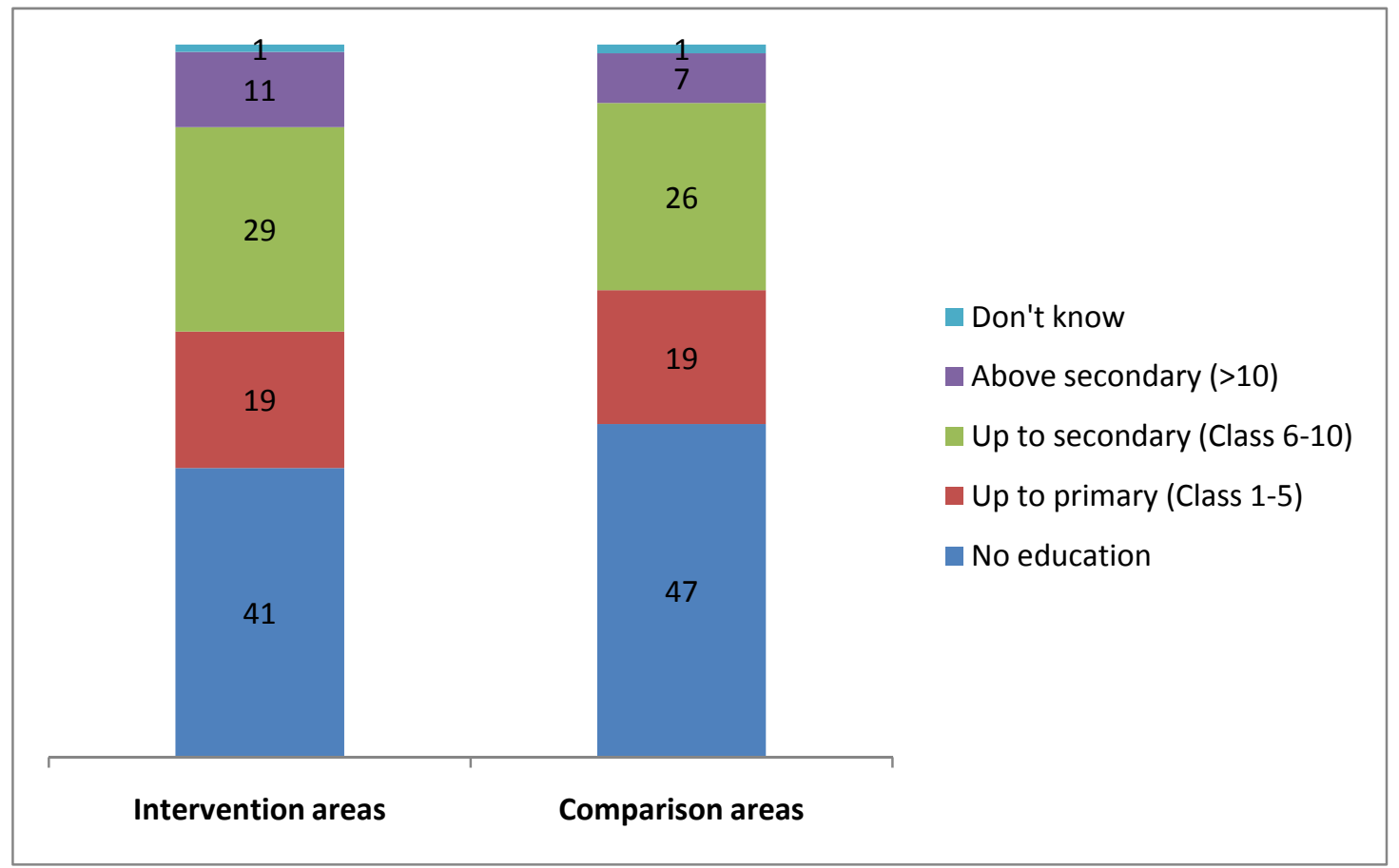

\section{Occupation}

A majority of the husbands in both areas were self-employed (Table 2.1). The second most common profession was government service. The percent engaged in private service was close to 4 percent in both areas.

Table 2.1: Percentage distribution of husbands, by areas, according to occupation

\begin{tabular}{lrr}
\hline Occupation & Intervention areas & Comparison areas \\
\hline Self employed & 81.5 & 88.8 \\
Government service & 9.1 & 4.4 \\
Private service & 4.7 & 4.2 \\
Unemployed & 4.1 & 2.2 \\
Other & 0.6 & 0.2 \\
Don't know & 0.1 & 0.1 \\
\hline
\end{tabular}

\section{Live Births (Parity)}

The proportions of women having 0 children and 1-2 children were similar in both areas, about 20 and 31 percent respectively. The proportion of women having 3-5 children was 29 percent in the intervention areas and 34 percent in the comparison areas (Table 2.2). 
Table 2.2: Percentage distribution of women, by areas, according to live births, stillbirths, abortions and antenatal care visits

\begin{tabular}{lrr}
\hline Variable & Intervention areas & Comparison areas \\
\hline Number of live births & 20.1 & 20.6 \\
0 & 30.8 & 31.4 \\
$1-2$ & 29.1 & 33.7 \\
$3-5$ & 20.0 & 14.4 \\
$5+$ & 3.0 & 2.8 \\
\hline Mean number of live births & & \\
\hline Number of stillbirths & 91.6 & 87.9 \\
0 & 6.5 & 8.5 \\
1 & 0.9 & 1.8 \\
2 & 0.7 & 0.9 \\
3 & 0.2 & 1.0 \\
\hline or more & & \\
\hline Number of abortions (spontaneous and induced)) & 75.1 & 74.0 \\
0 & 16.1 & 17.4 \\
1 & 6.7 & 5.6 \\
2 & 1.3 & 2.1 \\
3 & 0.9 & 1.0 \\
\hline 4 & & \\
\hline Number of antenatal visits & 56.3 & 58.8 \\
At least 1 antenatal visit & 43.7 & 41.2 \\
No antenatal visit & $(872)$ & $(826)$ \\
\hline (N) & & \\
\hline
\end{tabular}

\section{Stillbirths}

About 90 percent of the women in both areas never had a stillbirth (Table 2.2). Among those who had stillbirths, the majority in both intervention and comparison areas had only one stillbirth.

\section{Abortions}

About three-quarters of the women in both areas never had an abortion (Table 2.2). The smallest proportion in both areas belonged to the group with 4 or more abortions ( $\leq 1$ percent). Out of the total abortions in the intervention areas, 95 percent were spontaneous abortions and 5 percent were induced abortions; in the comparison areas, 96 percent of the total abortions were spontaneous and 4 percent were induced.

\section{Antenatal Care}

Antenatal care is defined as an examination of a woman by a skilled health care provider during pregnancy. According to WHO, four antenatal visits are recommended during pregnancy. Close to 60 percent of the women in both the intervention and comparison areas had made at least one antenatal visit, $(p=0.29)$ showing no statistically significant difference between the two areas (Table 2.2).

\section{Provider}

As shown in Table 2.3, a majority of the women who had antenatal checkups went to an MBBS doctor: 80 percent - intervention areas; 86 percent - comparison areas. A very negligible percentage mentioned 
receiving antenatal care from a dai.

Table 2.3: Percentage distribution of women, by areas, according to who provided their antenatal care

\begin{tabular}{lrr}
\hline Provider & Intervention areas & Comparison areas \\
\hline MBBS doctor & 79.6 & 85.8 \\
Nurse & 10.4 & 7.8 \\
LHV & 4.9 & 1.0 \\
Dai/TBA & 3.1 & 3.5 \\
Community midwife & 1.0 & 1.2 \\
Other & 0.8 & 0.4 \\
$(N)$ & $(490)$ & $(486)$ \\
\hline
\end{tabular}

\section{Procedures}

As Table 2.4 shows, among women who had an antenatal checkup, more than 70 percent in both intervention and comparison areas had an ultrasound examination. Essential components of an antenatal checkup -- blood test and urine test -- were each done in only 5 percent of the cases in the intervention areas, while in comparison areas a blood test was done in 10 percent of cases and a urine test in 5 percent.

Table 2.4: Percentage distribution of women, by areas, according to checkup components

\begin{tabular}{lrr}
\hline Component & Intervention areas & Comparison areas \\
\hline Blood deficiency checked & 34.5 & 28.6 \\
Blood pressure checked & 34.9 & 49.2 \\
Ultrasound performed & 70.4 & 73.9 \\
Fetal position checked & 32.2 & 33.7 \\
Weight measured & 4.1 & 15.2 \\
Blood test performed & 4.9 & 9.5 \\
Urine test performed & 5.1 & 5.1 \\
Fetal heart rate checked & 11.2 & 28.2 \\
Other & 1.4 & 0.4 \\
$(N)$ & $(490)$ & $(486)$ \\
\hline
\end{tabular}

Multiple response variable.

\section{Characteristics of Birth Attendants}

\section{Type}

Many of the women in the study used the services of the same birth attendants. There were a total of 566 attendants who helped study women deliver their babies both at home and at health facilities. About 80 percent of the birth attendants in both the intervention and comparison areas were traditional birth attendants/dais (Table 2.5). MBBS doctors were the second major group, but only 6 percent in the intervention areas and about 10 percent in the comparison areas. 
Table 2.5: Percentage distribution of birth attendants, by areas, according to type

\begin{tabular}{lrr}
\hline Type of birth attendant & Intervention & areas \\
\hline Untrained birth attendant/dai & 79.5 & 81.4 \\
MBBS doctor & 5.9 & 9.7 \\
LHV & 4.9 & 4.5 \\
CMW & 2.9 & 1.9 \\
Nurse & 0.7 & 1.5 \\
Homeopathic doctor & 0.3 & 0.4 \\
FWW & 1.0 & 0.4 \\
Midwife & 0.3 & 0.0 \\
Relative & 4.6 & 0.4 \\
(N) & $(303)$ & $(263)$ \\
\hline
\end{tabular}

\section{Age}

More than a quarter of the birth attendants in the intervention areas were in the age group 45-54 years and almost a similar number were 55-64 years of age. In the comparison areas, close to one-third belonged to each of the age groups 45-54 years and 55-64 years. Only small percentages were in the youngest age groups or the oldest age groups in both the intervention and comparison areas (Table 2.6).

Table 2.6: Percentage distribution of birth attendants, by areas, according to sociodemographic variables

\begin{tabular}{lrr}
\hline Variable & Intervention areas & Comparison areas \\
\hline Age & & \\
15-24 & 1.7 & 0.8 \\
$25-34$ & 7.6 & 5.3 \\
$35-44$ & 19.5 & 13.7 \\
$45-54$ & 28.1 & 28.9 \\
$55-64$ & 26.1 & 31.2 \\
$65-74$ & 14.2 & 19.0 \\
$75-85$ & 3.0 & 1.1 \\
Education & & \\
No education & 71.0 & 72.2 \\
Up to primary (class 1-5) & 7.9 & 5.7 \\
Up to secondary (class 6-10) & 9.2 & 7.6 \\
Up to intermediate (up to class 12) & 2.3 & 3.0 \\
Up to graduation (up to class 14) & 1.3 & 1.5 \\
Up to masters/medical graduates (class 16) & 8.3 & 9.9 \\
Marital status & & \\
Married & 64.7 & 57.5 \\
Widow & 30.0 & 39.9 \\
Separated & 1.0 & 0.0 \\
Single & 4.3 & 2.7 \\
(N) & $(303)$ & $(263)$ \\
\hline
\end{tabular}

Note: Total number of birth attendants in both areas was 576 but 10 were in accessible and could not be interviewed . They have been excluded from the analysis.

\section{Education}

Just over 70 percent of the birth attendants in both areas were illiterate. However, about 8 percent in 
the intervention areas and 10 percent in the comparison areas had post-graduate degrees or were medical graduates (Table 2.6).

\section{Marita/ Status}

A major proportion of birth attendants were currently married: 65 percent in the intervention areas and 58 percent in the comparison areas. Widows were the second most common group in both areas. Only a small percent of the birth attendants were single (Table 2.6).

\section{Work Experience}

Most of the birth attendants in both areas had a great deal of work experience, as shown in Figure 2.4. Only a very small percentage had less than a year of work experience.

Figure 2.4: Percentage distribution of birth attendants, by areas, according to years of work experience

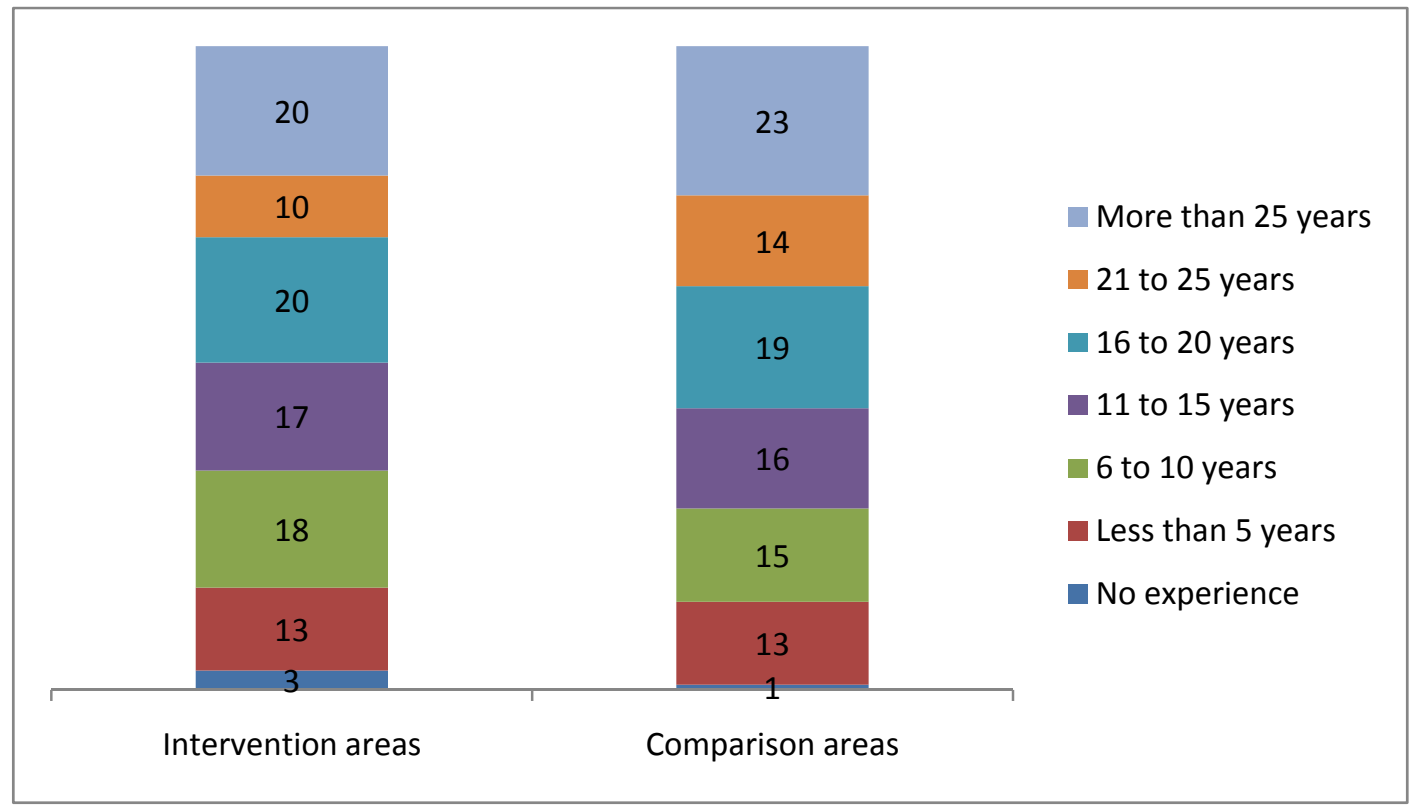

\section{Chapter Summary}

The data presented in this chapter show that respondents in both groups had similar characteristics. This chapter also provides a profile of birth attendants in rural communities and shows that traditional birth attendants are still the most popular source for maternal and child health care in rural areas. The birth attendants in this study were mostly middle-aged women, who were currently married or, to a lesser degree, widowed. One implication is that for widowed village women a career as a birth attendant or dai is a respectable option for earning a livelihood. 



\section{ChAPTER 3. KNOWLEDge: POSTPARTUM HEMORRHAGE AND MISOPROSTOL}

This chapter presents information about the knowledge of postpartum hemorrhage and misoprostol retained by the pregnant women from their initial briefing session carried out during the registration process. The knowledge of the birth attendants who conducted the births of study women was also obtained in a questionnaire that was conducted within 72 hours of the births.

\section{Women's Knowledge}

At the initial contact with the pregnant women, they had been given a short briefing about the study to help them decide if they were interested in participating. This briefing included information on pregnancy, pregnancy care, birth preparedness, and danger signs in pregnancy. For the pregnant women in the intervention areas, information was also provided on misoprostol. When the study teams visited the pregnant women one month before their expected delivery dates, and before giving them a more in-depth counseling session on all of the topics presented during the briefing, they were interviewed and their knowledge and perceptions regarding postpartum hemorrhage (and misoprostol for those in the intervention areas) were assessed. This was done to determine how much of the initial briefing information had been retained because the ability of the pregnant women to internalize the messages about these important pregnancy-related topics was considered an important indicator for compliance. The thinking was that if the women could appreciate why it was important for them to take misoprostol, they would be better prepared to do so. Furthermore, accurate knowledge might well translate into taking the tablets at the correct time and dosage.

\section{Postpartum Hemorrhage}

\section{Danger}

Postpartum hemorrhage is defined as excessive blood loss of $500 \mathrm{ml}$ or more from the genital tract in the first 24 hours following delivery. About 98 percent of women in the intervention areas and 72 percent in the comparison areas perceived that postpartum hemorrhage could be potentially dangerous (Table 3.1). Two percent of the respondents in the intervention areas and 27 percent in the comparison areas did not consider PPH to be dangerous.

Among the women who did not consider PPH to be dangerous, nearly a quarter in both areas believed it to be a normal phenomenon. Of those who thought PPH was not dangerous, 14 percent in the intervention areas and more than 20 percent in the comparison areas thought home remedies were effective or that the dai could easily manage the hemorrhage (Table 3.1).

\section{Causes}

When asked about the causes of postpartum hemorrhage, more than one-third of the women in the intervention areas said that it was caused by retained products of the placenta and another third said delayed delivery of the placenta (spontaneous response). This increased to about 56 percent each upon 
prompting. In the comparison areas, about 10 percent of the respondents considered retained products of placenta (spontaneous response) as a cause of postpartum hemorrhage and fewer thought delayed delivery was a cause (Table 3.2). Upon promoting cervical tears and uterine rupture were considered as an important cause by more than three-quarters of the respondents in the intervention areas and 60 percent in the comparison areas.

Table 3.1: Percentage distribution of women, by areas, according to perceptions and knowledge about postpartum hemorrhage

\begin{tabular}{|c|c|c|}
\hline Variable & Intervention areas & Comparison areas \\
\hline \multicolumn{3}{|l|}{ Perceptions about PPH } \\
\hline Dangerous & 97.6 & 72.3 \\
\hline Not dangerous & 2.4 & 27.1 \\
\hline Don't know & 0.0 & 0.6 \\
\hline$(N)$ & (872) & (826) \\
\hline \multicolumn{3}{|l|}{ Reasons why women thought PPH was not dangerous } \\
\hline Normal phenomena & 23.8 & 24.6 \\
\hline Home remedies are effective & 14.3 & 21.9 \\
\hline Dai can easily manage & 14.3 & 25.9 \\
\hline Don't know & 47.6 & 27.2 \\
\hline Other & 0.0 & 0.4 \\
\hline$(N)$ & (21) & (224) \\
\hline \multicolumn{3}{|l|}{ Signs and symptoms indicating need to refer for $\mathrm{PPH}^{*}$} \\
\hline Skin cold, wet and pale (fainting) & 41.0 & 44.6 \\
\hline Unconsciousness & 20.8 & 33.0 \\
\hline Heavy bleeding continues even after home management & 20.2 & 20.8 \\
\hline Uterus comes out with placenta & 2.8 & 7.4 \\
\hline Don't know & 26.3 & 21.4 \\
\hline Others & 1.2 & 0.7 \\
\hline$(N)$ & (851) & (597) \\
\hline \multicolumn{3}{|l|}{ Appropriate timing for referral } \\
\hline Within 1-2 hours of heavy bleeding & 93.5 & 88.9 \\
\hline Within 2-3 hours of heavy bleeding & 1.1 & 5.0 \\
\hline Within 3-4 hours of heavy bleeding & 0.6 & 0.8 \\
\hline Other & 1.2 & 0.5 \\
\hline Don't know & 3.6 & 4.9 \\
\hline$(N)$ & (851) & (597) \\
\hline
\end{tabular}

*Multiple response variable. 
Table 3.2: Percentage distribution of women, by areas, according to knowledge about causes of PPH*

\begin{tabular}{|c|c|c|c|c|c|c|}
\hline \multirow[b]{3}{*}{ Cause } & \multicolumn{3}{|c|}{ Intervention areas } & \multirow{2}{*}{\multicolumn{3}{|c|}{$\begin{array}{c}\text { Comparison areas } \\
\text { Knowledge }\end{array}$}} \\
\hline & \multicolumn{3}{|c|}{ Knowledge } & & & \\
\hline & Spontaneous & Prompted & None & Spontaneous & Prompted & None \\
\hline Uterine atony & 3.7 & 68.1 & 28.2 & 0.91 & 42.5 & 56.6 \\
\hline Retained products of placenta & 36.4 & 57.6 & 6.0 & 10.2 & 66.3 & 23.5 \\
\hline Delayed delivery of placenta & 33.1 & 56.3 & 10.6 & 6.8 & 56.8 & 36.4 \\
\hline Vaginal tears & 4.6 & 75.6 & 19.7 & 7.9 & 62.4 & 29.6 \\
\hline Cervical tears & 6.4 & 78.3 & 15.3 & 4.3 & 60.6 & 35.1 \\
\hline Uterine rupture & 6.2 & 81.2 & 12.6 & 5.0 & 66.1 & 29.0 \\
\hline$(N)$ & \multicolumn{3}{|c|}{$(872)$} & \multicolumn{3}{|c|}{ (826) } \\
\hline
\end{tabular}

*Multiple response variable.

\section{Referral}

Signs that referral is needed. Women who considered PPH to be dangerous were asked about the signs and symptoms to look for that could indicate a women needs to be referred to a higher-level facility. As seen in Table 3.1, more than 40 percent of the respondents in both areas considered that a woman with postpartum hemorrhage should be referred when her skin becomes cold, wet and pale. The second most common reason for referral was if she becomes unconscious. A quarter of the respondents in the intervention area and one-fifth in the comparison areas did not know the signs and symptoms that warrant the transfer of a woman to a referral facility.

Timing of referral. Respondents in both areas who considered PPH to be dangerous were asked when they thought a woman suffering from PPH should be referred to a health facility (Table 3.1). Most women correctly identified the timing as within 1-2 hour of heavy bleeding; 94 percent - intervention areas; 89 percent - comparison areas.

\section{Misoprostol}

Women in the intervention areas had been provided with information on misoprostol's advantages and use at the initial briefing session, in addition to the same pregnancy related information given to the women in the comparison areas. Most of the women (95 percent) in the intervention areas mentioned that tablets taken orally could prevent PPH. As shown in Table 3.3, about 52 percent of these women were able to recall the name of the drug misoprostol naming it as "Miso", while 48 percent could not do so.

Among those who knew about misoprostol, 92 percent of the women knew, correctly, that misoprostol should be ingested immediately after delivery of the baby and before delivery of the placenta; only 8 percent did not remember the proper time for administering misoprostol (Table 3.3). 


\section{Birth Attendants' Knowledge}

All of the birth attendants who had delivered women participating in the study, whether at home or at the health facility, were interviewed within 72 hours after the delivery, and their knowledge of PPH and misoprostol was assessed.

\section{Postpartum Hemorrhage}

A very high proportion of birth attendants (around 95 percent) in the intervention and comparison areas were able to correctly identify postpartum hemorrhage (Table 3.4).

Table 3.4: Percentage distribution of birth attendants, by areas, according to knowledge about PPH and misoprostol

\begin{tabular}{lrr}
\hline Variable & Intervention areas & Comparison areas \\
\hline Knowledge of PPH & & \\
$\quad$ Know & 95.7 & 95.0 \\
Don't know & 4.0 & 5.0 \\
(N) & $(303)$ & $(263)$ \\
Knowledge of misoprostol name & & na \\
$\quad$ Could recall name of tablet & 60.0 & na \\
$\quad$ Could not recall name of tablet & 40.0 & na \\
Knowledge of timing for administration of misoprostol & & na \\
Correct timing & 98.0 & na \\
Incorrect timing & 2.0 & na \\
Knowledge of side effects of misoprostol* & & na \\
Shivering/chills & 78.0 & na \\
Fever & 66.7 & na \\
Nausea & 25.1 & na \\
Vomiting & 37.6 & na \\
Abdominal pain & 22.0 & 8.2 \\
Don't know & 1.2 & \\
Other & & \\
\hline
\end{tabular}

*Multiple response variable. na=not applicable

\section{Misoprostol}

When asked about misoprostol in the intervention areas, most of the birth attendants (60 percent) could recall the name of the tablet. Close to all of the birth attendants (98 percent) knew the correct time for administering misoprostol. (See Table 3.4.)

About 78 percent of the birth attendants knew shivering is one of the side effects of misoprostol, and 67 percent knew about fever, while smaller percentages knew about other side effects (Table 3.4).

\section{Chapter Summary}

After their initial briefing session, a very high proportion of the pregnant women had a clear concept of what constitutes postpartum hemorrhage, why it is dangerous and what causes it. While 95 percent women in the intervention areas knew that an oral drug could help in preventing PPH, around half could also name it. A high proportion of the birth attendants also retained information about PPH and misoprostol that they had been given during their interactive training. 


\section{ChAPTER 4. Misoprostol Use: SAFETy, ACCEPTABILITY, REFERRAL}

The primary purpose of this research was to evaluate a process that motivated women giving birth at home to take misoprostol, and to take it correctly, and to obtain the cooperation of birth attendants. Apart from compliance, the satisfaction of the women who took misoprostol was also elicited based on their willingness to recommend the drug to others and to purchase it in future. These women were also asked about any side effects they experienced as a result of taking misoprostol. Women in both intervention and comparison areas were asked about their experience of postpartum bleeding.

\section{Safety}

\section{Use}

Out of the 890 women identified in the intervention areas as pregnant, 872 agreed to participate in the study, while 18 refused. Out of the 872 who agreed to participate, 770 delivered at home and were eligible for misoprostol. Among the remaining, 55 were deemed ineligible due to past history or present indication for having a C-section. Additionally, 47 women were excluded due to referral to a facility before delivery for obstetric complications identified during labor.

In the comparison areas, 826 agreed to participate in the study, and 720 women who had home deliveries were included. The other 106 women either had a history of C-sections ( 77 women) and were ineligible or were referred to a facility for other obstetric complications ( 29 women) and excluded from the analysis.

As seen in Table 4.1, 770 eligible women who delivered at home. Out of these 678 (88 percent) ingested misoprostol tablets provided to them in the clean delivery kits, while 92 women (12 percent) did not.

Bivariate analysis revealed no statistically significant difference for number of living children or husband's education on the intake of misoprostol tablets.

Table 4.1: Distribution of women according to misoprostol use and other variables

\begin{tabular}{lcccc}
\hline & \multicolumn{2}{c}{ Did not use misoprostol } & \multicolumn{2}{c}{ Used misoprostol } \\
\cline { 2 - 5 } Variable & Number & Percent & Number & Percent \\
\hline $\begin{array}{l}\text { Place of delivery } \\
\quad \text { Home }(N=770)\end{array}$ & 92 & 11.9 & 678 & 88.0 \\
$\quad \begin{array}{l}\text { Number of living children }(\mathbf{P = 0 . 0 8 )} \\
\quad-1 \quad(N=330)\end{array}$ & 33 & 10.0 & 297 & 90.0 \\
$\quad \begin{array}{l}\quad \text { or more }(N=484) \\
\text { Education of husbands }(\mathbf{P}=\mathbf{0 . 9 )}\end{array} \quad 68$ & 14.0 & 416 & 86.0 \\
$\quad$ Never attended school $(N=332)$ & 41 & 12.3 & 291 & 87.7 \\
$\quad$ Ever attended school $(N=479)$ & 60 & 12.5 & 419 & 87.5 \\
\hline
\end{tabular}




\section{Timing and Dosage}

The recommended time and dosage of misoprostol administration is three tablets to be ingested after the birth of the baby but prior to the delivery of the placenta. Women who delivered at home $647(84$ percent) took the tablets correctly (correct time and correct dose) (Table 4.2). No woman took the tablets before the birth of the baby. There were three twin deliveries in the intervention areas; all of the women delivering twins took the tablets correctly, after the birth of the second twin.

Table 4.2: Distribution of women who used misoprostol, according to variables of use

\begin{tabular}{lrr}
\hline Variable & Number & Percent \\
\hline Dose and timing & & \\
Misoprostol taken correctly (correct time and correct dose: three & 647 \\
$\quad$ tablets, after birth, before delivering placenta) & 31 & 84.0 \\
Misoprostol taken incorrectly (incorrect time or incorrect dose) & 3.0 \\
Side effects ( $N$ =647) & 387 \\
No side effects & 260 & 59.8 \\
Side effects (total)* & 178 & 40.1 \\
Shivering/chills & 68 & 69.3 \\
Fever & 23 & 26.5 \\
Vomiting & 43 & 8.9 \\
Nausea & 42 & 16.7 \\
Abdominal pain & 46.3 \\
\hline
\end{tabular}

*Multiple response variable.

\section{Side Effects}

The 647 women who took misoprostol tablets correctly (correct dose and correct time) were asked about the side effects and 40 percent reported that they had experienced side effects (Table 4.2). The majority reported suffering shivering/chills (69 percent), followed by fever ( 27 percent) and nausea (17 percent). However, in all these cases, the symptoms were transient and did not require referral for specialized care.

\section{Acceptability}

\section{Women}

As seen in Table 4.3, 91 percent of the women who delivered at home said that they would use misoprostol in the future (94 percent in Dadu; 89 percent in Khanewal). When the women who said they would use misoprostol in the future were asked if they would also be willing to purchase the tablets, 93 percent expressed their willingness to do so (99 percent in Khanewal; 87 percent in Dadu). Overall, almost 100 percent of the women who used misoprostol during their home deliveries and said that they would be willing to use misoprostol in the future also said that they would recommend misoprostol to others (only 2 were not willing to recommend misoprostol to others). 
Table 4.3: Distribution of women who used misoprostol and delivered at home, according to variables indicating acceptability of misoprostol

\begin{tabular}{|c|c|c|c|c|c|c|c|c|c|c|c|c|}
\hline \multirow[b]{3}{*}{ Variable } & \multicolumn{4}{|c|}{ Khanewal } & \multicolumn{4}{|c|}{ Dadu } & \multicolumn{4}{|c|}{ Total } \\
\hline & \multicolumn{2}{|c|}{ Willing } & \multicolumn{2}{|c|}{ Not willing } & \multicolumn{2}{|c|}{ Willing } & \multicolumn{2}{|c|}{ Not willing } & \multicolumn{2}{|c|}{ Willing } & \multicolumn{2}{|c|}{ Not willing } \\
\hline & $\mathbf{N}$ & $\%$ & $\mathbf{N}$ & $\%$ & $\mathbf{N}$ & $\%$ & $\mathbf{N}$ & $\%$ & $\mathbf{N}$ & $\%$ & $\mathbf{N}$ & $\%$ \\
\hline Take in future & 309 & 88.5 & 40 & 11.5 & 305 & 93.6 & 21 & 6.4 & 614 & 91.0 & 61 & 9.0 \\
\hline Purchase in future & 305 & 98.7 & 4 & 1.3 & 268 & 87.3 & 39 & 12.8 & 571 & 93.0 & 43 & 7.0 \\
\hline Recommend to others & 309 & 100.0 & 0 & 0.0 & 305 & 99.3 & 2 & 0.7 & 614 & 99.7 & 2 & 0.3 \\
\hline
\end{tabular}

A total of 92 eligible women in the intervention areas who had agreed to use misoprostol did not take the tablets after delivery (Table 4.4). The main reason the women gave for not taking misoprostol was that they forgot; in 22 cases, respondents forgot to take the tablets because of what was described as an emergency situation. Family opposition was seen to be negligible, with only 13 cases reporting hindrance from relatives. Out of these 13 cases, there was only one woman who reported that her husband opposed the use of misoprostol.

Table 4.4: Distribution of women, according to the main reason for not taking misoprostol

\begin{tabular}{lrr}
\hline Reason & Number & Percent \\
\hline Self reservation & 11 & 11.9 \\
Family members opposed & 13 & 14.3 \\
Forgot & 49 & 53.2 \\
TBA / dai opposed & 11 & 11.9 \\
Other & 08 & 8.7 \\
Total & 92 & 100.0 \\
\hline
\end{tabular}

Respondents who were willing to purchase misoprostol tablets in the future were asked about the amount they would be willing to pay. Just over half of the women in both districts said that they would be willing to pay up to Rs. 25 for the three tablets (Table 4.5).

Table 4.5: Distribution of women, according to the amount (in Pakistan rupees) they would be willing to pay for misoprostol, by district

\begin{tabular}{lrrrrrr}
\hline & \multicolumn{2}{c}{ Khanewal } & \multicolumn{2}{c}{ Dadu } & \multicolumn{2}{c}{ Total } \\
\cline { 2 - 7 } Amount & Number & Percent & Number & Percent & Number & Percent \\
\hline $1-25$ & 137 & 55.0 & 97 & 50.8 & 234 & 53.2 \\
$26-50$ & 45 & 18.1 & 65 & 34.0 & 110 & 25.0 \\
$51-100$ & 50 & 20.1 & 21 & 11.0 & 71 & 16.1 \\
$>100$ & 17 & 6.8 & 8 & 4.2 & 25 & 5.7 \\
Total & 249 & 100.0 & 191 & 100.0 & 440 & 100.0 \\
\hline
\end{tabular}

\section{Birth Attendants}

Another indicator of the acceptance of misoprostol is that 98 percent of the birth attendants in the intervention areas who had administered misoprostol tablets and knew the name of the tablets (60 percent of all birth attendants) said that they would recommend the tablets to other clients. 


\section{Referrals}

\section{Referrals for Management of PPH}

As Table 4.6 shows, 3 women in the intervention areas ( 0.38 percent) suffered from postpartum hemorrhage that required referral to a higher-level facility. Out of these, 2 had ingested misoprostol and 1 had not. The woman who had not ingested misoprostol died on reaching the facility, while the other 2 were discharged after receiving routine management. All 3 referred women from the intervention areas were above the age of 30 , and 2 were grand multipara, while one had 3 children. In the comparison areas, 5 women (0.64 percent) were referred for severe PPH. Out of these, 2 died before reaching the appropriate facility. The number of referrals due to postpartum hemorrhage was lower than anticipated while calculating the sample size.

Table 4.6: Distribution of PPH referrals and deaths (as percents of all referrals and all deaths), by areas

\begin{tabular}{|c|c|c|c|c|}
\hline \multirow[b]{2}{*}{ Variable } & \multicolumn{2}{|c|}{ Intervention areas } & \multicolumn{2}{|c|}{ Comparison areas } \\
\hline & $\begin{array}{l}\text { Number } \\
(\mathrm{N}=770)\end{array}$ & Percent & $\begin{array}{l}\text { Number } \\
(\mathrm{N}=720)\end{array}$ & Percent \\
\hline Referrals for PPH & 3 & 0.38 & 5 & 0.64 \\
\hline Deaths due to PPH & 1 & 0.12 & 2 & 0.27 \\
\hline
\end{tabular}

The smaller percents in the intervention areas, although based on small numbers, are given credence by women's perceptions of heavy bleeding by area and use of misoprostol.

\section{Perception of Bleeding in Postpartum Period}

Among the 770 women in the intervention areas and 720 women in the comparison areas who delivered at home, 5.1 percent in the intervention areas and 11.3 percent in the comparison areas perceived heavy bleeding (Table 4.7). It was seen that women in the comparison areas were twice as likely to perceive suffering from heavy bleeding as compared to the intervention areas, with a statistically significant difference.

Table 4.7: Distribution of women who had home deliveries, by areas, according to perception of excessive postpartum vaginal bleeding, by areas

\begin{tabular}{lrrrrr}
\hline & \multicolumn{5}{c}{ Perception of heavy bleeding } \\
\cline { 2 - 6 } Area & Not perceived & Percent & Perceived & Percent & Odds ratio \\
\hline Comparison & 638 & 88.6 & 82 & 11.3 & 1 \\
Intervention & 730 & 94.8 & 40 & 5.1 & 0.42 \\
\hline Pvalue $=0.00$ & &
\end{tabular}

$P$ value $=0.00$

\section{Perception of Bleeding in Postpartum Period and Misoprostol Intake}

While examining perception of postpartum bleeding with the correct or incorrect intake and no intake of misoprostol we found that respondents who correctly took misoprostol were less likely to have perceived heavy bleeding in the postpartum period (Table 4.8). 
Table 4.8: Distribution of women who had home deliveries, by correct intake, incorrect intake and no intake of misoprostol tablets, according to perception of excessive postpartum vaginal bleeding

\begin{tabular}{lrrrrrr}
\hline & \multicolumn{5}{c}{ Perception of heavy bleeding } \\
\cline { 2 - 7 } Area & $\begin{array}{r}\text { Not } \\
\text { perceived }\end{array}$ & Percent & Perceived & Percent & Odds ratio & P value \\
\hline $\begin{array}{l}\text { Intervention } \\
\text { (incorrectly taken) }\end{array}$ & 29 & 93.5 & 2 & 6.5 & 0.53 & 0.4 \\
$\begin{array}{l}\text { Intervention } \\
\text { (correctly taken) }\end{array}$ & 615 & 95.6 & 32 & 4.9 & 0.40 & 0.00 \\
Not taken & 86 & 85.0 & 6 & 15.0 & 0.76 & 0.5 \\
\hline
\end{tabular}

Comparison area is the reference

\section{Referrals Due to Other Obstetric Complications and MMR}

In the intervention areas, 47 women were referred to a health facility by the available birth attendant due to obstetric complications before delivery; while in the comparison areas 29 women were referred. Table 4.9 shows the distribution of all referrals by cause. Besides mortalities due to PPH, 2 other obstetric deaths occurred in the intervention areas and 3 additional obstetric deaths took place in the comparison areas. Total deaths in the intervention areas were 3. Apart from PPH, the other causes of mortality were antepartum hemorrhage and eclampsia. In comparison areas, there were 5 deaths. Apart from PPH the other causes of mortality included complications of cancer of the larynx, uterine rupture and cardiac disease. Maternal mortality ratio (MMR) in the intervention area was $344 / 100,000$ live births and 605/100,000 live births in the comparison area.

Table 4.9: Distribution of all referrals in intervention and comparison areas, by cause

\begin{tabular}{|c|c|c|c|c|c|}
\hline \multicolumn{3}{|c|}{ Intervention areas } & \multicolumn{3}{|c|}{ Comparison areas } \\
\hline Cause & $\begin{array}{r}\text { Number of } \\
\text { referrals }\end{array}$ & Percent & Cause & $\begin{array}{r}\text { Number of } \\
\text { referrals }\end{array}$ & Percent \\
\hline Antepartum hemorrhage & 3 & 6.4 & Antepartum hemorrhage & 3 & 10.3 \\
\hline Prolonged labor & 33 & 70.2 & Prolonged labor & 18 & 62.1 \\
\hline Malpresentation (breech) & 4 & 8.5 & Malpresentation (breech) & 1 & 3.4 \\
\hline $\begin{array}{l}\text { Premature rupture of } \\
\text { membrane }\end{array}$ & 2 & 4.3 & $\begin{array}{l}\text { Premature rupture of } \\
\text { membrane }\end{array}$ & 1 & 3.5 \\
\hline Postpartum hemorrhage & 3 & 6.3 & Postpartum hemorrhage & 5 & 17.2 \\
\hline Self-referral & 2 & 4.3 & Self-referral & 1 & 3.5 \\
\hline Total & 47 & 100.0 & Total & 29 & 100.0 \\
\hline
\end{tabular}




\section{Chapter Summary}

Results from this chapter demonstrate that through proper counseling and information exchange it is possible to introduce a new intervention in rural communities. Of the eligible women delivering at home, 88 percent took the tablets and out of these 84 percent were able to take the correct dose at the right time, despite the women's high level of illiteracy. The side effects reported by the women were of a transient nature and did not require hospital management. 


\section{CHAPTER 5. DISCUSSION AND RECOMMENDATIONS}

\section{Discussion}

In Pakistan, around 60 percent of the population resides in rural areas, often not near health facilities, which tend to be concentrated in urban areas. With 61 percent of deliveries still being carried out by unskilled birth attendants at home, Pakistan is one of the few countries in the region that continues to have a high maternal mortality ratio. Due to the paucity of emergency obstetric care facilities, encouraging institutional deliveries is not a viable option for improving maternal outcomes at this time. For this reason, the government of Pakistan introduced the national MNCH program in 2006. A goal of this program is to employ 12,000 trained community midwives to improve access to skilled birth attendants in rural communities. At present, the deployment of these workers has been limited, as few have been able to meet their placement requirements. Those who have returned to their respective communities require some time before they are fully established and recognized as a viable and worthwhile alternative to the existing traditional birth attendants.

To make pregnancy safer, an interim strategy has to be introduced until such time that community midwives are in a position to completely replace traditional birth attendants. One approach is to train the existing TBAs to adopt skills that can make their practice safer. Such an approach has been tried in many parts of the world but with mixed results. In Pakistan the Population Council, through the Safe Motherhood Applied Research and Training Project (Miller and Rashida, 2006), was able to demonstrate a 22 percent fall in perinatal mortality through community awareness and training of traditional birth attendants (in DG Khan district, Punjab province). A study, using a cluster randomized controlled trial in Sindh province, showed a significant reduction in perinatal mortality in intervention clusters where TBAs were trained (Jokhio, Winter and Cheng, 2005).

The Pakistan Demographic and Health Survey 2006-07 shows that the leading cause of maternal mortality in Pakistan is postpartum hemorrhage. Globally, efforts are underway to improve the prevention of postpartum hemorrhage through advocating the active management of the third stage of labor (AMTSL). Empirical evidence shows that the administration of uterotonic drugs in the third stage of labor can markedly reduce the incidence of PPH. Among the safest options available are the injectable drugs oxytocin and methergin; however, both require skilled attendants for administration and, being heat labile, special storage conditions. In resource-constrained settings, misoprostol provides a good alternative because it is inexpensive, heat stable, taken orally, has a long shelf life and can be administered within thpe home setting. While WHO does not recommend misoprostol use over injectable oxytocin, it recognizes the problems associated with the use of oxytocin in rural communities and, therefore, encourages more research on the use of misoprostol. 
The Ministry of Health and Family Welfare in India has endorsed the use of misoprostol for deliveries in rural settings, (Ministry of Health and Family Welfare, 2005). In January 2006, the Nigerian health agency also approved the use of misoprostol tablets, initially in hospital and clinic settings, for the prevention and treatment of postpartum hemorrhage (Greensfelder, 2006).

While the efficacy of misoprostol has been well established, the feasibility of its administration in societies that are very closely governed by traditional values has not been documented extensively. As in many developing countries, rural communities in Pakistan are steeped in traditions and cultural norms, including those followed by traditional birth attendants, who have usually learned their skills from previous generations of TBAs in their families whose practices are at times detrimental to health. Emerging evidence shows that trained community health workers can be utilized to distribute misoprostol tablets through a home-based approach. For instance, in a study from Indonesia, researchers trained community volunteers to provide women with information about the prevention of postpartum hemorrhage, give them misoprostol tablets, and provide follow-up support. This community-based approach was noted as being safe and acceptable to the women, contributing to their willingness and ability to use the drug appropriately (JHPIEGO, 2004).

In another study, from Afghanistan, it was seen that through proper education 70 percent of the eligible women used misoprostol in the target communities (Sanghvi et al., 2010). Another study, from rural Tanzania, also shows that after training TBAs, they were able to recognize and manage PPH effectively (Prata et al., 2005).

This OR study was designed to test, on a large scale, the hypothesis that it is feasible to safely distribute 600 micrograms of misoprostol through birth attendants trained in its use, who would ensure that the drug was taken correctly by women delivering at home. Our results show that 88 percent of eligible women ingested the drug (90 percent compliance in Khanewal and 84 percent in Dadu), reinforcing the assumption that proper counseling and training can alter well-entrenched behaviors and practices. Our results also show that side effects, experienced by 41 percent of the women who took the drug, were transient and did not require any specific management. In fact, this did not prevent 91 percent of the women who took misoprostol at home from saying that they would take the drug for future deliveries. Nearly 100 percent of the women who took misoprostol at home and said they would be willing to use it in future also expressed their willingness to recommend the drug to others.

In this study, as in the study in Indonesia, the safety and acceptability of the drug, and the feasibility of creating awareness about misoprostol and managing distribution of the tablets, were considered key to the successful use of misoprostol to prevent PPH. Three important factors contributed to the proportion of women who accepted and used the tablets. First and foremost was community awareness, which, to a great extent, was facilitated by local lady health workers (LHWs) targeting community pregnant women and their family members; second, and also part of community awareness, were discussions with community elders and influentials; and, third were the counseling sessions that provided accurate and credible information directly to the women, their family members and husbands, and birth attendants, and included culturally appropriate IEC materials. Women who were given the misoprostol tablets were briefed using a pictorial booklet designed especially for this purpose. Another pictorial instruction sheet was enclosed in the clean delivery kits that contained misoprostol tablets. We found 
that both the use of the booklet and the instruction sheet in counseling the pregnant women and their chosen birth attendants, including next of kin, greatly contributed to the high rate of women using the tablets correctly and safely (84 percent of the women used the tablets correctly at home).

After providing information regarding postpartum hemorrhage and misoprostol, we interviewed the women close to their time of delivery to see what information they had retained. Our research shows a high level of awareness in women regarding postpartum hemorrhage, with a substantially high proportion of them holding the view that postpartum hemorrhage is potentially dangerous. Another heartening finding was that the majority knew the point at which it was necessary to refer a woman in case of postpartum hemorrhage. Nearly half of the respondents in the intervention area (52 percent) remembered the name of misoprostol (most referred to it as "miso").

An indicator related to the correct use of misoprostol is the number of referrals. In our study, we found that the number of women who were referred for PPH-related complications was nearly half those in the comparison areas. Although the numbers are small, 3 women were referred from the intervention areas, while 5 were referred from the comparison areas. Furthermore, the women in the intervention areas perceived less bleeding in the postpartum period as compared to the comparison areas. As for maternal mortality, there was one death from PPH reported in the intervention areas (in this case, the woman had not taken misoprostol tablets) and two PPH-related deaths in the comparison areas. These facts indicate that women in the intervention areas were less likely to be transferred to a higher-level facility than women in the comparison areas. In total, there were 4 maternal deaths in the intervention areas and 5 deaths in the comparison areas.

In the intervention areas of our study, we provided clean delivery kits to both the birth attendants and the pregnant women to ensure that a clean delivery kit and misoprostol tablets were available at the time of delivery, in case the birth attendant did not arrive at the delivery in time.

A majority of the 12 percent of the women who did not take misoprostol said that they forgot to take the tablets on time. This reaffirms the need to remind women to keep the tablets readily available once labor pains commence.

Another finding from our study that may have programmatic implications is that the majority of the TBAs were married and in the middle age groups, the next largest group was widows. The national $\mathrm{MNCH}$ program may try to target widows who are self-supporting and require a respectable way of making a living.

Results from a study in Egypt recommend the use of misoprostol even in hospital settings if there are staff shortages, refrigeration issues and/or high caseloads, since misoprostol offers the advantage of a one-drug regimen, stability and easy administration, as compared to injectable uterotonics (Prata et al., 2006).

The results from our study provide a useful addition to the literature on the feasibility of home-based administration of misoprostol in the region, furthering the case for inclusion of the drug in the protocol for active management of the third stage of labor at the community level. Our study also dispels the notion that TBAs cannot contribute to lowering maternal mortality: by introducing a simple, low-cost, 
easy-to-use technology, TBAs can play a role in reducing one of the largest single causes of maternal deaths.

\section{Recommendations}

- Train community based providers in the use of misoprostol in resource constrained settings

The results from our study further substantiate the already available empirical evidence that recommends the use of misoprostol in resource-constrained settings by community providers. For this purpose training needs to be imparted to LHW's and community midwives in the use of misoprostol including its dosage, side effects and their management.

- Empower families to make pregnancies safer through information

Raising community awareness regarding the need for birth spacing, antenatal checkups, proper nutrition during pregnancy, use of supplements, immunization, use of clean delivery kits at the time of delivery, and postpartum use of misoprostol must be carried out, especially in rural communities. In this regard LHWs through their support group meetings can especially raise awareness regarding use of misoprostol by delivering women. 


\section{BIBLIOGRAPHY}

Abou Zhar, C; Royston, E. 1991. Maternal mortality: A global factbook. Geneva: WHO.

Afolabi E O, Kuti O, Orji E O, Ogunniyi S O 2010. Oral misoprostol versus intramuscular oxytocin in the active management of the third stage of labour. Singapore Med J 2010; 51(3): 207

Blum, J; Alfirevenic, Z; Walraven, G; Weck, A; Winikoff, B. 2007. Treatment of postpartum hemorrhage with misoprostol. Int J Gyn \& Obst 99: 202-205.

Carpenter, JP. 2001. Misoprostol for prevention of postpartum hemorrhage: An evidence-based review by the US Pharmacopeia. US Pharmacopeia, Global Assistance Initiative: Rockville, MD.

Cook, CM; Spurrett, MM; Murray, H. 1999. A randomized clinical trial comparing oral misoprostol with synthetic oxytocin or syntometrine in the third stage of labor. Aust and NZ J Obstet Gynaecol 39(4): 414-9.

Derman, R; Kodkany, BS; Goudar, SS; Geller, SE; Naik, VA; Bellad, MB; Patted, SS; Edlavitch, SA; Hartwell, $\mathrm{T}$; Chakraborty, H; Moss, N. 2006. Oral misoprostol in preventing postpartum haemorrhage in resource-poor communities: A randomized controlled trial. The Lancet 368 (9543): 1248-1253.

Goldberg, AB; Greenberg, MB; Darney, PD. 2001. Misoprostol and pregnancy. N Engl J Med 344:38-47.

Greensfelder, L. Old drugs new use will save Nigerian women's lives. Berkeley: UC Berkeley News, 2006.

Gülmezoglu, AM; Villar, J; Ngoc, NT; Piaggio, G; Carroli, G.; Adetoro, L; Abdel-Aleem, H; Cheng, L; Hofmeyr, G; Lumbiganon, P; Unger, C.; Prendiville, W; Pinol, A; Elbourne, D; El-Refaey, H; Schulz, K. 2001. WHO multicentre randomised trial of misoprostol in the management of the third stage of labour. Lancet 358: 689-95.

Gynuity Health Projects, Aga Khan University Karachi and Family Care International. 2009. Misoprostol for the Prevention of Postpartum Hemorrhage: Findings from Clinical Research Trial in Chitral, Pakistan. Available at: http://gynuity.org/resources/info/misoprostol-for-the-prevention-of-pphen/. Last accessed September 14, 2010.

JHPIEGO. 2004. Program Brief. Preventing Postpartum Hemorrhage: A community-based approach proves effective in rural Indonesia. Baltimore, USA: Maternal and Neonatal Health Program, JHPIEGO.

Jokhio, AH; Winter, H; and Cheng, KK. 2005. An Intervention Involving Traditional Birth Attendants and Perinatal and Maternal Mortality in Pakistan. Obstetrical \& Gynecological Survey 60(10):641-42.

Kodkany, BS; Derman, RJ; Goudar, SS; Geller, SE; Edlavitch, SA; Naik, VA; Patel, A; Bellad, MB; and Patted, SS. 2004. Initiating a novel therapy in preventing postpartum hemorrhage in rural India: A joint collaboration between the United States and India. Int J Fertil Womens Med 49(2): 9196.

Kwast, BE. 1991. Postpartum hemorrhage: its contribution to maternal mortality. Midwifery 7: 64-70.

Langenbach, C. 2006. Misoprostol in preventing postpartum hemorrhage: A meta-analysis. Int J 
Gynaecol Obstet 92: 10-18.

Miller P and Rashida G. 2006. Safe Motherhood Applied Research and Training Project (SMART) Project Overview; report no.1, Population Council, Islamabad.

Ministry of Health and Family Welfare. 2005. Guidelines for ante-natal care and skilled attendance at birth by ANMs and LHVs. New Delhi, India: Government of India, Maternal Health Division, Department of Family Welfare.

NIPS (National Institute of Population Studies) and Macro International, Inc. 2008. Pakistan Demographic and Health Survey (PDHS) 2006-07. National Institute of Population Studies and Macro International Inc.: Islamabad, Pakistan and Calverton, Maryland.

Ng, PS; Chan, AS; Sin, WK; Tang, LC; Cheung, KB; Yuen, PM. 2001. A multicentre randomized controlled trial of oral misoprostol and i.m. syntometrine in the management of the third stage of labour. Hum Reprod 16: 31-35.

Prata, N; Hamza, S; Gypson, R; Nada K. 2006. Misoprostol and active management of the third stage of labor. Special article. Int Jour Gyne Obst 94: 149-155.

Prata, N; Mbaruku, N; Campbell, M; Potts, M; Vahidnia, F. 2005. Controlling postpartum hemorrhage after home births in Tanzania. Special article. Int Jour Gyne Obst 90: 51-55.

Ratnam, SS; Viegas, OAC; Singh, K. 1989. Magnitude and causes of maternal mortality as a basis for its prevention. In E. Kassel and A.K. Awan, editors, Maternal and child care in developing countries, pp. 80-90. Ott Publishers: Zurich, Switzerland.

Rosner B. 1995 Fundamentals of biostatistics. 4th ed. Harrisonburg, VA: Wadsworth.

Sample size calculations. 2009. Accessed at: [http://www.sgul.ac.uk/index.cfm?DD25D103-C079-6609F78D-BC005970DCD9\#three] on February 13, 2009.

Sanghvi, H; Ansari, N; Prata, NJV; Gibson, H; Ehsan, AT; Smith, JM. 2010. Prevention of postpartum hemorrhage at home birth in Afghanistan. Int Jour Gyne Obst 108(3): 276-281.

Sanghvi, H; Lewison, D. 2006. Preventing mortality from postpartum hemorrhage in Africa: Moving from research to practice. Conference Report, Uganda, pp. 33-36. Accessed at: [http://www.accesstohealth.org/toolres/pdfs/ACCESSpphconfrptEN.pdf] on February 13, 2009.

Sanghvi, HCG; Kinzie, B; McCormick, ML. 2002. Reducing postpartum hemorrhage: Routine use of active management of the third stage of labor. In Making Childbirth Safer Through Promoting Evidence-Based Care. Technical Report. Washington, D.C.: Global Health Council.

Selo-Ojeme, DO. 2002. Primary postpartum haemorrhage. J Obstet Gynaecol 22: 463-69.

Sultana, N; Khatun, M. 2007. Misoprostol versus oxytocin in the active management of the third stage of labour. J Bangladesh Coll Phys Surg 25:73-76.

Turmen, T. 1996. Safe motherhood: a global problem. In: Report from a symposium on the prevention and management of anemia in pregnancy and postpartum hemorrhage, pp. 1-13. Zurich: World Health Organization. Zurich.

Walraven, G; Blum, J; Dampha, Y; Sowe, M; Morison, L; Winikoff, B; Sloan, N. 2005. Misoprostol in the management of the third stage of labour in the home delivery setting in rural Gambia: $A$ 
randomised controlled trial. BJOG 112(9): 1277-83.

Wiknjosastro, G; Sanghvi, H. 2004. Preventing PPH among women living in areas where a high proportion of births are not attended by skilled providers: Safety, acceptability, feasibility and program effectiveness (SAFE) demonstration project of community-based distribution of misoprostol for prevention of PPH in rural Indonesia. Proceedings of Preventing Postpartum Hemorrhage: From Research to Practice, pp. 20-24.. Bangkok, Thailand, January 20-24, 2004.

World Health Organization. 2004. Maternal Mortality in 2000: Estimates Developed by WHO, UNICEF and UNFPA. Geneva: World Health Organization.

World Health Organization. 2009. Statement: WHO statement regarding the use of misoprostol for postpartum hemorrhage prevention and treatment. Geneva: World Health Organization, Department of Reproductive Health and Research.

World Health Organization. 2010. Statement: Clarifying WHO position on misoprostol use in the community to reduce maternal death. Geneva: World Health Organization, Department of Reproductive Health and Research.

Zuberi, NF; Durocher, J; Sikander, R; Baber, N; Blum, J; Walraven, G. 2008. Misoprostol in addition to routine treatment of postpartum hemorrhage: A hospital-based randomized-controlled trial in Karachi, Pakistan. BMC Pregnancy and Childbirth 8:40. 



\section{ANNEX}

\section{Annexure 1. Mobile Network}

In case of emergency

\begin{tabular}{|c|}
\hline Husband /Next of kin \\
Will call \\
Logistics supervisor \\
\hline
\end{tabular}

Community person responsible for provision of transport

Patient shifted to referral facility

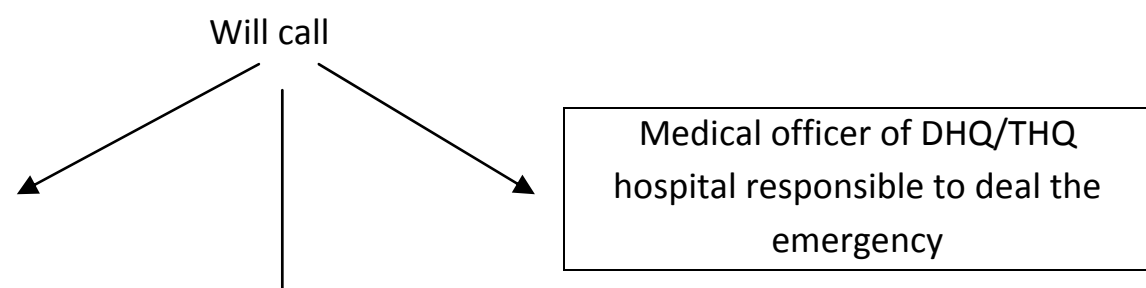

Social scientist and inform about the emergency

Will inform

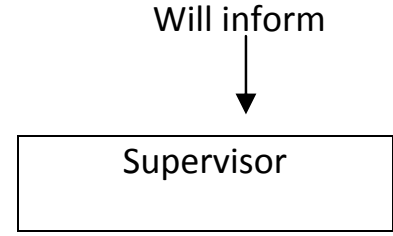

Will inform

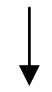

Principal investigator

Note: Separate referral cards were made for intervention \& comparison areas and provided in households of all the recruited women 


\section{Annexure 2: Referral Form}

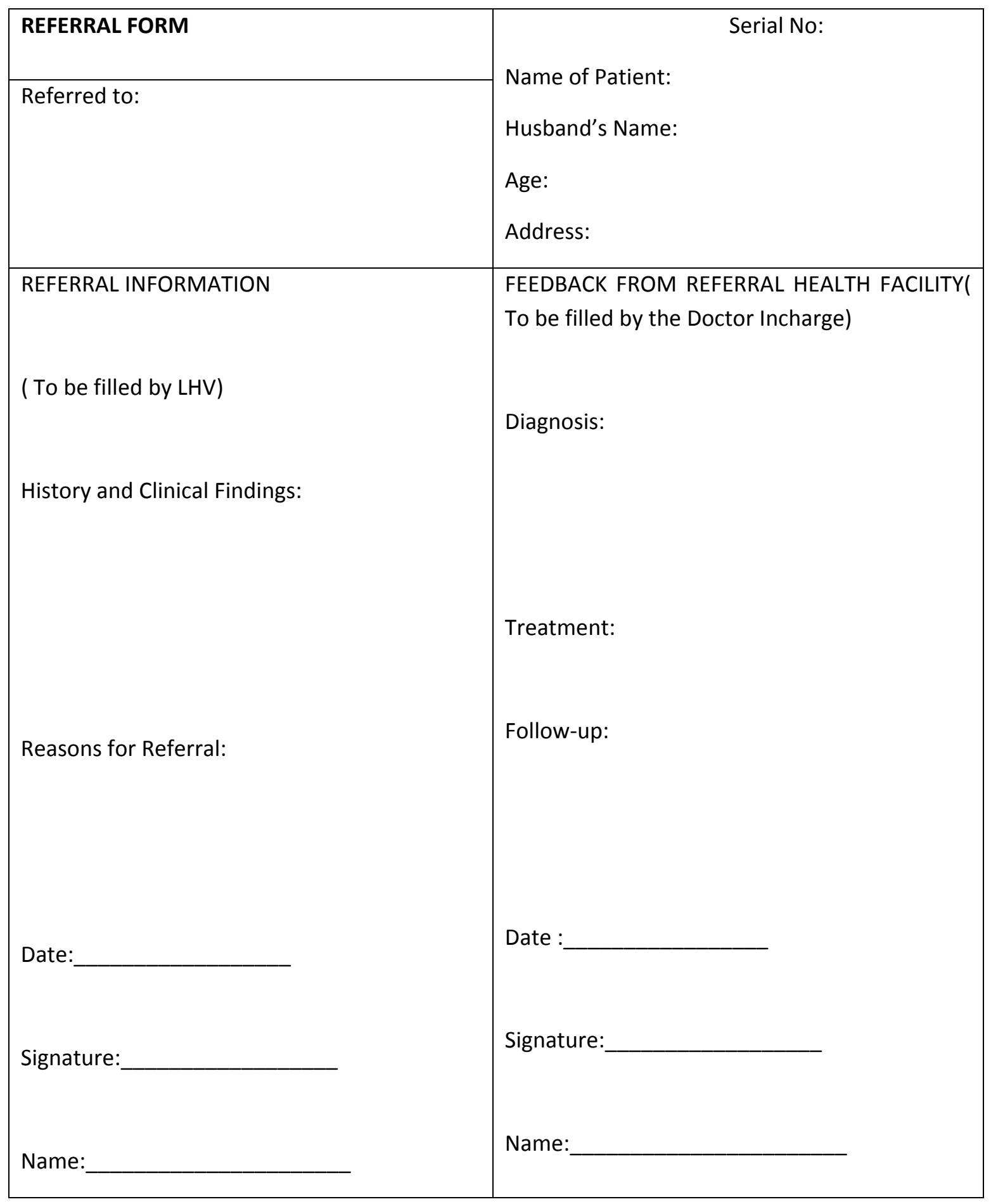




\section{Annexure 3: Pregnant Woman Registration Form}

\begin{tabular}{|c|c|c|c|c|}
\hline 1 & \multicolumn{2}{|l|}{ 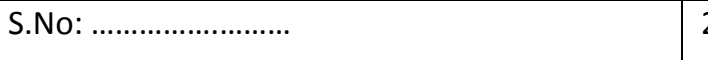 } & \multicolumn{2}{|c|}{ Registration Date } \\
\hline 3 & \multicolumn{2}{|l|}{ Name: } & \multicolumn{2}{|c|}{ Husband's Name: } \\
\hline 5 & \multicolumn{4}{|l|}{$\begin{array}{l}\text { Address/Village } \\
\text { ( Postal Address ) }\end{array}$} \\
\hline 6 & \multicolumn{4}{|l|}{ Age (Years) } \\
\hline 7 & \multicolumn{4}{|l|}{ Last Menstrual Period (LMP) } \\
\hline 8 & \multicolumn{4}{|l|}{$\begin{array}{l}\text { Expected Date of Delivery ( } \\
\text { EDD ) }\end{array}$} \\
\hline \multirow{3}{*}{9} & \multirow{3}{*}{ Trimester of Pregnancy } & \multicolumn{2}{|c|}{1 - 3 Months of pregnacy } & 1 \\
\hline & & \multicolumn{2}{|c|}{ 4-6 Months of pregnacy } & 2 \\
\hline & & \multicolumn{2}{|c|}{7 - 9 Months of pregnacy } & 3 \\
\hline 10 & Gravida ( No. of pregnancies ) & \multirow{2}{*}{\multicolumn{3}{|c|}{ ( If answer is 1 then go to column 14 ) }} \\
\hline 11 & $\begin{array}{l}\text { Parity ( No. of births after } 28 \\
\text { weeks of Pregnancy) }\end{array}$ & & & \\
\hline 12 & No. of Abortions & \multicolumn{3}{|c|}{ ( If answer is none write 00 ) } \\
\hline \multirow{6}{*}{13} & \multirow{6}{*}{ Past Complications } & \multicolumn{2}{|c|}{$\begin{array}{ll}\text { Hemorrhage } & \text { during } \\
\text { pregnancy } & \end{array}$} & 01 \\
\hline & & \multicolumn{2}{|c|}{ Postpartum Hemorrhage } & $\mathrm{O} 2$ \\
\hline & & \multicolumn{2}{|l|}{ Cesarean Section } & $\mathrm{O3}$ \\
\hline & & \multicolumn{2}{|l|}{ Epilepsy / Fits } & 04 \\
\hline & & \multicolumn{2}{|l|}{ Others ( Specify ) } & 77 \\
\hline & & \multicolumn{2}{|l|}{ No Complications } & 00 \\
\hline
\end{tabular}




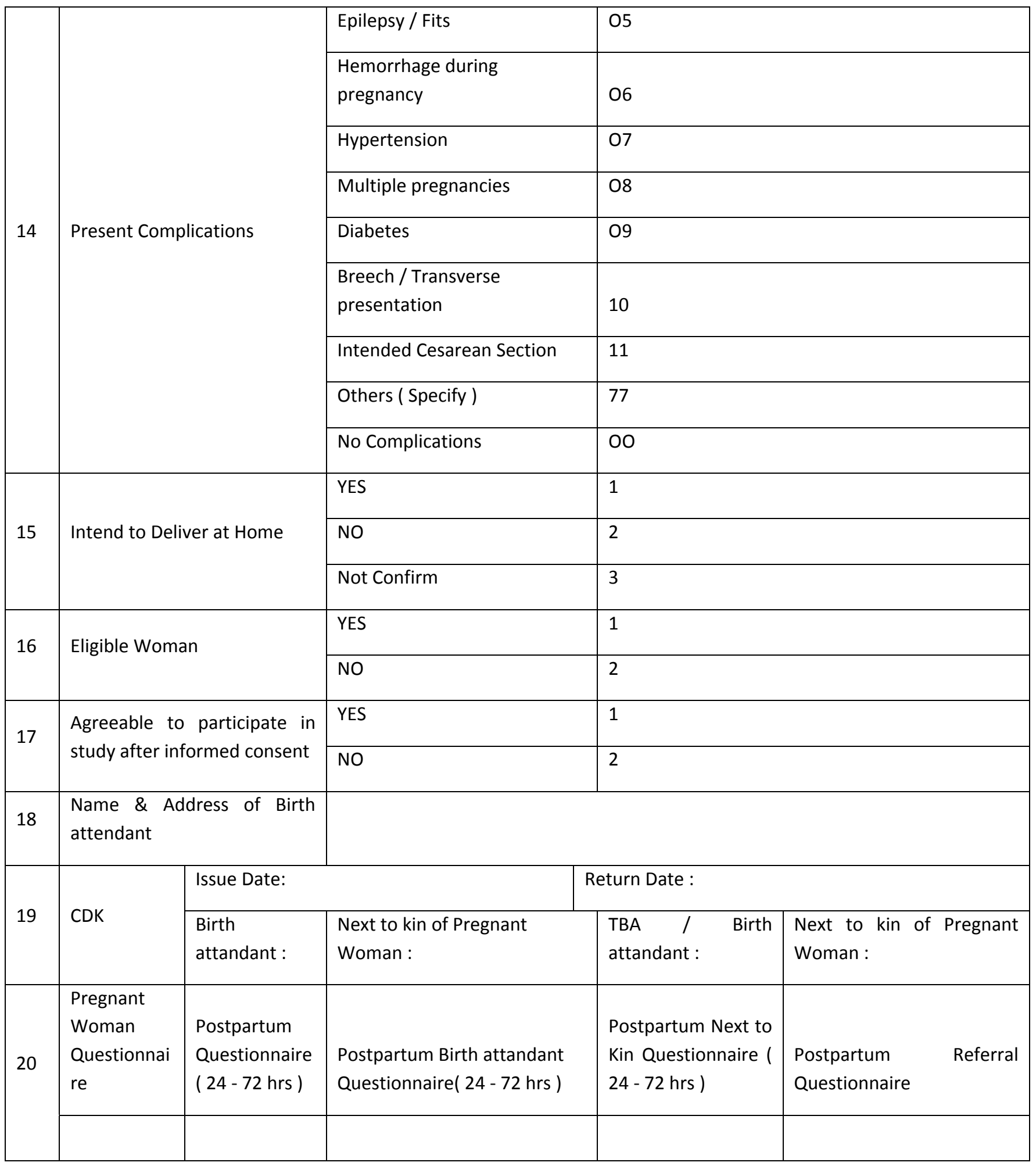




\section{Annexure 4: Serious Adverse Event Report}

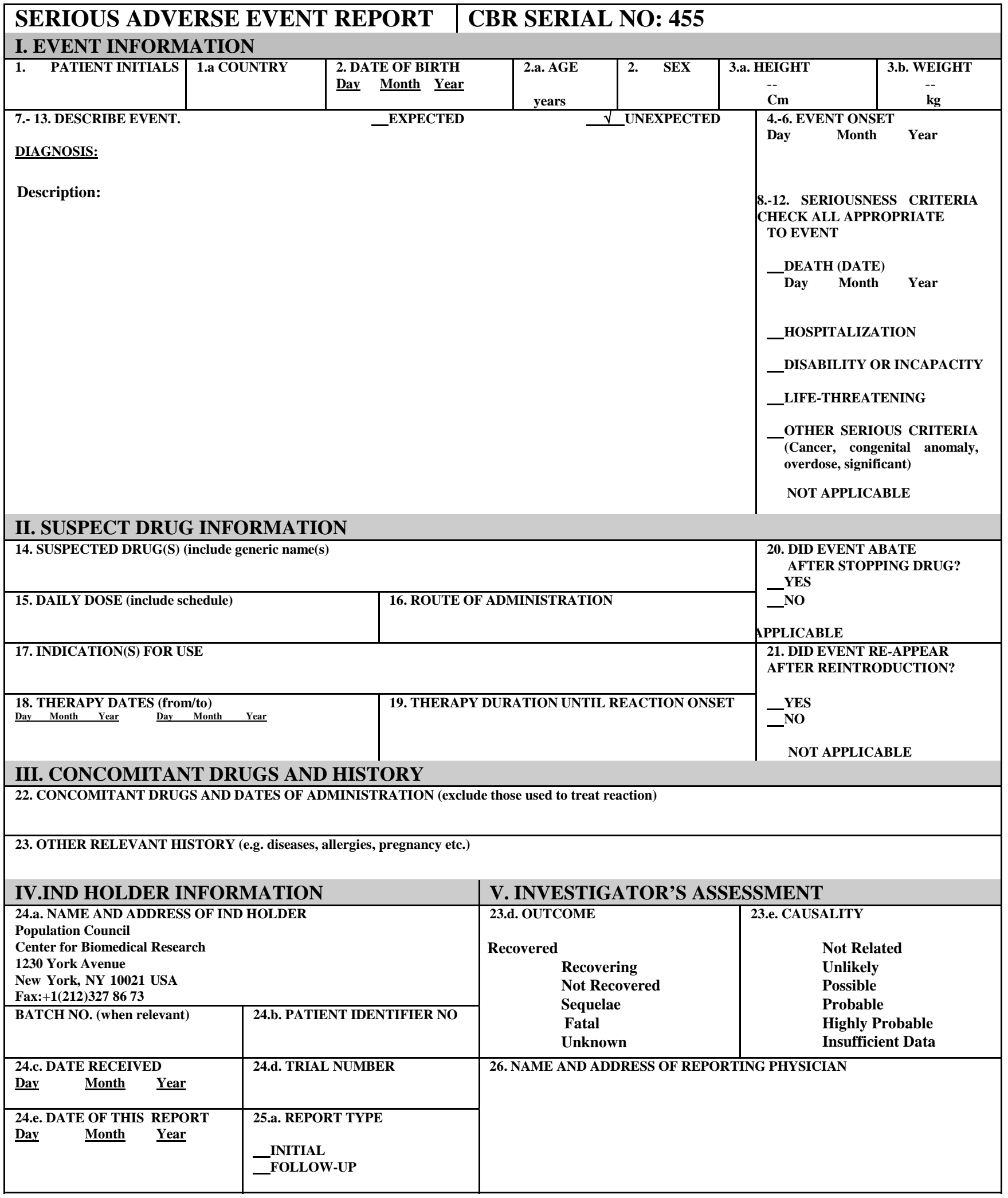




\section{Annexure 5: Timeline}

\section{Activity in Months}

UC identification

Selection of Social Scientists

Identification of Birth Attendants \& LHVs

Development \& Urdu translation of training material \& questionnaires Development of pictorial

Training of Social Scientists, Birth attendants \& LHVs

\section{Registration of Eligible pregnant women}

Orientation \& awareness of women

Supply of Misoprostol to Birth Attendants \& EPWs in CDKs

Data collection

Monitoring visits

Data analysis

Report preparation

Dissemination \begin{tabular}{|l|l|l|l|l|l|l|l|l|l|l|l|l|l|}
\hline May Jun & July & Aug & Sep & Oct & Nov & Dec & Jan & Feb & Mar & Apr & May Jun & Jul & Aug
\end{tabular}
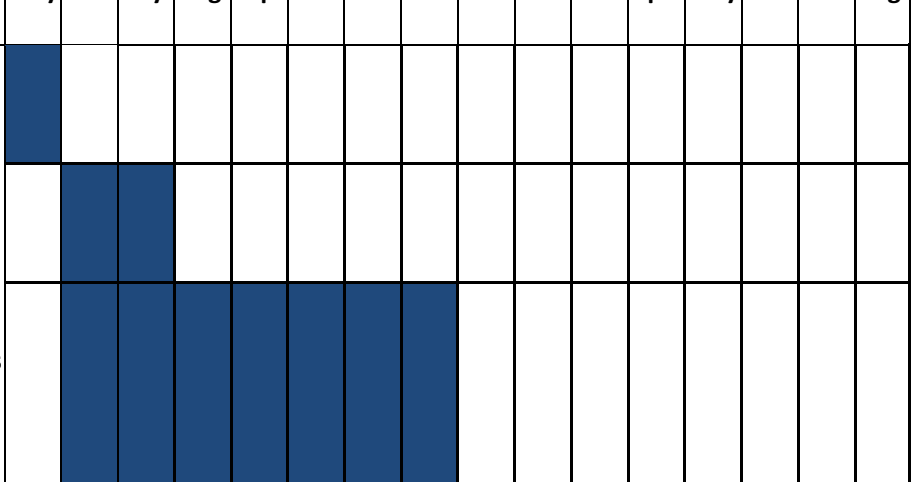

(1)

Int
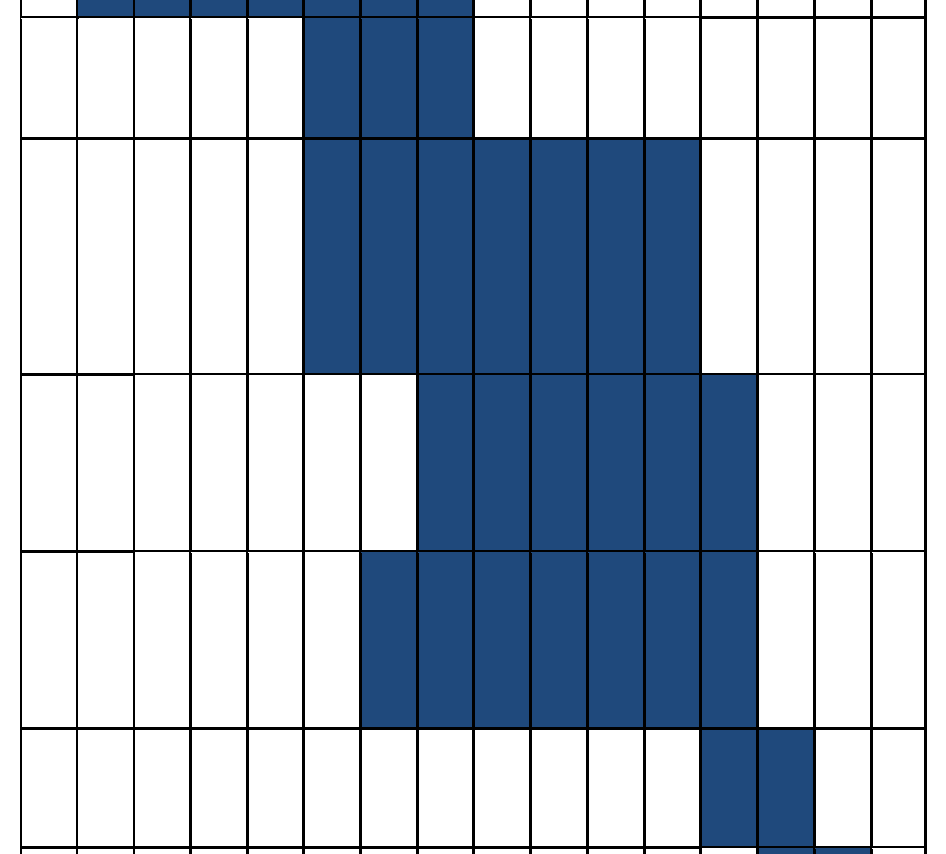

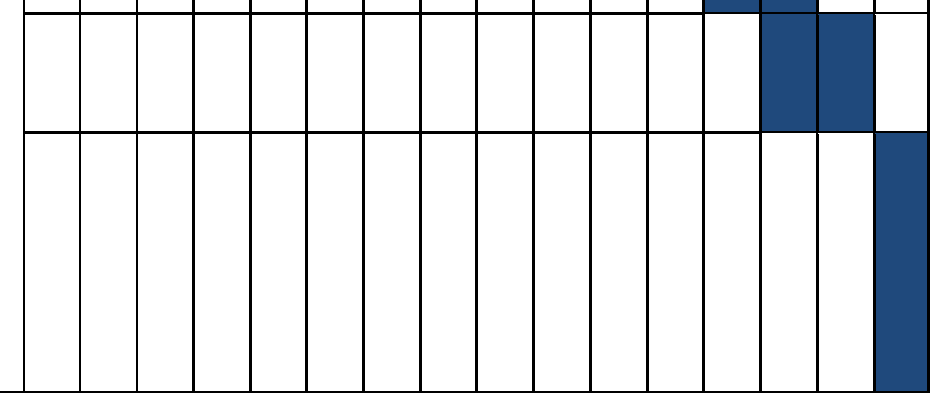




\section{Annexure 6: Study Team Members}

\begin{tabular}{|c|c|c|c|}
\hline \multicolumn{2}{|c|}{ District Khanewal } & \multicolumn{2}{|c|}{ District Dadu } \\
\hline Name & Roles/ Responsibilities & Name & Roles/ Responsibilities \\
\hline Dr.Samreen Afzal & District Supervisor & Dr. Sonia Memon & District Supervisor \\
\hline Sajida Yasmeen & Social Scientist & Sumaira Anwer & Social Scientist \\
\hline Naheed Mustafa & Social Scientist & Afroz Channa & Social Scientist \\
\hline Sadiq Ali & Logistic Supervisor & Najam Uddin Panhwar & Logistic Supervisor \\
\hline Mumtaz Batool & Social Scientist & Saima Ahmed & Social Scientist \\
\hline Zainab Amir & Social Scientist & Shams Rehman & Social Scientist \\
\hline Shahid Ali Tahir & Logistic Supervisor & Rafique Ahmed & Logistic Supervisor \\
\hline Munaza Iqbal & Social Scientist & Albia Bano & Social Scientist \\
\hline Samina Mustafa & Social Scientist & Musarat Phanwer & Social Scientist \\
\hline Muh. Mujahid Zia & Logistic Supervisor & Amjad Ali Surhio & Logistic Supervisor \\
\hline Sundas Khaliq & Social Scientist & Sumaira Shah & Social Scientist \\
\hline Shehzadi Nausheen & Social Scientist & Tahira Khanum & Social Scientist \\
\hline M. Nadeem Hassan & Logistic Supervisor & Saeed Ahmad Memon & Logistic Supervisor \\
\hline
\end{tabular}




\section{Annexure 7: Characteristics of Dadu and Khanewal districts}

\begin{tabular}{|c|c|c|c|c|c|c|}
\hline Characteristics & \multicolumn{3}{|c|}{ Khanewal } & \multicolumn{3}{|c|}{ Dadu } \\
\hline Total Population & \multicolumn{3}{|c|}{2898231} & \multicolumn{3}{|c|}{1405453} \\
\hline Contraceptive Prevalence Rate (CPR) & \multicolumn{3}{|c|}{$34 \%$} & \multicolumn{3}{|c|}{$21.0 \%$} \\
\hline Unmet need for family planning & \multicolumn{3}{|c|}{$27 \%$} & \multicolumn{3}{|c|}{$39.9 \%$} \\
\hline Literate Women (15-49 Years) & \multicolumn{3}{|c|}{$40 \%$} & \multicolumn{3}{|c|}{$22.6 \%$} \\
\hline Literate Husband & \multicolumn{3}{|c|}{$73 \%$} & \multicolumn{3}{|c|}{$64 \%$} \\
\hline \multirow[t]{3}{*}{ Overall Literacy Rate } & \multicolumn{3}{|c|}{$37.2 \%$} & \multicolumn{3}{|c|}{$33.5 \%$} \\
\hline & \multicolumn{2}{|c|}{ Public } & \multirow[t]{2}{*}{ Private } & \multicolumn{2}{|c|}{ Public } & \multirow[t]{2}{*}{ Private } \\
\hline & Govt. & LHWs & & Govt. & LHWs & \\
\hline $\begin{array}{l}\text { Facilities Providing Maternal Health } \\
\text { Care Services }\end{array}$ & 176 & 1616 & 2776 & 85 & 934 & 324 \\
\hline Reproductive Health Care Providers & \multicolumn{2}{|c|}{339} & 631 & \multicolumn{2}{|c|}{218} & 272 \\
\hline
\end{tabular}

\section{Sources:}

- $\quad$ http://www.cssforum.com.pk/css-compulsory-subjects/pakistan-affairs/8805-literacy-rate-pakistandistrict-wise.html

- Pakistan Population Data Sheet, National Institute of Population Studies (NIPS)

- Baseline Household Survey FALAH, Population Council, Islamabad

- Mapping of Health and reproductive Health Services FALAH, Population Council, Islamabad 


\title{
Annexure 8: IBR Approval Letter
}

\section{(P) Population Council}

\author{
Institutional Review Board \\ Population Council \\ 1230 York Avenue \\ New York, NY 10065
}

\section{APPROVAL OF PROTOCOL}

DATE: July 22, 2009

TO: $\quad$ Ali Mohammad Mir and Abdul Wajid, Principal Investigators

FROM: $\quad$ Nick Gontarz, IRB Administrator, on behalf of Dr. Sheldon Segal, Chairman Institutional Review Board (IRB)

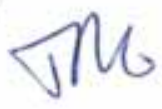

RE: Approval of Protocol No. 455: Feasibility of home administration of Misoprostol in the prevention of $\mathrm{PPH}$ in rural Pakistan

The Institutional Review Board (IRB) on human research of the Population Council has approved the above request to involve humans as research subjects.

\section{APPROVAL DATE OF PROTOCOL: $\quad$ APRIL 1, 2009}

ADVERSE REACTIONS/COMPLICATIONS: All serious and/or unexpected side effects must be reported immediately by fax to the Population Council's SAE Desk (SAE Desk Fax No.: 212-3278673), which will notify the IRB of the Population Council.

MODIFICATIONS: All protocol changes involving subjects must have prior IRB approval.

If this project is to continue, it must be renewed as specified by the IRB. THE EXPIRATION DATE FOR THIS PROJECT IS APRIL 1,2010. This renewal application consists of a brief status report summarizing the results obtained during the past period and a short statement of the research plan for the coming year.

If you have any questions, please contact Nick Gontarz at telephone No. [212] 327-7112 or FAX No. [212] $327-7678$.

cc: IRB Records and Reports File for Protocol 455 


\section{Annexure 9: Maps of Khanewal and Dadu Districts}

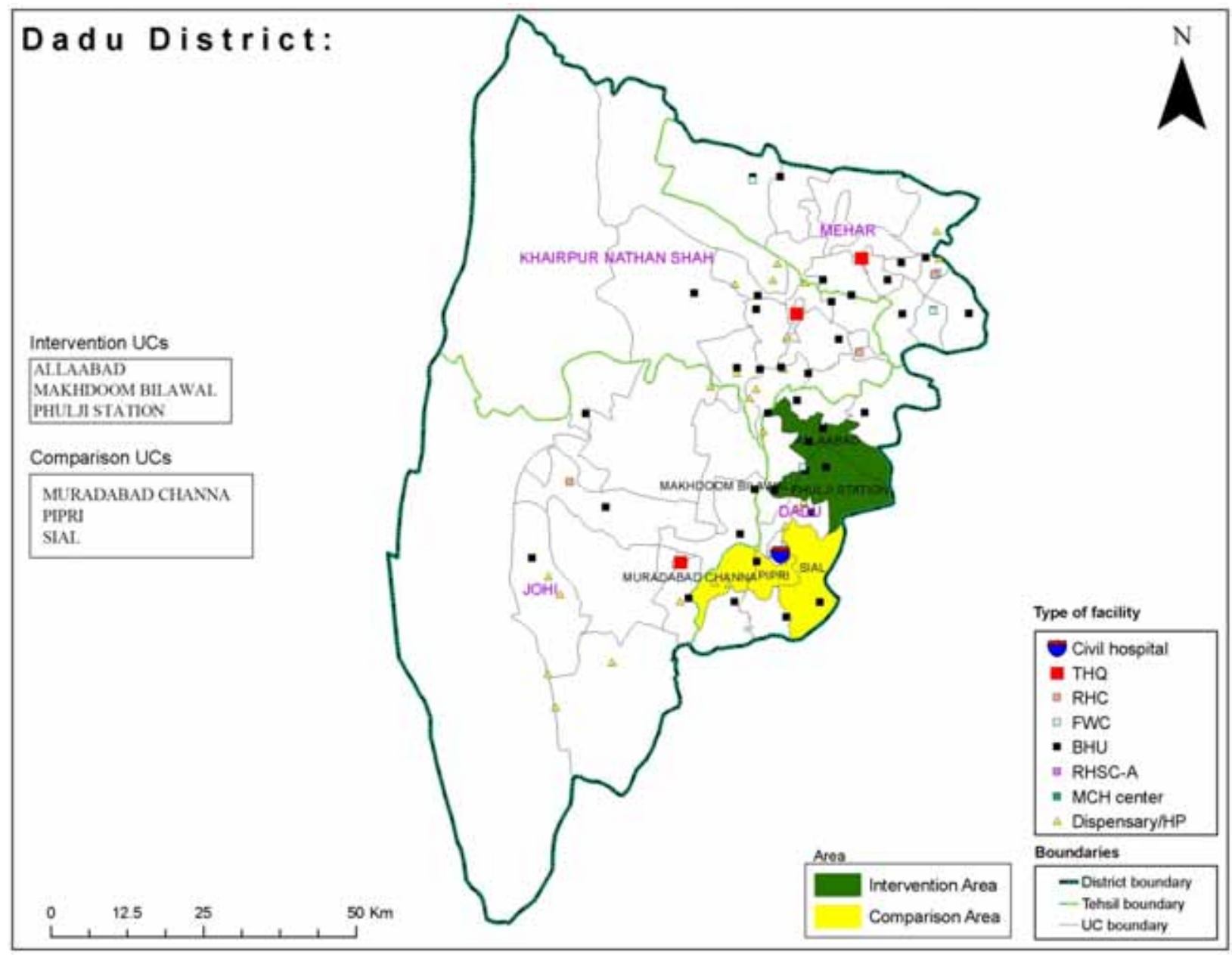




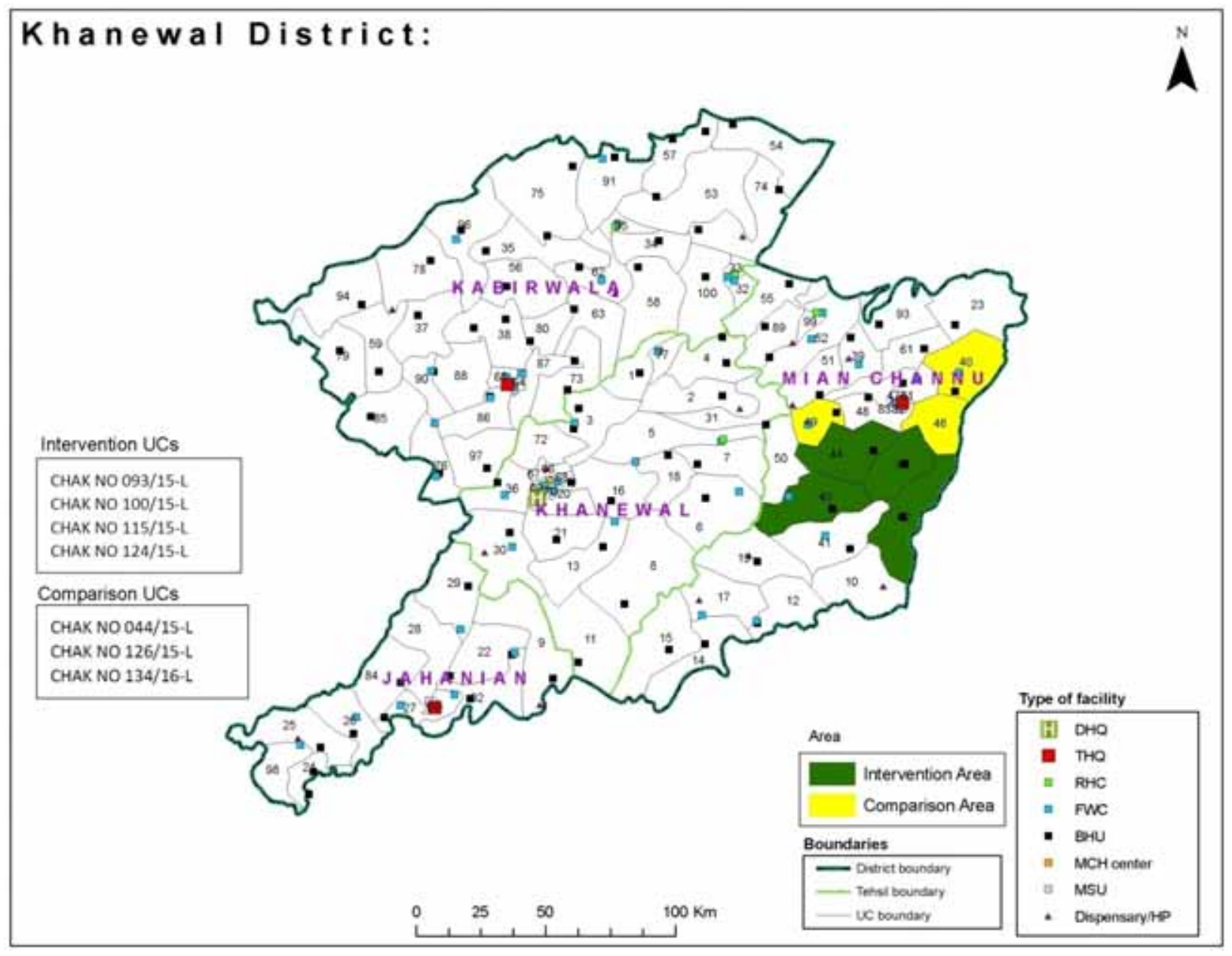


Annexure 10: Questionnaires

Processing Code
\begin{tabular}{|c|c|c|c|c|c|c|c|}
\hline & & & & & & & \\
\hline Dist & Teh & UC & \multicolumn{3}{|c|}{ House no. } & Women no \\
\hline
\end{tabular}

Pakistan Initiative for Mothers and Newborns (PAIMAN)

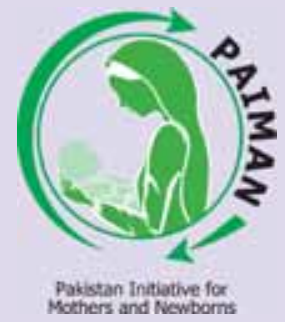

Assessing the feasibility of home administration of Misoprostol in the prevention of PPH in rural Pakistan An OR Study

\author{
Interviews With \\ Pregnant Women of 15-49 Years
}

(1) Population Council 
رضامنركفارمبراحُموالنام

\section{(Intervention Area )}

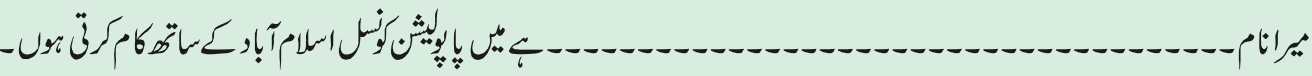

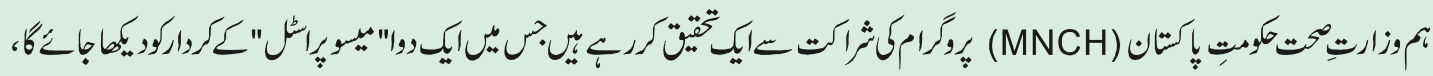

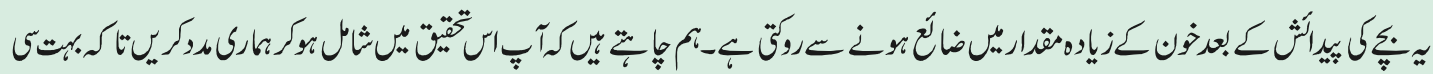

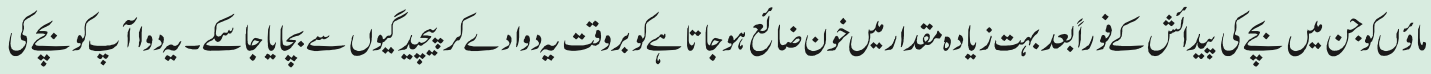

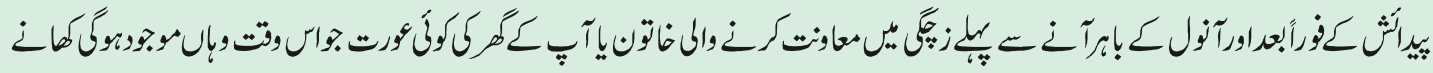

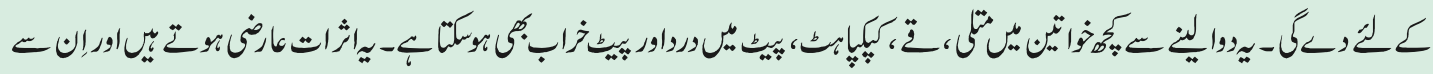

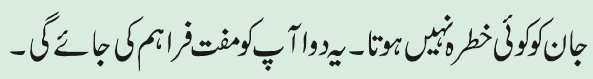

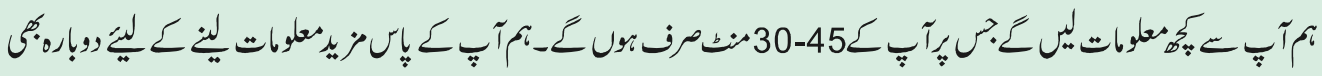

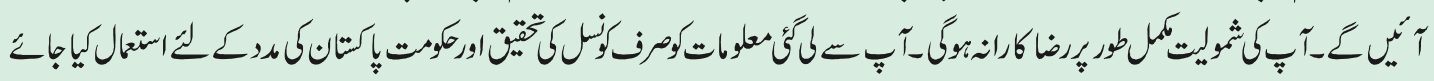

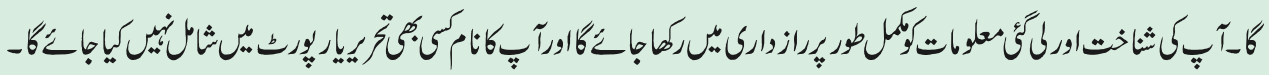

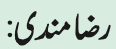

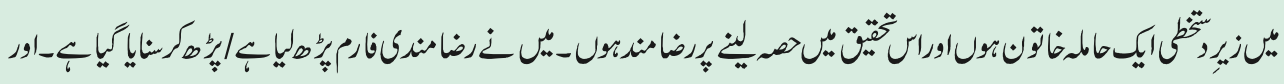

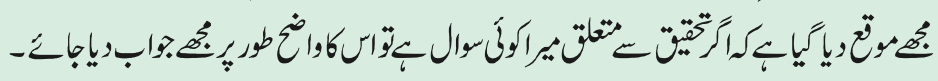
تارث

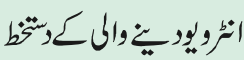

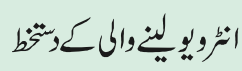

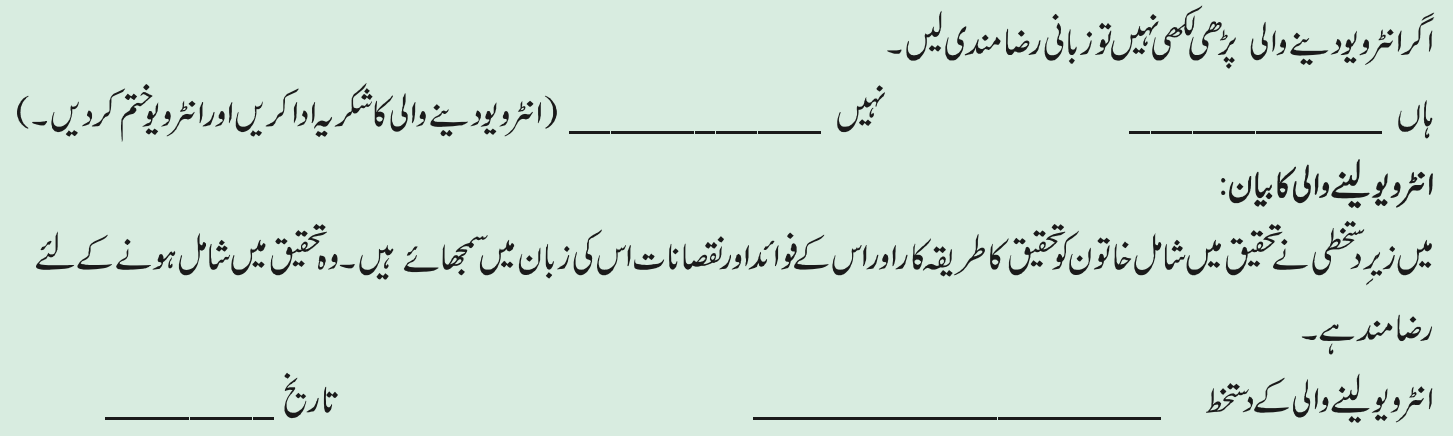


رضامنركنارمبراعُبوالنام

\section{(Comparison Area)}

السام:مليك:

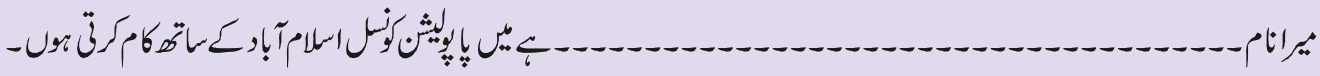

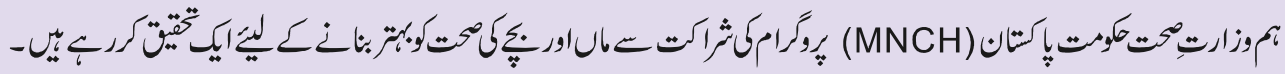

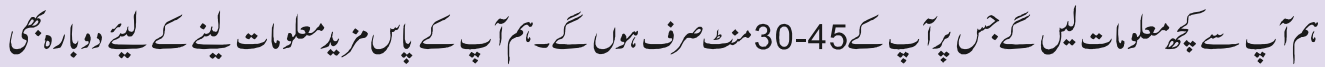

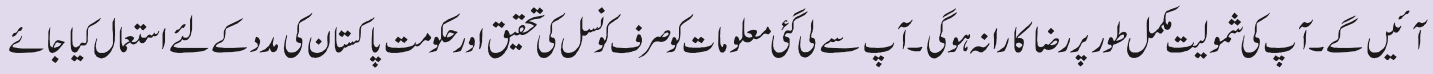

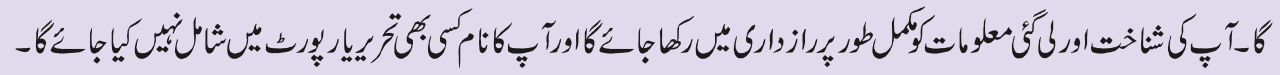
رضامنرى:

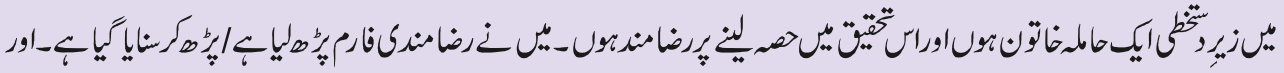

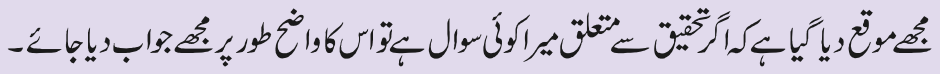

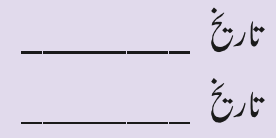

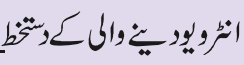

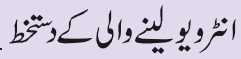

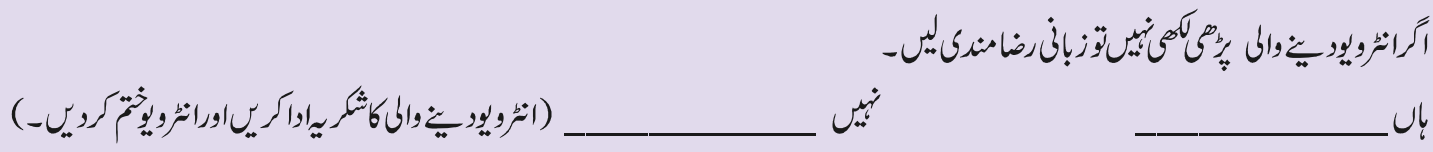
انزرويليخروانكابيان:

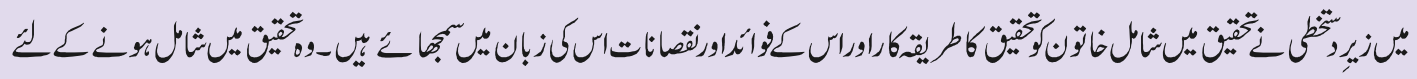
رضامندب تانق

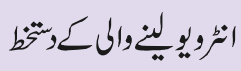




\section{Household Identification}

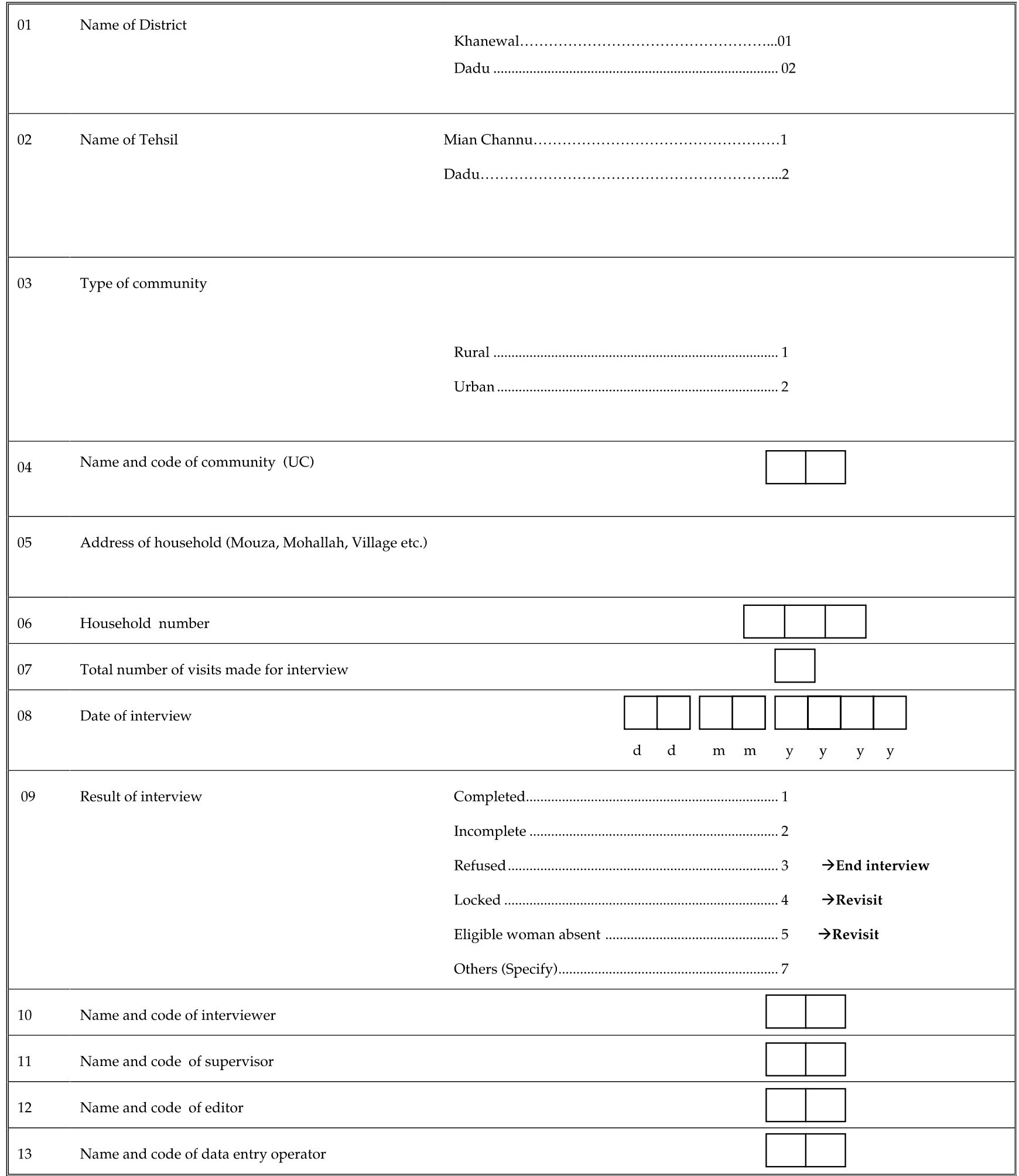


Please encircle eligible women

1: Household Roster

\begin{tabular}{|c|c|c|c|c|c|c|c|}
\hline 101 & & 102 & & 103 & 104 & 105 & 106 \\
\hline \multirow[b]{2}{*}{ Line } & \multirow{2}{*}{$\begin{array}{l}\text { Please give me the name of } \\
\text { the persons who usually live } \\
\text { in your household starting } \\
\text { with the head of the } \\
\text { household }\end{array}$} & \multicolumn{2}{|l|}{ Sex } & \multirow{2}{*}{$\begin{array}{l}\begin{array}{l}\text { Relationship } \\
\text { with HHH }\end{array} \\
\text { (See codes } \\
\text { given below } \\
\text { the table) }\end{array}$} & \multirow{2}{*}{$\begin{array}{l}\text { Current Age } \\
\text { (If less than } 1 \text { year, } \\
\text { write } 00 ; \text { ) } \\
\text { [If age less than } 5 \text { years } \\
\text { go to next line] }\end{array}$} & \multirow{2}{*}{$\begin{array}{l}\text { Classes passed } \\
\text { (If age is less than } 5 \\
\text { years don't ask this } \\
\text { question) } \\
\text { (If no class passed, } \\
\text { write } 00 \text { ) } \\
\text { Write " } 16 \text { " if } 16 \text { or } \\
\text { more classes passed }\end{array}$} & \multirow{2}{*}{$\begin{array}{l}\text { Marital Status } \\
\text { (If age is less than } 12 \\
\text { yrs don't ask this } \\
\text { question) } \\
\text { 1. Married } \\
\text { 2. Widowed } \\
\text { 3. Divorced } \\
\text { 4. Separated } \\
\text { 5. Single } \\
\end{array}$} \\
\hline & & Male & Female & & & & \\
\hline 01 & & 1 & 2 & & & & \\
\hline 02 & & 1 & 2 & & & & \\
\hline 03 & & 1 & 2 & & & & \\
\hline 04 & & 1 & 2 & & & & \\
\hline 05 & & 1 & 2 & & & & \\
\hline 06 & & 1 & 2 & & & & \\
\hline 07 & & 1 & 2 & & & & \\
\hline 08 & & 1 & 2 & & & & \\
\hline 09 & & 1 & 2 & & & & \\
\hline 10 & & 1 & 2 & & & & \\
\hline 11 & & 1 & 2 & & & & \\
\hline 12 & & 1 & 2 & & & & \\
\hline 13 & & 1 & 2 & & & & \\
\hline 14 & & 1 & 2 & & & & \\
\hline 15 & & 1 & 2 & & & & \\
\hline 16 & & 1 & 2 & & & & \\
\hline 17 & & 1 & 2 & & & & \\
\hline 18 & & 1 & 2 & & & & \\
\hline 19 & & 1 & 2 & & & & \\
\hline 20 & & 1 & 2 & & & & \\
\hline
\end{tabular}

Please attach additional sheet if household members are more than 20.

\section{Relationship Codes}

01 . Head of the household

02. Spouse

03. Son/Daughter

04. Son/Daughter in law

05. Grand Son/Daughter
06. Father/Mother in law

07. Brother/Sister in law

08. Father/Mother

09. Brother/Sister

10. Uncle/Aunt
11. Niece/Nephew

12. Grand parents

13. Adopted/Stepchild

14. Other Relative

15. Servant

77. Others(Specify)

\begin{tabular}{|c|cll|l|}
\hline 107. & Total number of household members & Total & & \\
& & Male & & \\
& & Female & & \\
& & &
\end{tabular}

108. Total currently married (15-49 yrs) women in $\mathrm{HH}$

109. Total number of eligible pregnant women (15-49) in $\mathrm{HH}$

110. Pregnant women (15-49 yrs) interviewed in $\mathrm{HH}$ 


\section{1: Household Characteristics}

\begin{tabular}{|c|c|c|}
\hline Que & tions and Filters & Responses and Codes \\
\hline & 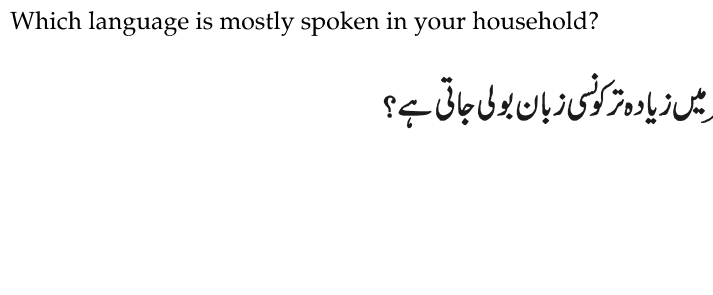 & Urdu $\begin{array}{l}\text { Punjabi } \\
\text { Saraiki } \\
\text { Sindhi } \\
\text { Balochi }\end{array}$ \\
\hline 112 & What is the main source of drinking water for your household? & $\begin{array}{l}\text { Govt. supply (tap water inside) } \\
\text { Govt. supply (communal) } \\
\text { Motorized/Hand pump (inside) } \\
\text { Motorized/Hand pump (outside) } \\
\text { Well (inside) } \\
\text { Tell (outside) } \\
\text { Pube-well }\end{array}$ \\
\hline & What kind of toilet facility do members of your household use? & $\begin{array}{l}\text { Flush to sewerage } \\
\text { Flush connected to septic tank } \\
\text { Flush connected to open drain } \\
\text { Raised latrine }\end{array}$ \\
\hline
\end{tabular}




\begin{tabular}{|c|c|c|c|c|c|}
\hline \multirow[t]{3}{*}{114} & \multirow{3}{*}{ 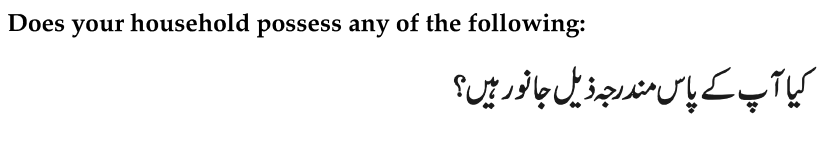 } & \multicolumn{2}{|l|}{1} & \multirow{2}{*}{\multicolumn{2}{|c|}{ Are kept in residential area at night }} \\
\hline & & \multirow[t]{2}{*}{ Yes } & \multirow{2}{*}{ No } & & \\
\hline & & & & Yes & No \\
\hline a. & Cattle (Buffalo, Cow, Donkey, Horse, Ox etc.) & 1 & 2 & 1 & 2 \\
\hline b. & Sheep and/or goats & 1 & 2 & 1 & 2 \\
\hline 115 & 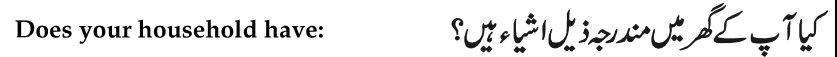 & \multicolumn{2}{|l|}{ Yes } & \multicolumn{2}{|c|}{ No } \\
\hline a. & Electric fan & \multicolumn{2}{|l|}{1} & \multicolumn{2}{|c|}{2} \\
\hline b. & Sewing machine & \multicolumn{2}{|l|}{1} & \multicolumn{2}{|c|}{2} \\
\hline c. & Washing machine & \multicolumn{2}{|l|}{1} & \multicolumn{2}{|c|}{2} \\
\hline d. & Radio or Cassette player & \multicolumn{2}{|l|}{1} & \multicolumn{2}{|c|}{2} \\
\hline e. & TV & \multicolumn{2}{|l|}{1} & \multicolumn{2}{|c|}{2} \\
\hline f. & Telephone/mobile & \multicolumn{2}{|l|}{1} & \multicolumn{2}{|c|}{2} \\
\hline g. & Refrigerator & \multicolumn{2}{|l|}{1} & \multicolumn{2}{|c|}{2} \\
\hline h. & Air cooler & \multicolumn{2}{|l|}{1} & \multicolumn{2}{|c|}{2} \\
\hline i. & Computer & \multicolumn{2}{|l|}{1} & \multicolumn{2}{|c|}{2} \\
\hline j. & Cycle & \multicolumn{2}{|l|}{1} & \multicolumn{2}{|c|}{2} \\
\hline k. & Motorcycle & \multicolumn{2}{|l|}{1} & \multicolumn{2}{|c|}{2} \\
\hline 1. & Car/Jeep & \multicolumn{2}{|l|}{1} & \multicolumn{2}{|c|}{2} \\
\hline q. & Tractor/Truck & 1 & & 2 & \\
\hline 116 & 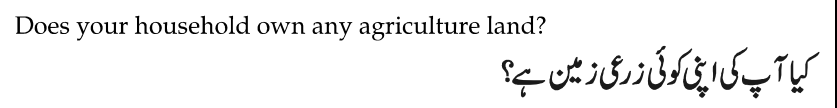 & $\begin{array}{l}\text { Yes.... } \\
\text { No..... }\end{array}$ & . & 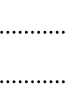 & $\rightarrow$ Go to 118 \\
\hline 117 & 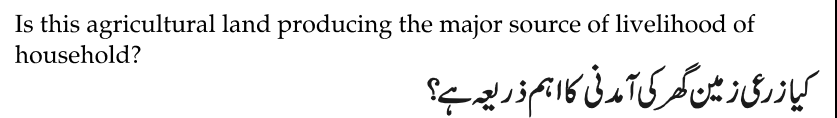 & $\begin{array}{l}\text { Yes.... } \\
\text { No..... }\end{array}$ & . & 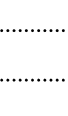 & \\
\hline 118 & Line number of eligible woman & (Write & number from $\mathrm{HH}$ & ster).. & -1 \\
\hline
\end{tabular}




\section{2: Background Characteristics of Pregnant woman}

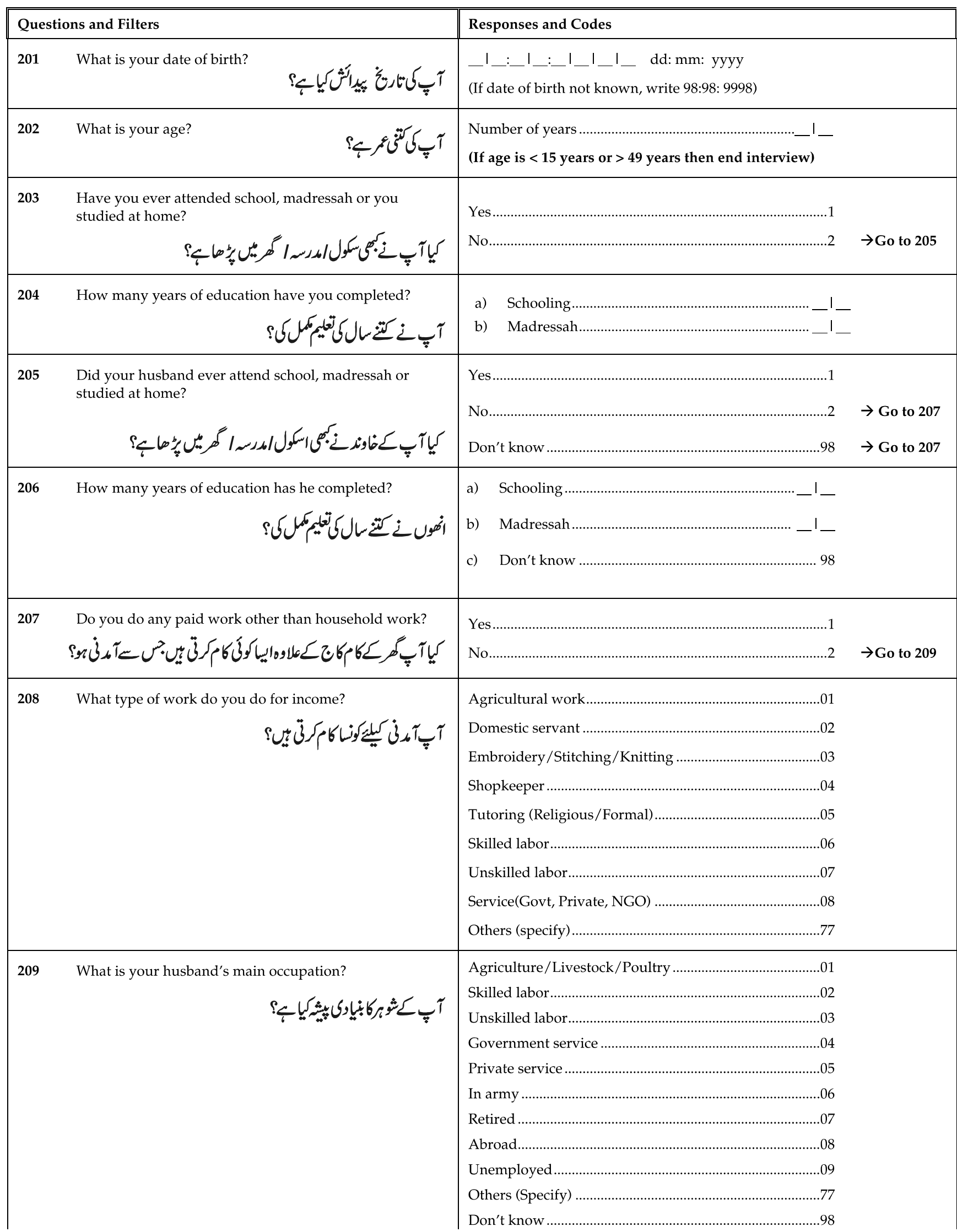




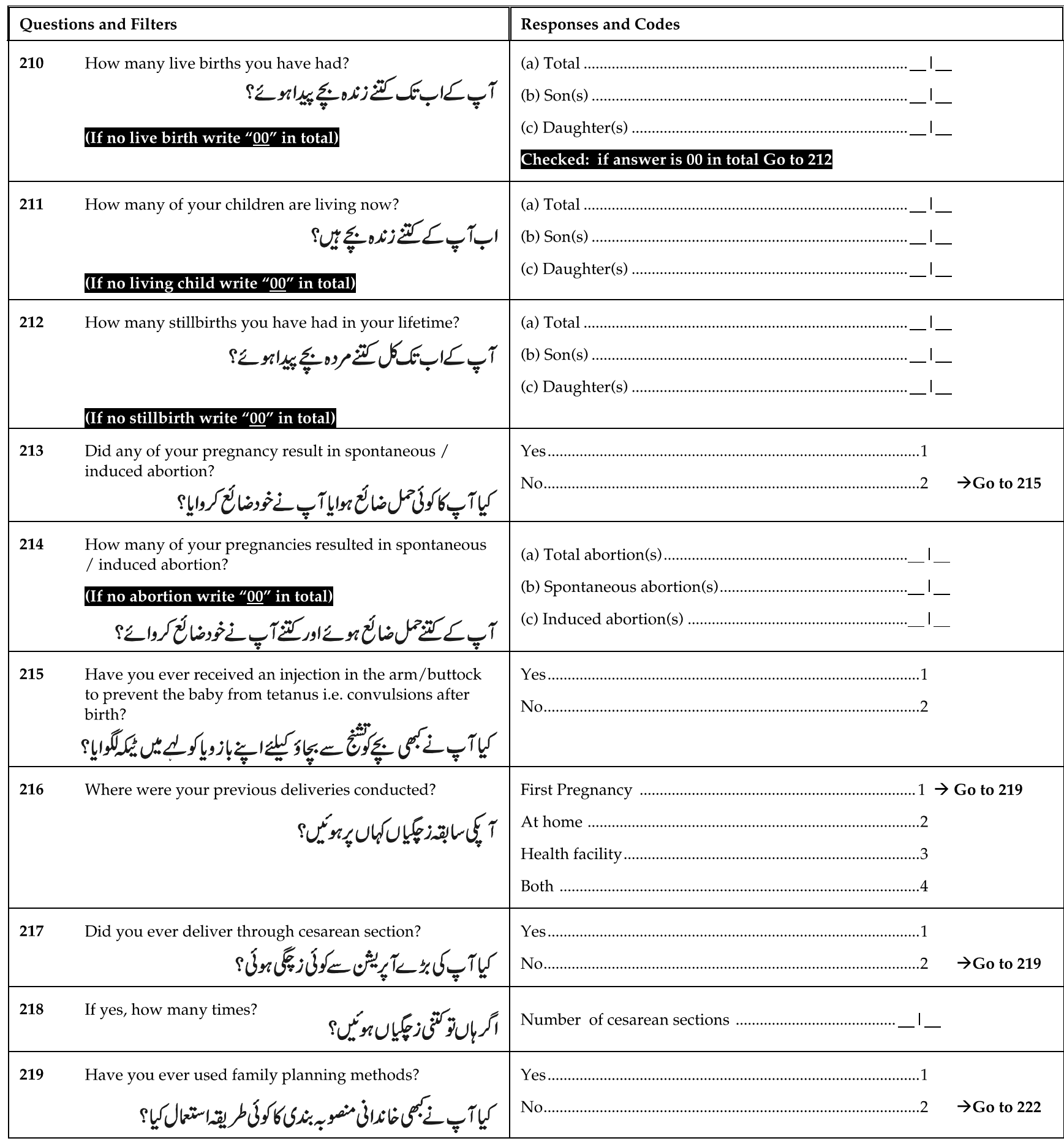




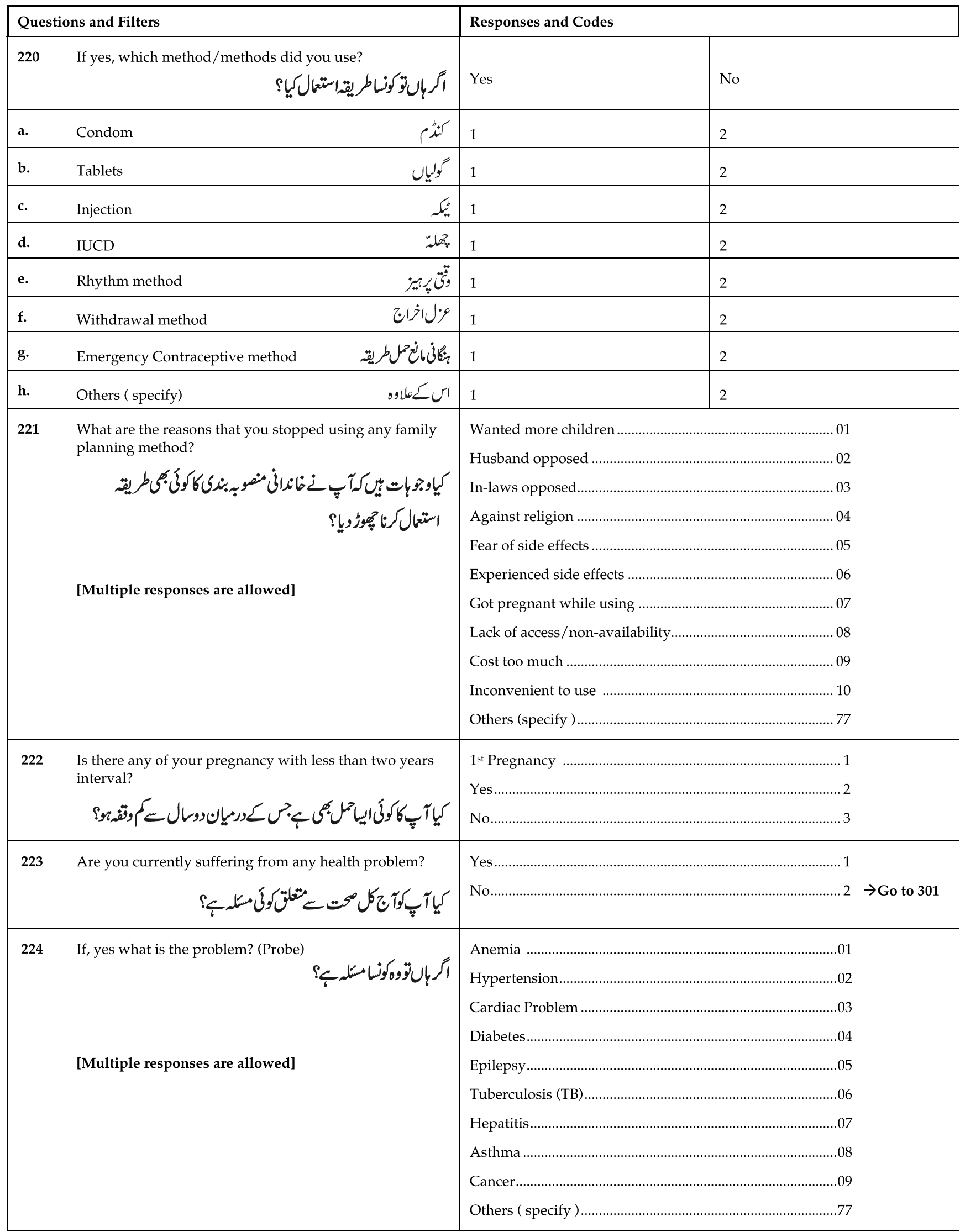




\section{3: Pregnancy History during Last 3 Years}

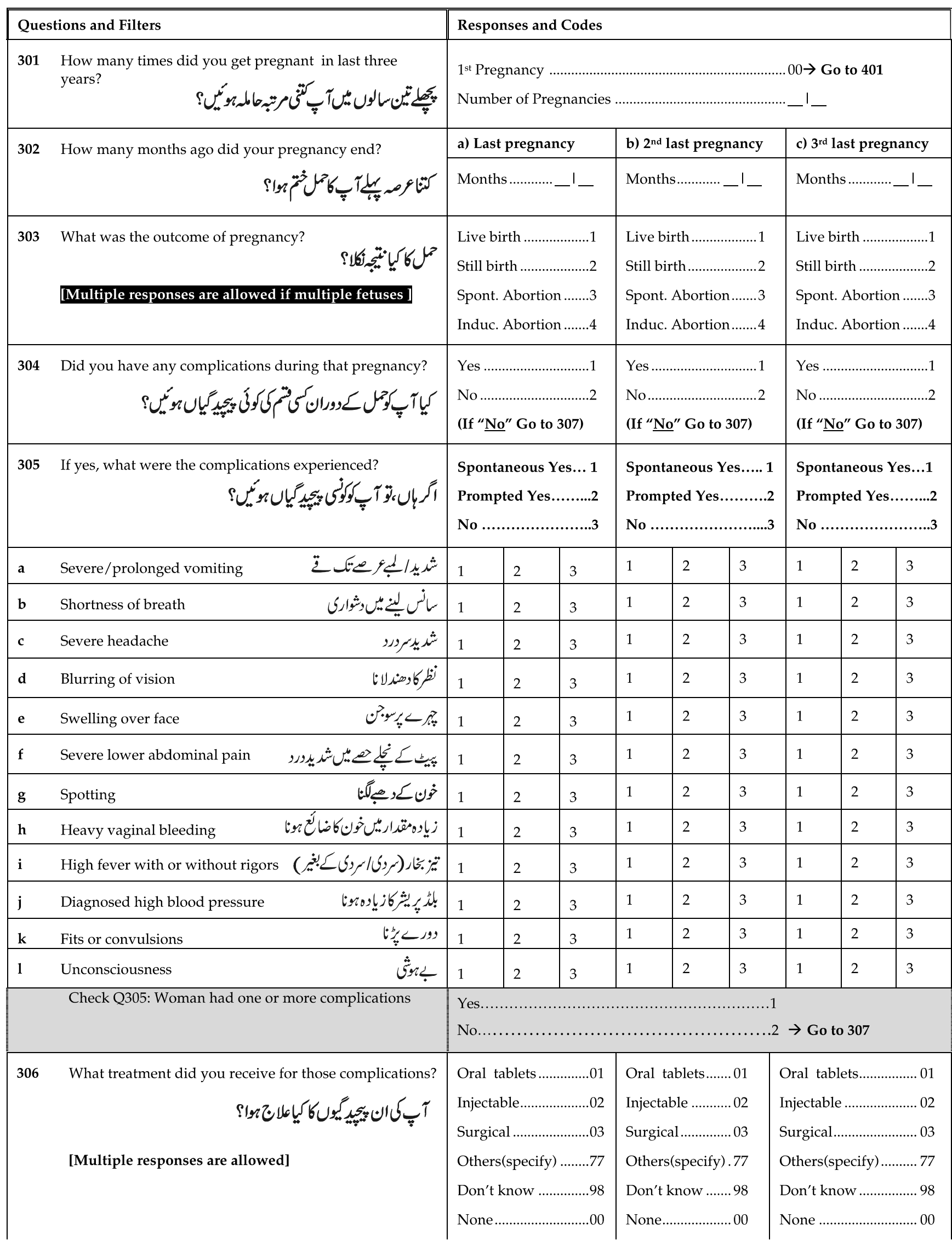




\begin{tabular}{|c|c|c|c|c|}
\hline Que & ons and Filters & \multicolumn{3}{|c|}{ Responses and Codes } \\
\hline \multicolumn{5}{|c|}{ Instructions: Now I am going to ask you few questions about your last delivery } \\
\hline 307 & $\begin{array}{l}\text { Did you experience any serious complications during / } \\
\text { after last delivery? }\end{array}$ & \multicolumn{3}{|c|}{ Yes } \\
\hline 308 & If yes, what were the complications experienced & Spontaneous Yes & Prompted Yes & No \\
\hline a. & 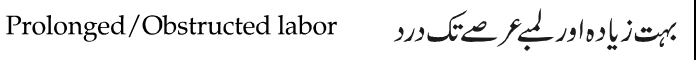 & 1 & 2 & 3 \\
\hline b. & Bleeding before labor began & 1 & 2 & 3 \\
\hline c. & 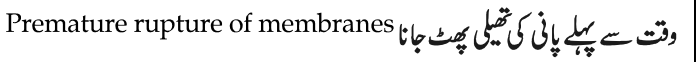 & 1 & 2 & 3 \\
\hline d. & 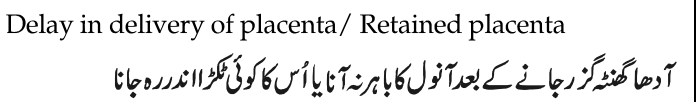 & 1 & 2 & 3 \\
\hline e. & 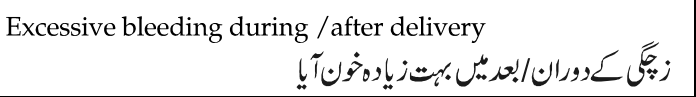 & 1 & 2 & 3 \\
\hline f. & 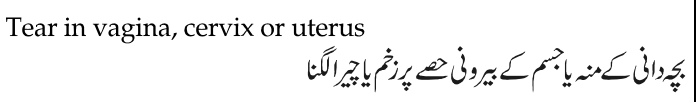 & 1 & 2 & 3 \\
\hline g. & 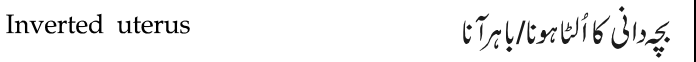 & 1 & 2 & 3 \\
\hline h. & High fever & 1 & 2 & 3 \\
\hline i. & Abnormal position fetus الطايا آرُطانيح & 1 & 2 & 3 \\
\hline & Check Q308: Woman had one or more complications & 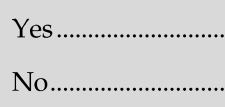 & (n) & .................... 1 \\
\hline 309 & $\begin{array}{l}\text { From whom did you get treatment for the complication? } \\
\text { [Multiple responses are allowed] }\end{array}$ & $\begin{array}{l}\text { Did not get treatm } \\
\text { Community Midn } \\
\text { LHW }\end{array}$ & (1) & 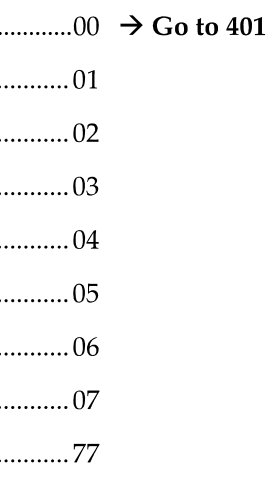 \\
\hline 310 & From where did you get treatment for the complication? & At home ................ & 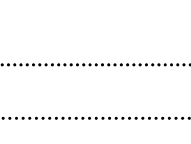 & ........00 Go to 315 \\
\hline
\end{tabular}




\begin{tabular}{|c|c|c|}
\hline \multicolumn{2}{|c|}{ Questions and Filters } & Responses and Codes \\
\hline & $\begin{array}{l}\text { Who made the decision to seek health care from health } \\
\text { facility? }\end{array}$ & Community Midwife \\
\hline & $\begin{array}{l}\text { If went to the health facility, what was the mode of } \\
\text { transport used to reach health facility? }\end{array}$ & 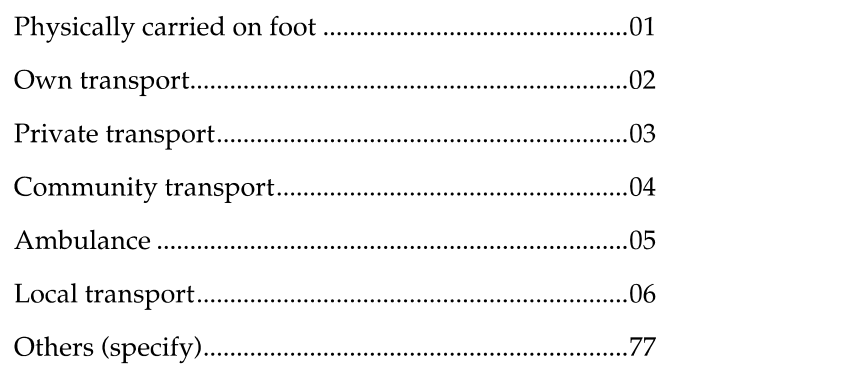 \\
\hline 313 & How long did it take you to reach the health facility? & a) Time in minutes \\
\hline 314 & $\begin{array}{l}\text { How much time did it take to receive any treatment } \\
\text { after reaching at health facility? }\end{array}$ & 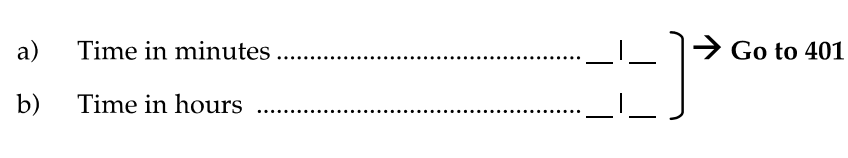 \\
\hline 315 & $\begin{array}{l}\text { What was the main reason that you didn't get treatment } \\
\text { from a health facility? }\end{array}$ & 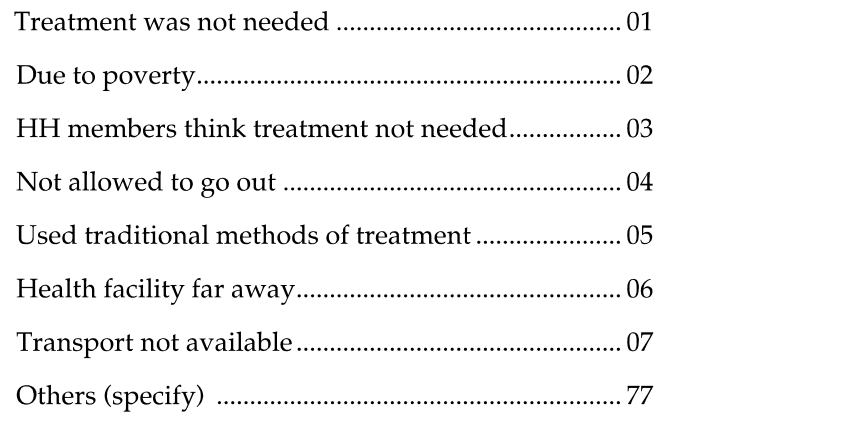 \\
\hline
\end{tabular}




\section{4: History of present pregnancy}

\begin{tabular}{|c|c|}
\hline Questions and Filters & Responses/codes \\
\hline 401 What is the duration of your current pregnancy? & Time in months ................................................... I \\
\hline $\begin{array}{l}\text { Have you been examined by a health care provider during this } \\
\text { pregnancy? }\end{array}$ & No \\
\hline When was the last check up done? & 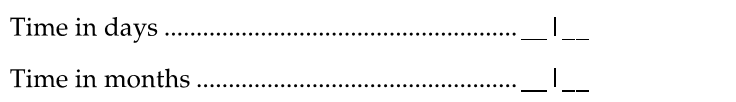 \\
\hline From whom did you have this check up? & Community Midwife \\
\hline $\begin{array}{l}\text { What did the check up consist of? (Probe) } \\
\text { (Multiple answers are allowed) }\end{array}$ & 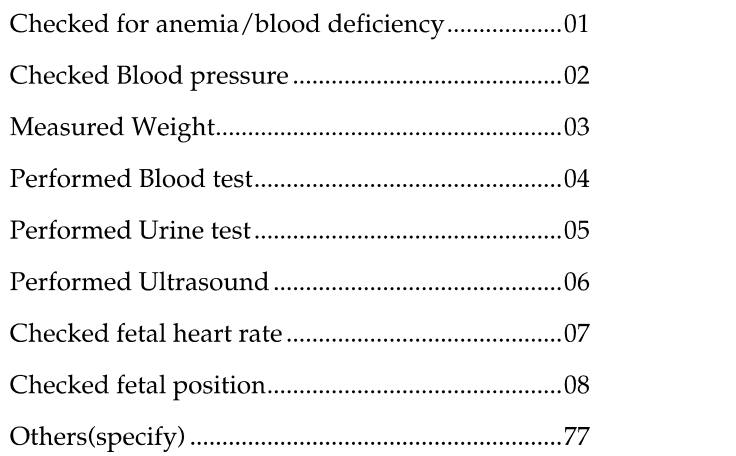 \\
\hline $\begin{array}{l}\text { During your check up have you been informed about any problem } \\
\text { with your pregnancy? }\end{array}$ & 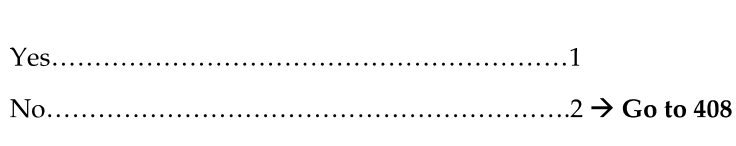 \\
\hline
\end{tabular}




\begin{tabular}{|c|c|c|c|c|}
\hline 407 & 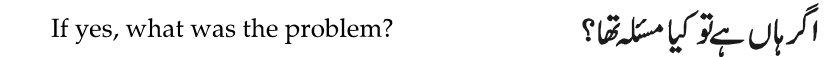 & Spontaneous Yes & Prompted Yes & No \\
\hline a. & 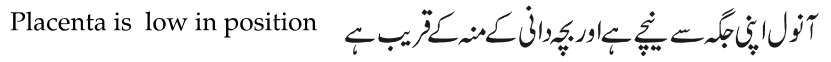 & 1 & 2 & 3 \\
\hline b. & 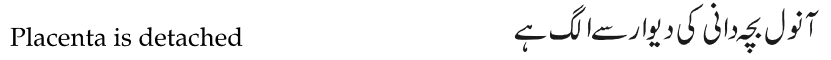 & 1 & 2 & 3 \\
\hline c. & 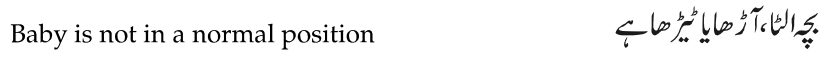 & 1 & 2 & 3 \\
\hline d. & 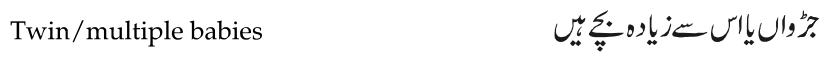 & 1 & 2 & 3 \\
\hline e. & Anemia & 1 & 2 & 3 \\
\hline f. & Diabetes & 1 & 2 & 3 \\
\hline g. & 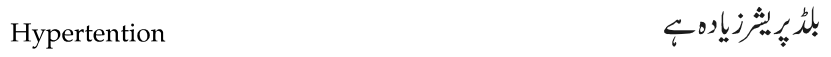 & 1 & 2 & 3 \\
\hline h. & Edema & 1 & 2 & 3 \\
\hline i. & Small sized fetus & 1 & 2 & 3 \\
\hline 408 & 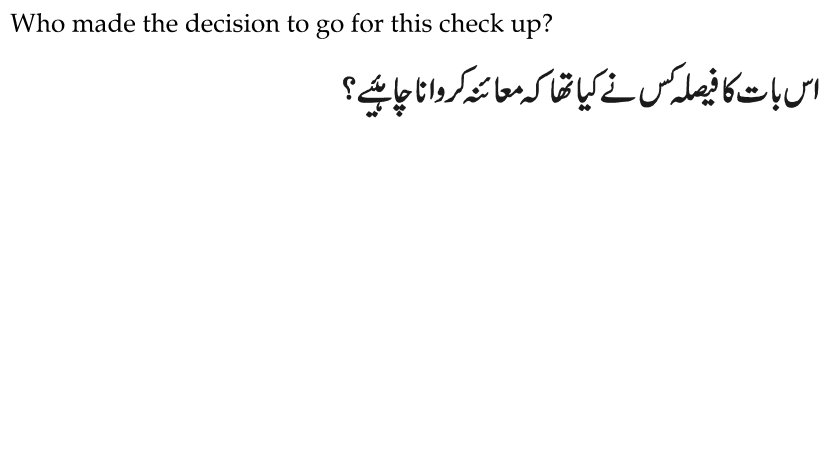 & \multicolumn{3}{|c|}{ Community Midwife 00} \\
\hline 409 & 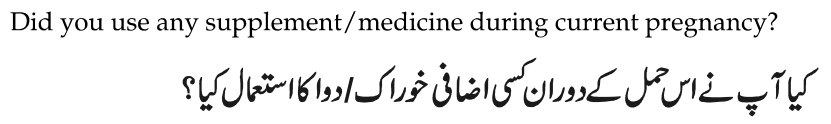 & \multicolumn{3}{|c|}{ Yes } \\
\hline 410 & $\begin{array}{l}\text { What was that? } \\
\text { (Multiples answers are allowed) }\end{array}$ & \multicolumn{3}{|c|}{ 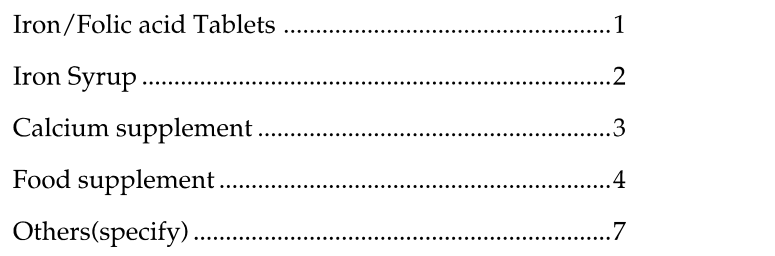 } \\
\hline
\end{tabular}




\section{5: Knowledge and Attitude towards Post Partum Hemorrhage}

\begin{tabular}{|c|c|c|c|c|}
\hline \multicolumn{2}{|c|}{ Questions and Filters } & \multicolumn{3}{|c|}{ Responses and Codes } \\
\hline 501 & 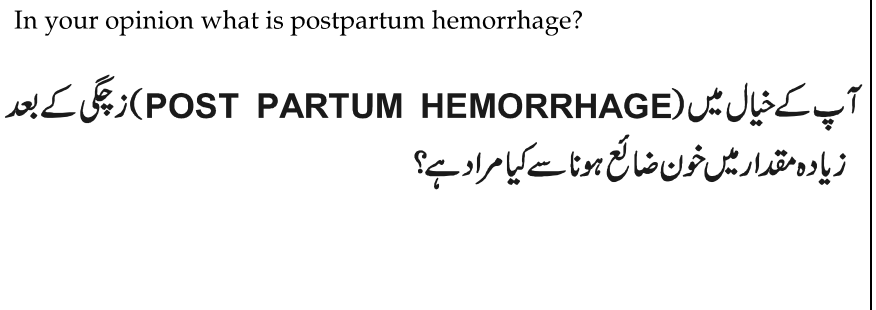 & \multicolumn{3}{|c|}{ 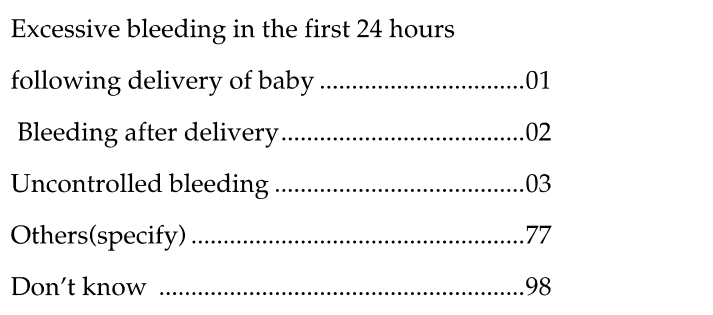 } \\
\hline \multirow[t]{7}{*}{502} & $\begin{array}{l}\text { What do you think are the causes of PPH/excessive bleeding from the } \\
\text { genital tract in the first } 24 \text { hours following delivery of the baby? }\end{array}$ & Spontaneous Yes & Prompted Yes & No \\
\hline & 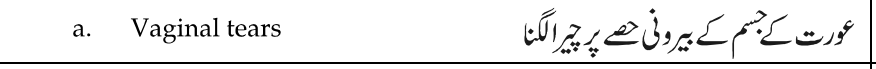 & 1 & 2 & 3 \\
\hline & 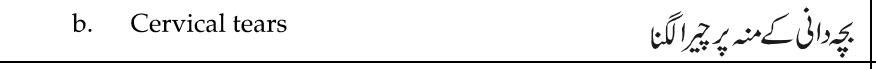 & 1 & 2 & 3 \\
\hline & c. Retained products of placenta & 1 & 2 & 3 \\
\hline & d. Delayed delivery of placenta & 1 & 2 & 3 \\
\hline & نيجرانظ & 1 & 2 & 3 \\
\hline & f. Uterine rupture & 1 & 2 & 3 \\
\hline 503 & 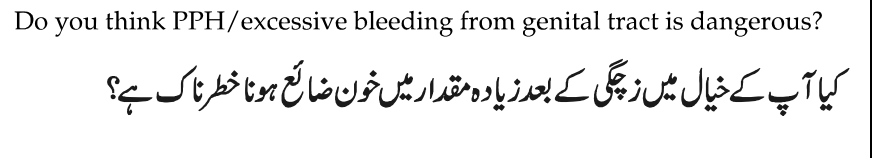 & 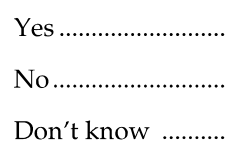 & 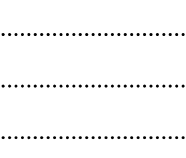 & $\begin{array}{l}\ldots . .1 \\
\ldots .2 \rightarrow \text { Go to } 508 \\
\ldots \text { Go to } 509\end{array}$ \\
\hline 504 & $\begin{array}{l}\text { In your opinion which measures can be taken at home to manage } \\
\text { postpartum hemorrhage, before referral to hospital? }\end{array}$ & $\begin{array}{l}\text { Nothing can be do } \\
\text { Massage of uterus } \\
\text { Trained birth atten } \\
\text { TBA / Dai can be } \\
\text { Oral tablets can be } \\
\text { Injection can be gi } \\
\text { IV fluids can be gi } \\
\text { Others (specify) .... } \\
\text { Don't know ............ }\end{array}$ & int can be called. & $\begin{array}{r}\ldots 00 \\
\ldots 01 \\
\ldots 02 \\
\ldots 03 \\
\ldots 04 \\
\ldots 05 \\
\ldots 06 \\
\ldots 77 \\
\ldots 90\end{array}$ \\
\hline 505 & $\begin{array}{l}\text { When do you think a woman with postpartum hemorrhage be shifted to } \\
\text { the health facility? }\end{array}$ & $\begin{array}{l}\text { Heavy/constant b } \\
\text { management at ho } \\
\text { Uterus comes out } \\
\text { Signs of shock. (fai } \\
\text { skin cold \& wet, pa } \\
\text { Unconsciousness.. } \\
\text { Others (specify) .... } \\
\text { Don't know ............ }\end{array}$ & 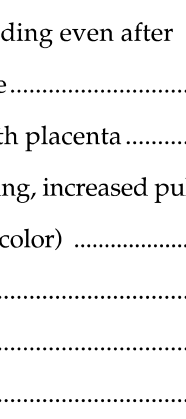 & 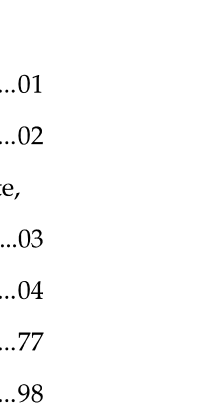 \\
\hline
\end{tabular}




\begin{tabular}{|c|c|c|c|}
\hline \multicolumn{2}{|c|}{ Questions and Filters } & \multicolumn{2}{|l|}{ Responses and Codes } \\
\hline & $\begin{array}{l}\text { If excessive bleeding is not controlled after delivery, in what time } \\
\text { interval a woman should be shifted to the health facility? }\end{array}$ & 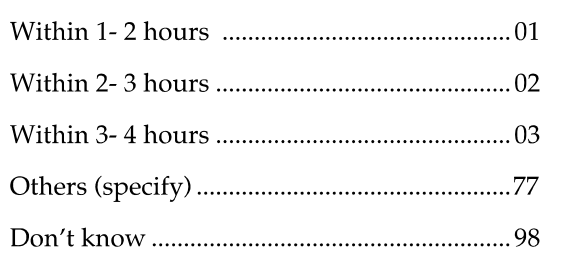 & \\
\hline 507 & $\begin{array}{l}\text { In your opinion which treatment can be provided at the health facility? } \\
\text { [Multiple responses are allowed] }\end{array}$ & Injection & $\rightarrow$ Go to 509 \\
\hline & $\begin{array}{l}\text { Why do you think excessive bleeding from genital tract is not } \\
\text { dangerous? }\end{array}$ & 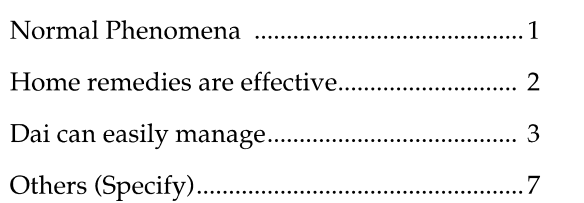 & \\
\hline
\end{tabular}

509 During postpartum period, for which danger signs, it is necessary to seek medical advice/treatment?

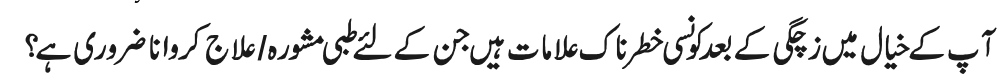

\begin{tabular}{|c|c|c|c|c|}
\hline & Type of complication & Spontaneous Yes & Prompted Yes & NO \\
\hline a. & Excessive vaginal bleeding & 1 & 2 & 3 \\
\hline b. & 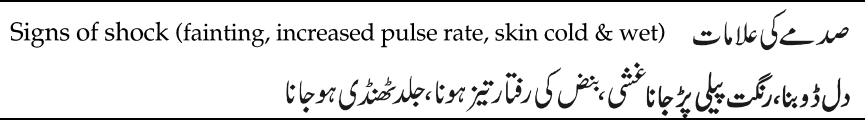 & 1 & 2 & 3 \\
\hline c. & High grade fever (with or without rigors) تيزّار(تروك/روك) & 1 & 2 & 3 \\
\hline d. & Inverted uterus & 1 & 2 & 3 \\
\hline e. & Pain and/or swelling in breasts & 1 & 2 & 3 \\
\hline f. & Severe pain in lower abdomen & 1 & 2 & 3 \\
\hline g. & Foul smelling vaginal discharge & 1 & 2 & 3 \\
\hline h. & Others (Specify) & 1 & & 3 \\
\hline
\end{tabular}




\section{6: Knowledge and acceptability regarding use of Misoprostol}

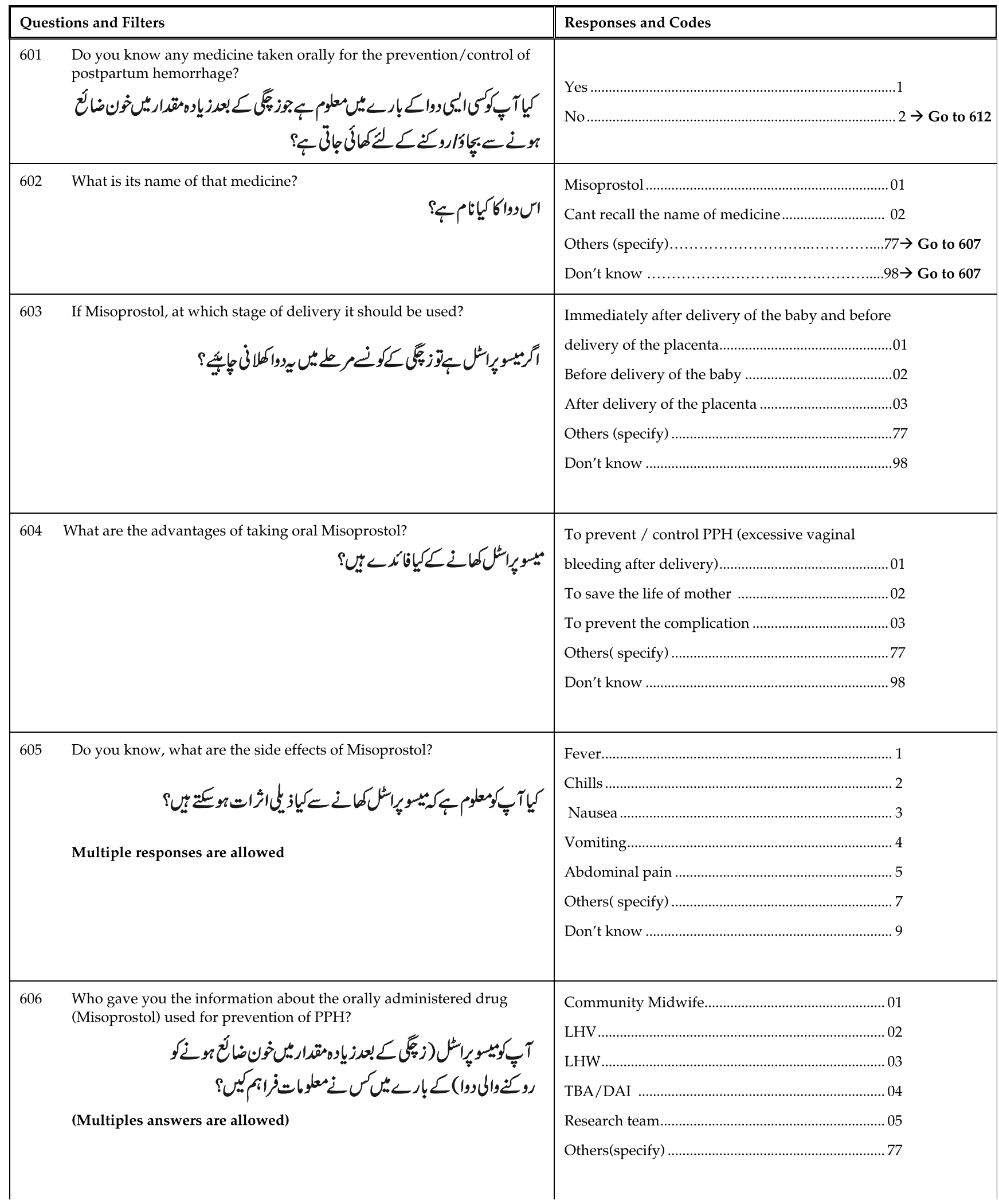




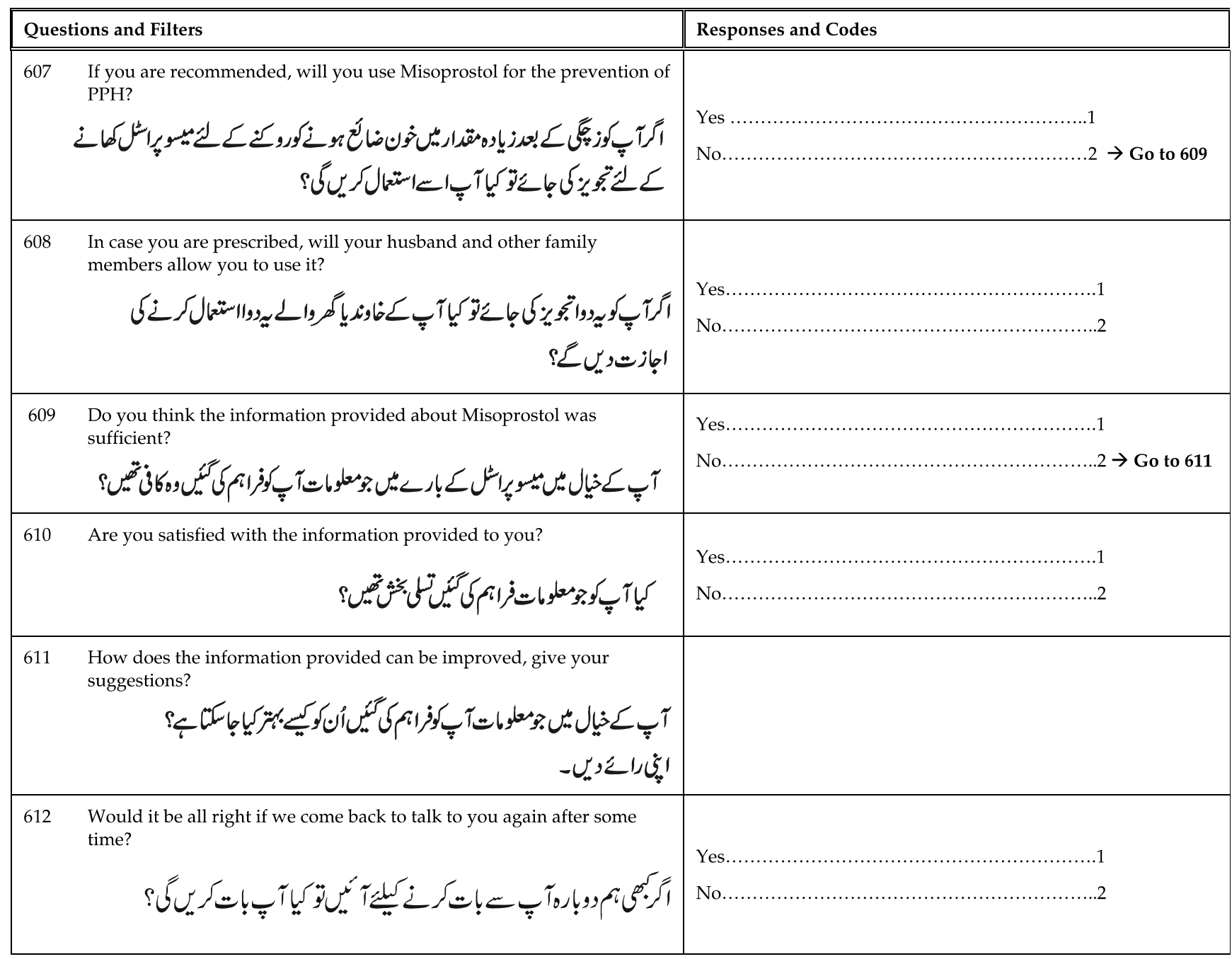

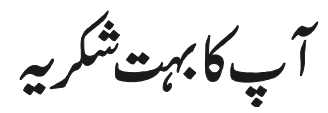




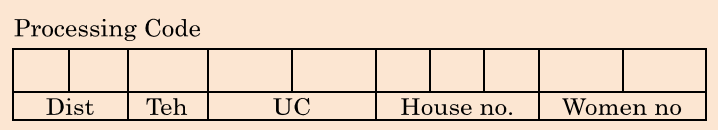

\section{Pakistan Initiative for Mothers and Newborns (PAIMAN)}

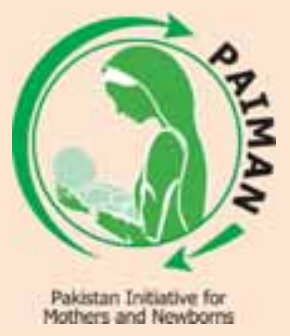

Assessing the feasibility of home administration of Misoprostol in the prevention of PPH in rural Pakistan An OR Study

\section{Post Partum Interview (B) (Women of 15-49 years)}

12 Population Council 


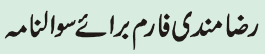

( Intervention Area )

السالم:

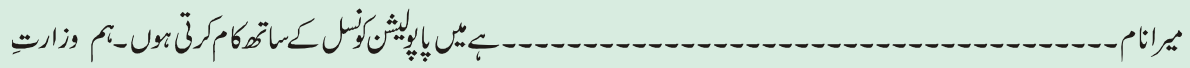

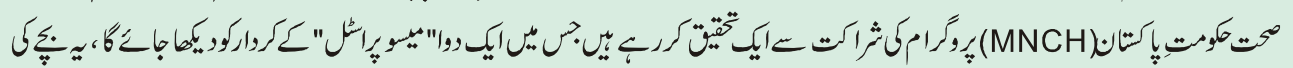

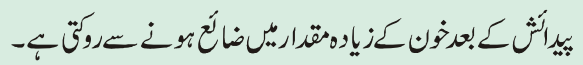

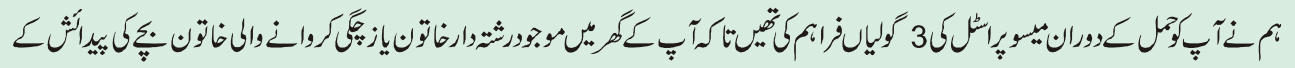

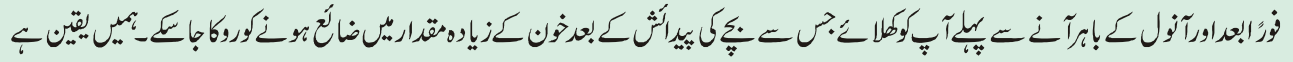

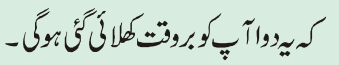

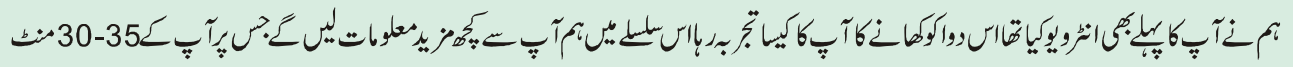

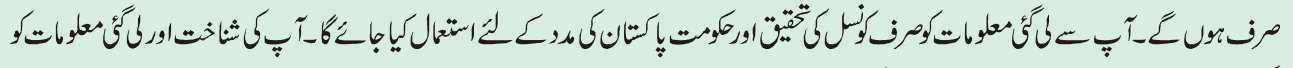

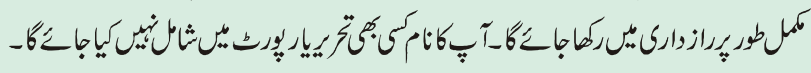

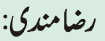

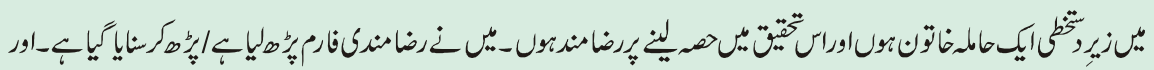

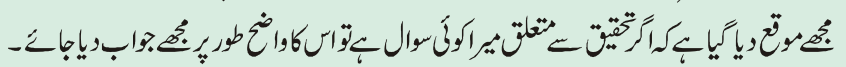

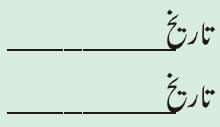

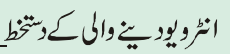

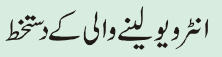

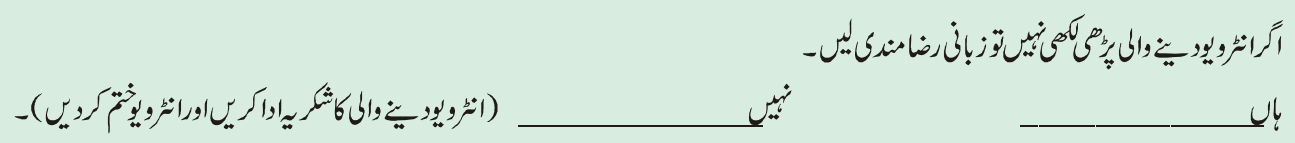

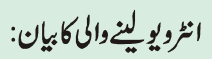

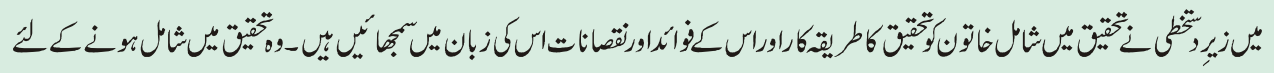

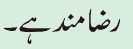
ثان

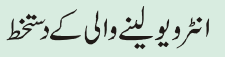


رضامندكفارمباحمبوالنام

\section{(Comparison Area)}

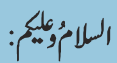

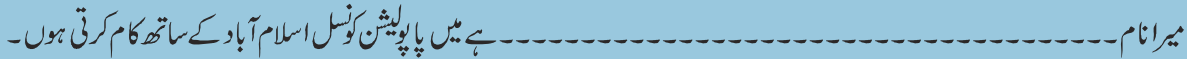

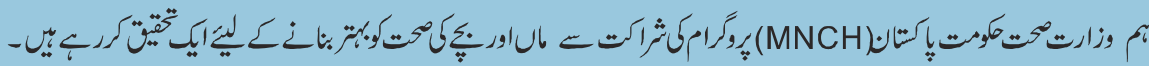

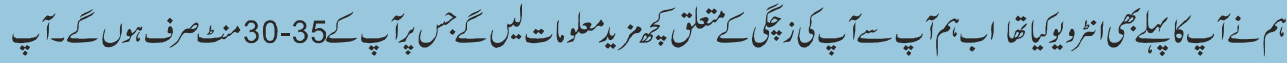

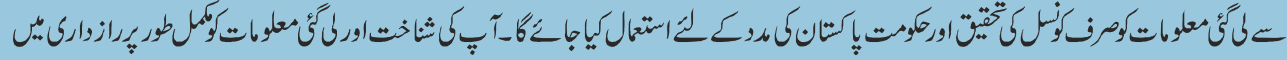

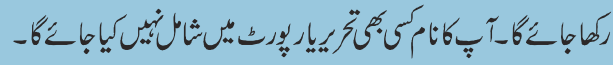

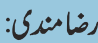

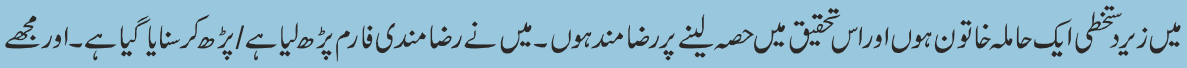

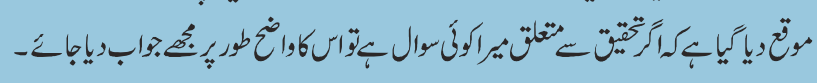

تارتخ

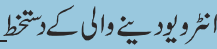

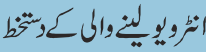

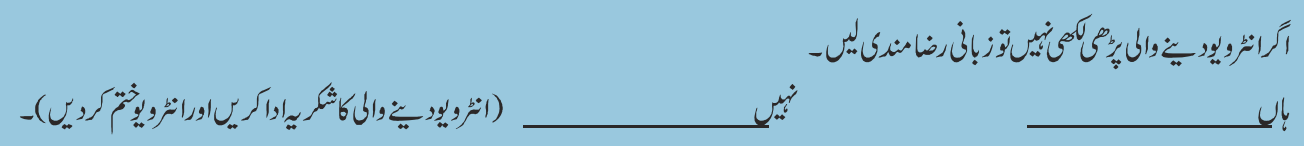

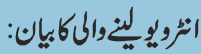

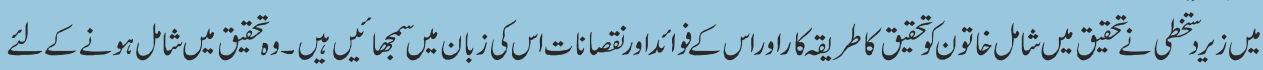

رضامناب

$\xi$

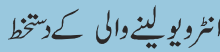




\section{Identification}

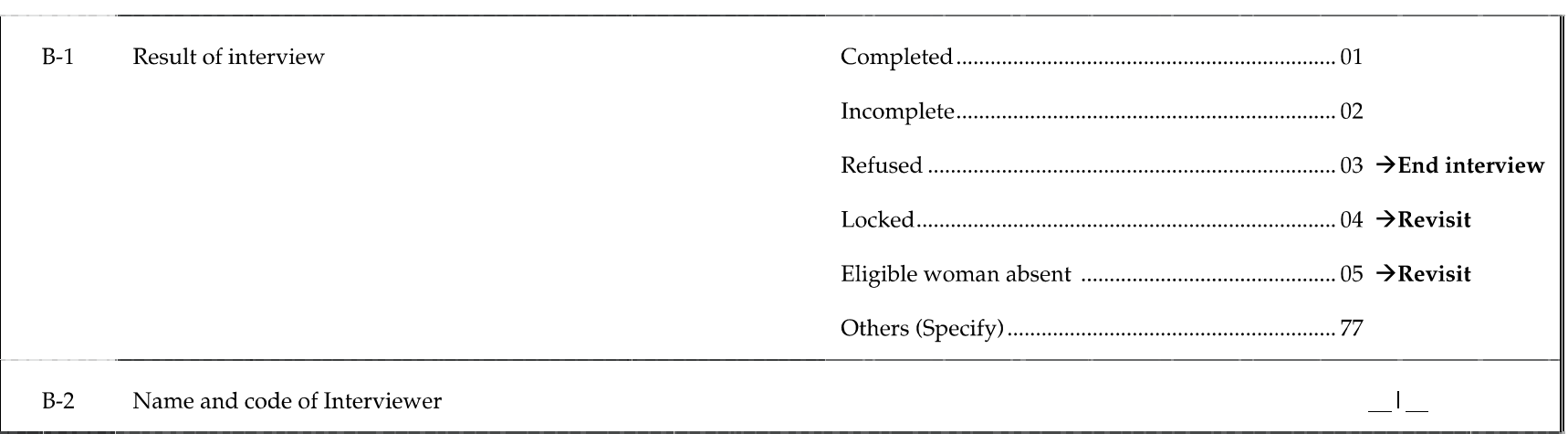




\section{History of last Pregnancy and Post partum period}

\begin{tabular}{|c|c|c|c|c|c|}
\hline \multicolumn{2}{|r|}{ Questions and Filters } & \multicolumn{4}{|c|}{ Responses/codes } \\
\hline B-3 & $\begin{array}{l}\text { When you were pregnant with the child just delivered, did you } \\
\text { have antenatal check up? }\end{array}$ & \multicolumn{4}{|c|}{ Yes } \\
\hline B-4 & 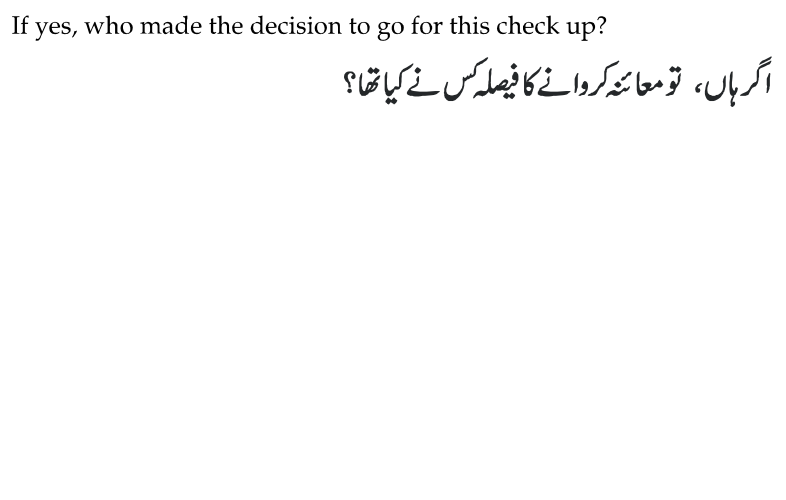 & \multicolumn{4}{|c|}{ Husband } \\
\hline B-5 & 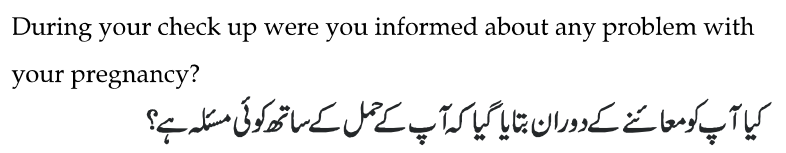 & \multicolumn{4}{|c|}{ Yes } \\
\hline B-6 & 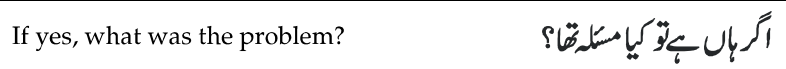 & Spontaneous Yes & Prompted Yes & & No \\
\hline & 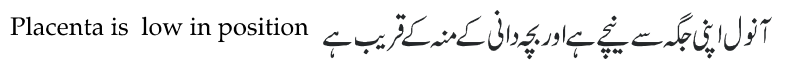 & 1 & 2 & & 3 \\
\hline & 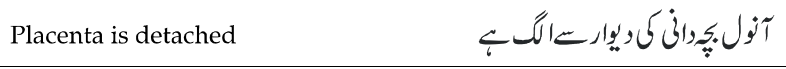 & 1 & 2 & & 3 \\
\hline & Baby is not in a normal position & 1 & 2 & & 3 \\
\hline & Twin/multiple babies & 1 & 2 & & 3 \\
\hline & Anemia & 1 & 2 & & 3 \\
\hline & Diabetes & 1 & 2 & & 3 \\
\hline & Hypertention & 1 & 2 & & 3 \\
\hline & 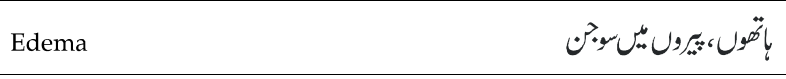 & 1 & 2 & & 3 \\
\hline & 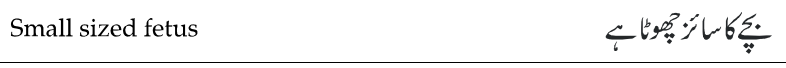 & 1 & 2 & & 3 \\
\hline B-7 & 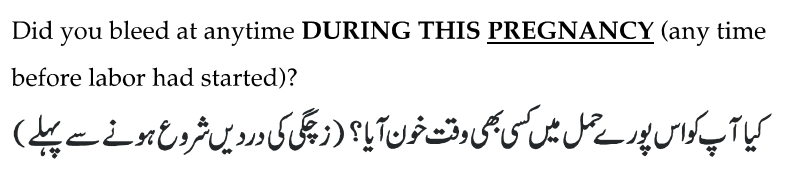 & 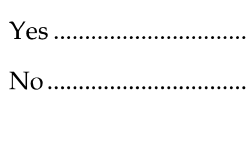 & 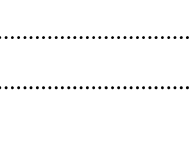 & $\ldots .1$ & $\rightarrow$ Go to B-9 \\
\hline B-8 & If yes, number of bleeding episodes? & Number of times........ & 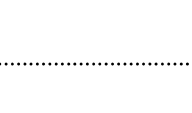 & & \\
\hline
\end{tabular}




\begin{tabular}{|c|c|c|c|}
\hline B-9 & 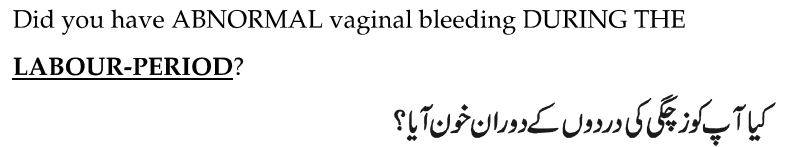 & 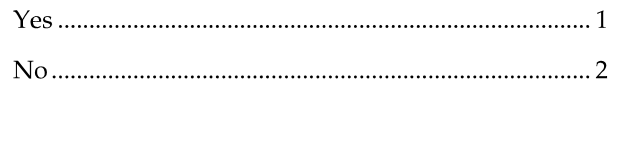 & $\rightarrow$ Go to B-12 \\
\hline B-10 & 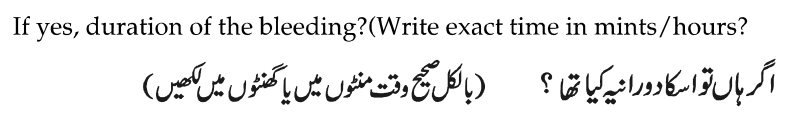 & 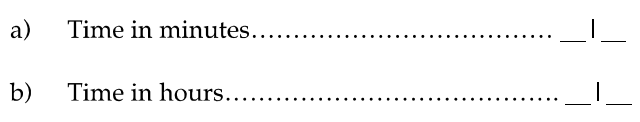 & \\
\hline B-11 & 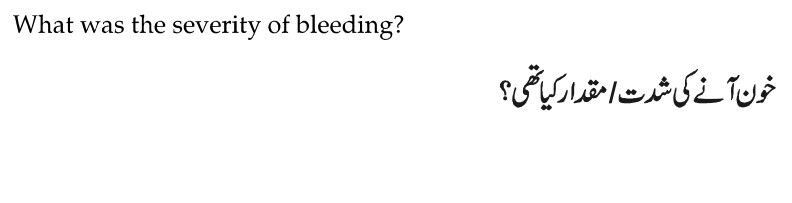 & 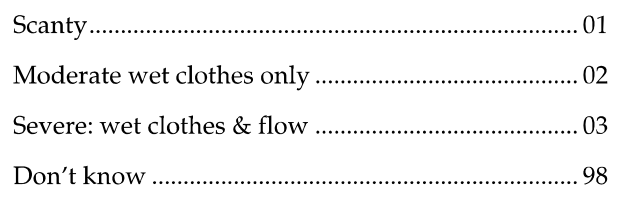 & \\
\hline B-12 & Who delivered the baby? & MBBS doctor & \\
\hline B-13 & $\begin{array}{l}\text { On getting the information about the commencement of your } \\
\text { labour pains after how much time you were visited by the Birth } \\
\text { attendant? }\end{array}$ & a) Time in minutes................................ & \\
\hline B-14 & What was the mode of delivery? & 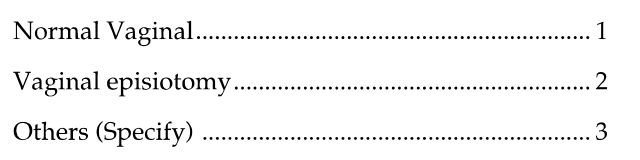 & \\
\hline B-15 & 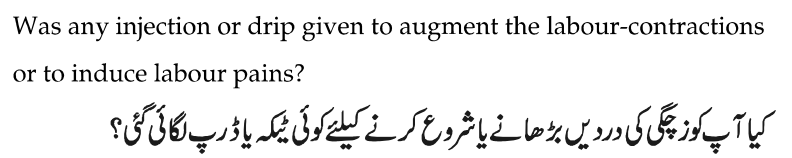 & Yes & $\rightarrow$ Go to B-17 \\
\hline B-16 & 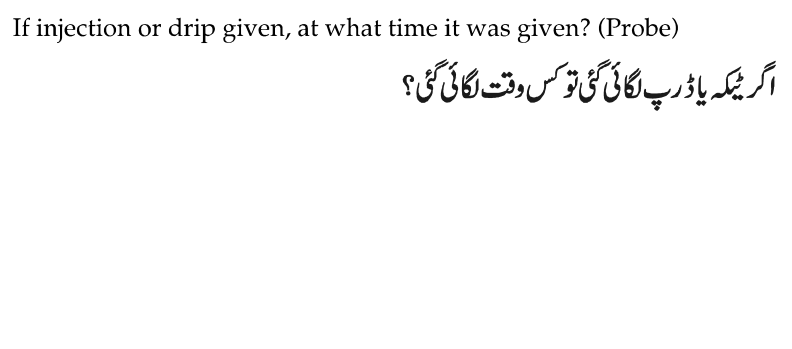 & 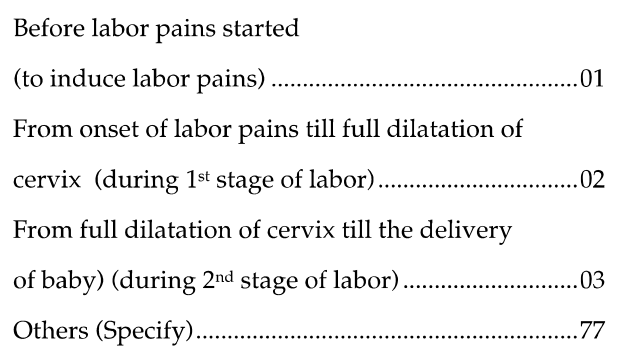 & \\
\hline B-17 & 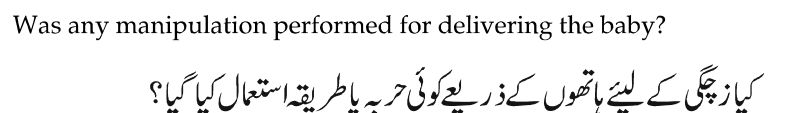 & 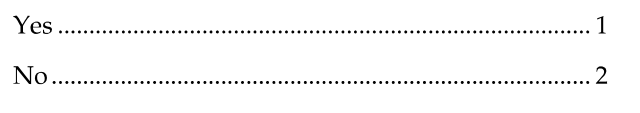 & $\rightarrow$ Go to B-19 \\
\hline
\end{tabular}




\begin{tabular}{|c|c|c|c|}
\hline & 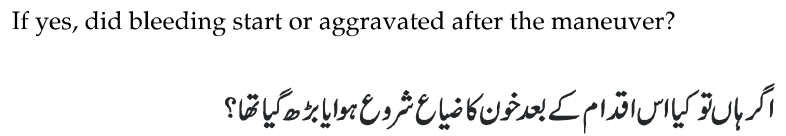 & Yes & \\
\hline B-19 & 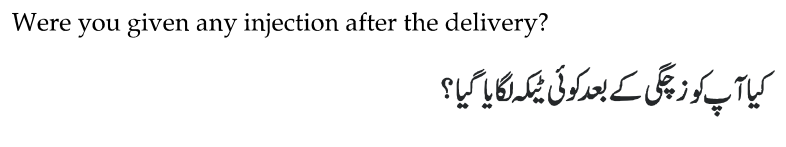 & Yes & $\begin{array}{l}\rightarrow \text { Go to B-22 } \\
\rightarrow \text { Go to B-22 }\end{array}$ \\
\hline B-20 & If yes, at what time this was given? & 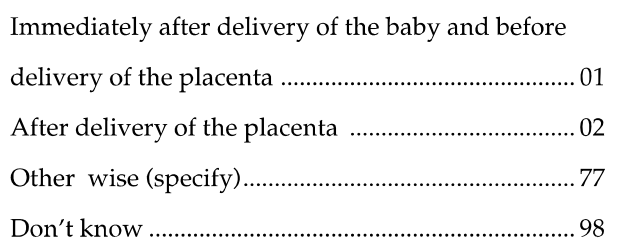 & \\
\hline B-21 & 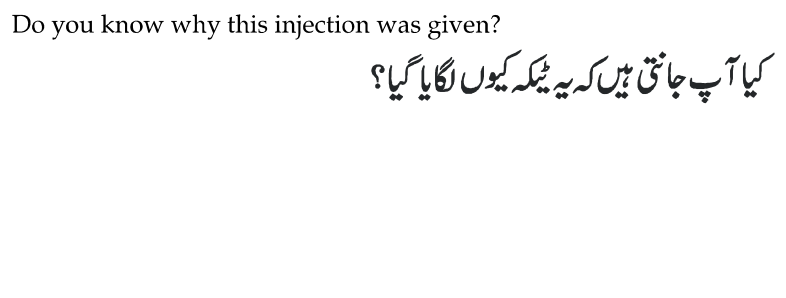 & 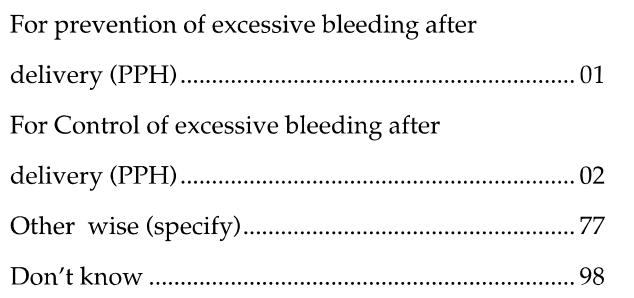 & \\
\hline B-22 & 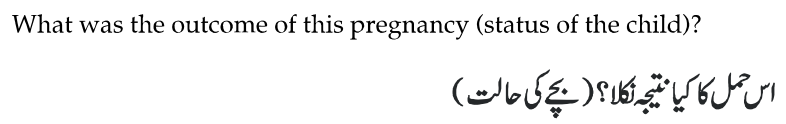 & 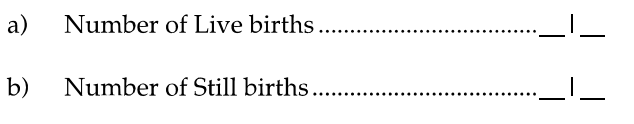 & \\
\hline B-23 & 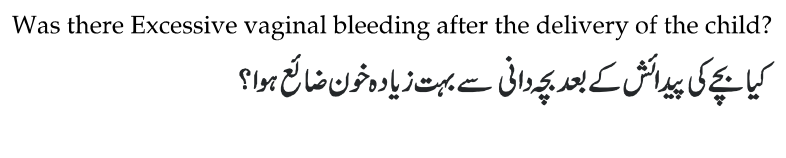 & Check: If no End interview in comparison & $\rightarrow$ Go to B-30 \\
\hline B-24 & If yes, duration of the bleeding? & 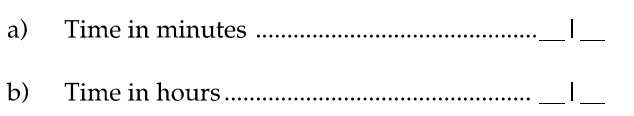 & \\
\hline B-25 & 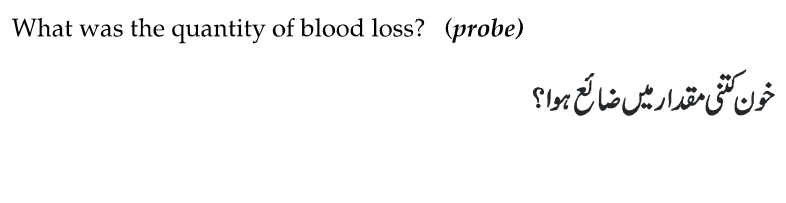 & Spotting & \\
\hline B-26 & $\begin{array}{l}\text { What was done to stop the bleeding anytime during or after } \\
\text { delivery at the household level? }\end{array}$ & 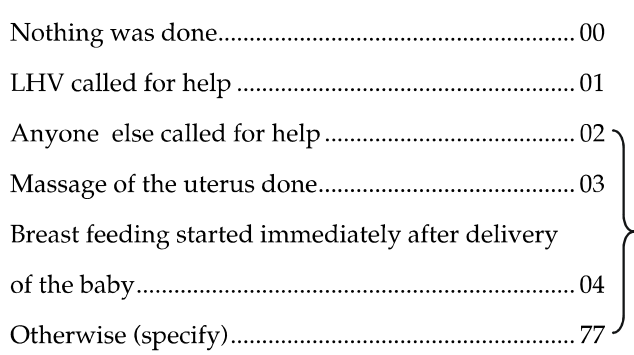 & $\begin{array}{l}\rightarrow \text { Go to B-29 } \\
\rightarrow \text { Go to B-28 }\end{array}$ \\
\hline
\end{tabular}




\begin{tabular}{|c|c|c|}
\hline B-27 & 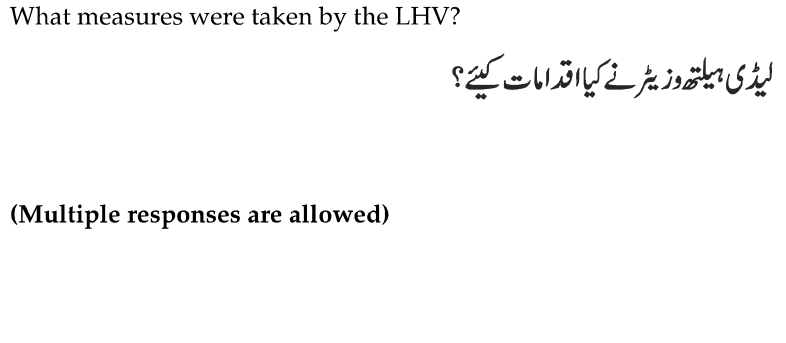 & 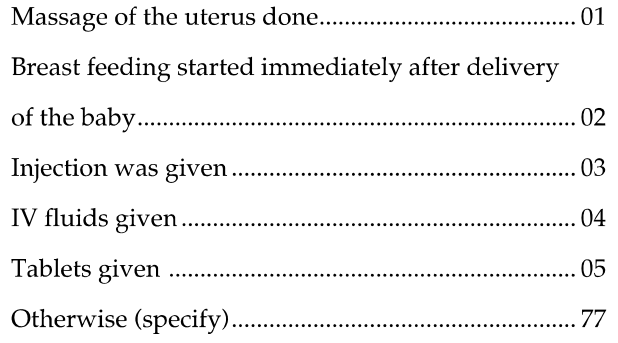 \\
\hline B-28 & 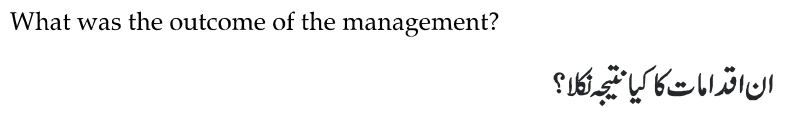 & $\begin{array}{l}\text { Excessive blood loss controlled .................................... } 1 \\
\text { Excessive blood loss not controlled ............................. } 2\end{array}$ \\
\hline B-29 & $\begin{array}{l}\text { If not given any treatment at the health facility, what was the main } \\
\text { reason? }\end{array}$ & 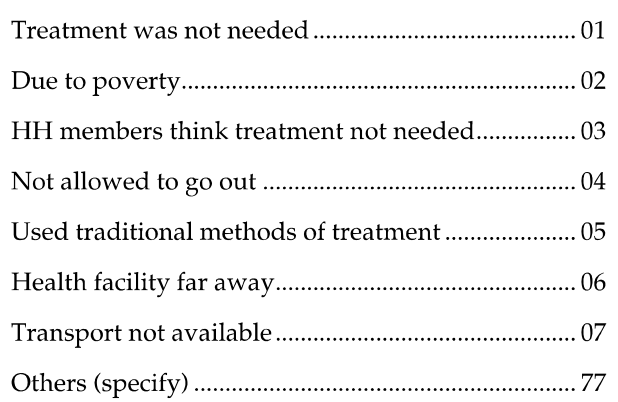 \\
\hline
\end{tabular}




\section{Only for Intervention Area}

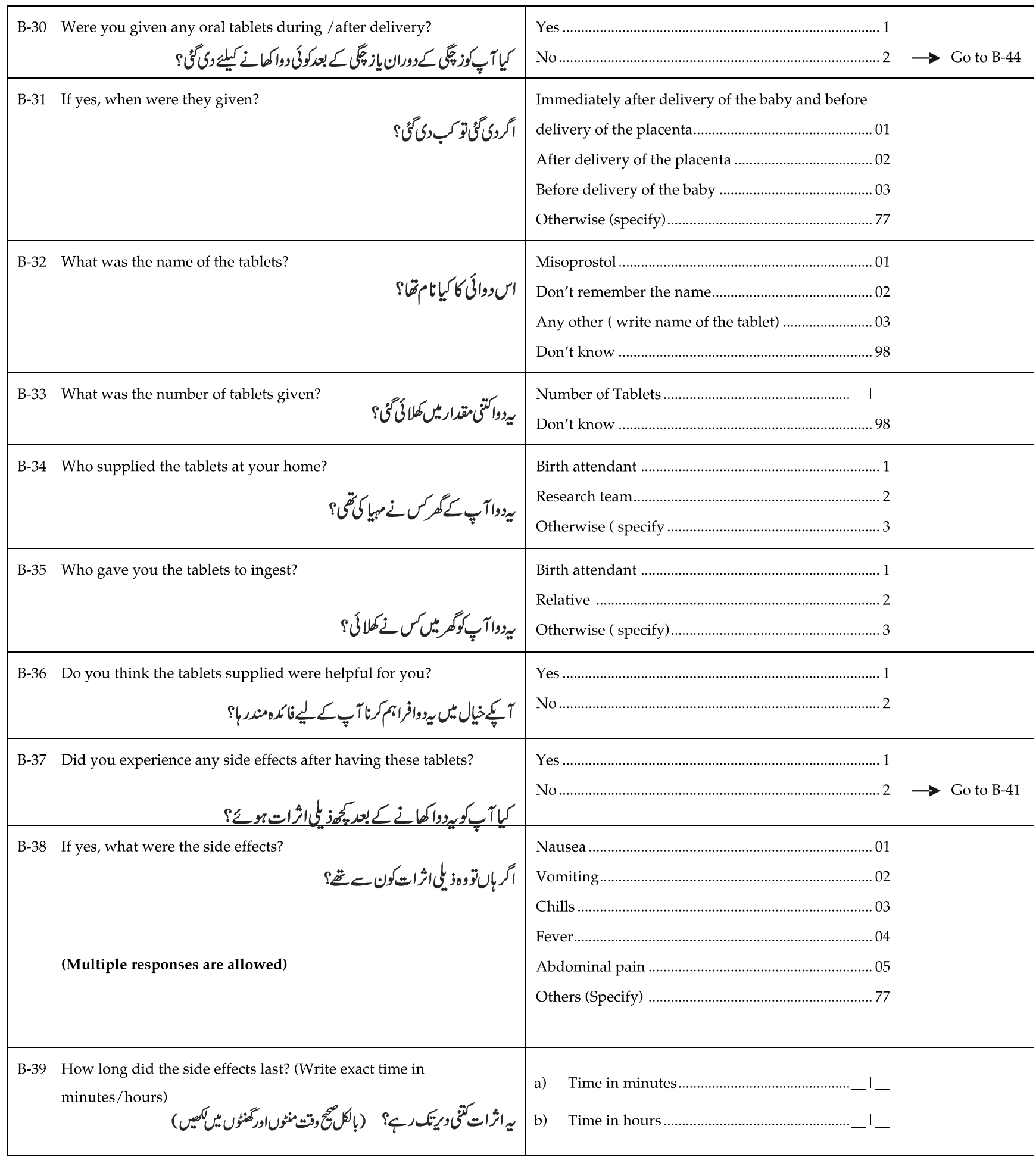




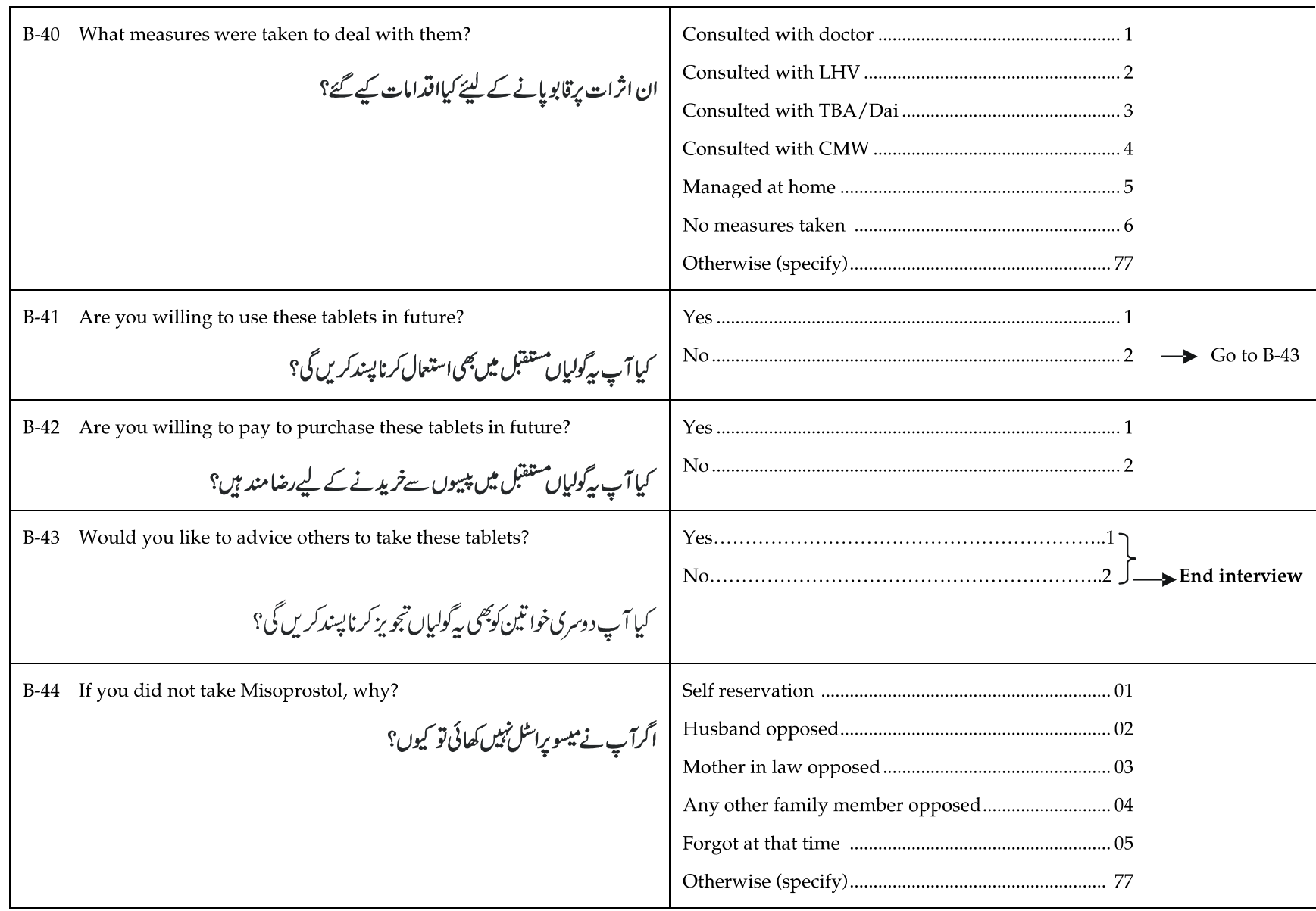




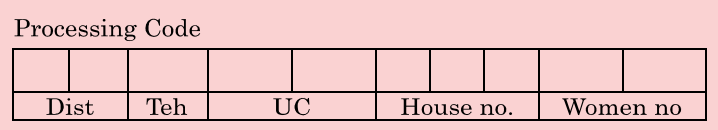

\section{Pakistan Initiative for Mothers and Newborns (PAIMAN)}

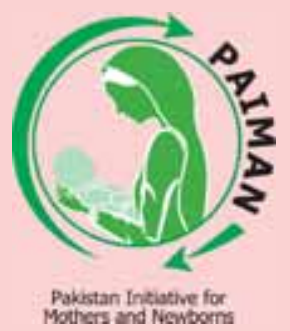

Assessing the feasibility of home administration of Misoprostol in the prevention of PPH in rural Pakistan An OR Study

\section{Post Partum Interview (C) (Referred for Emergency Care) (Women of 15-49 years) \\ (1) Population Council}


رضامندىفارمبا خعوالنام

\section{(Intervention Area)}

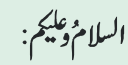

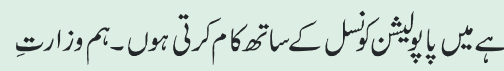

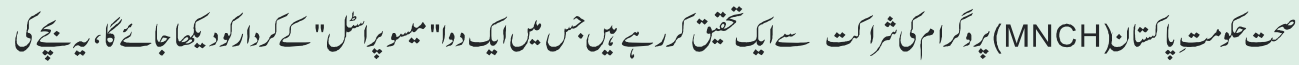

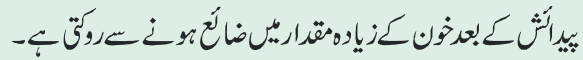

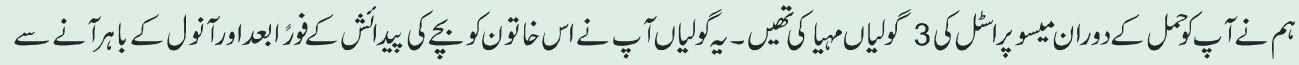

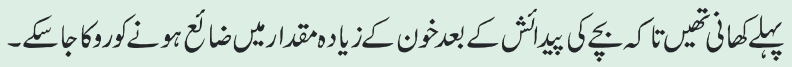

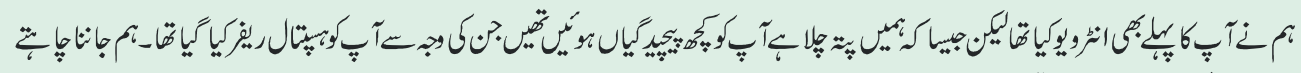

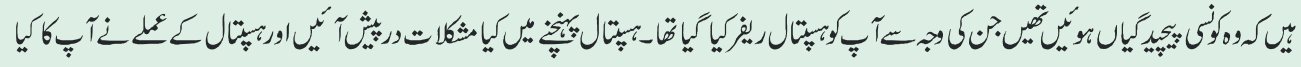

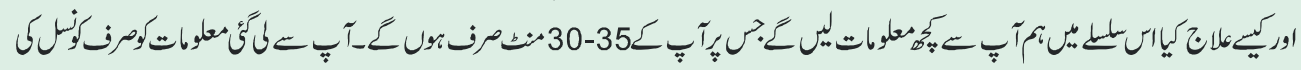

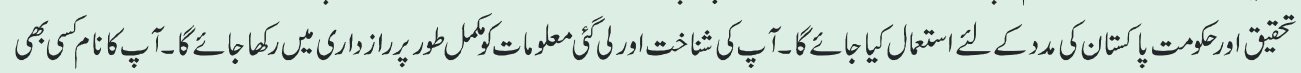

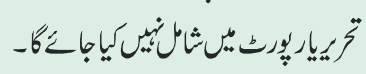
رضامندى:

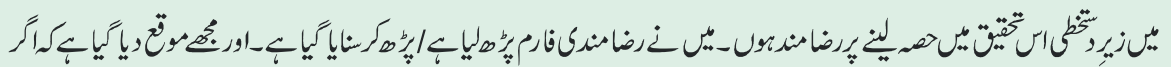

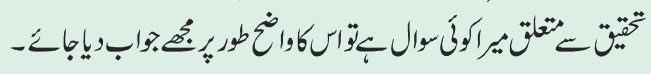

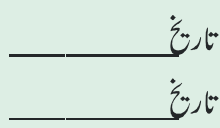

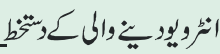

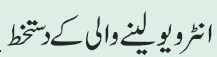

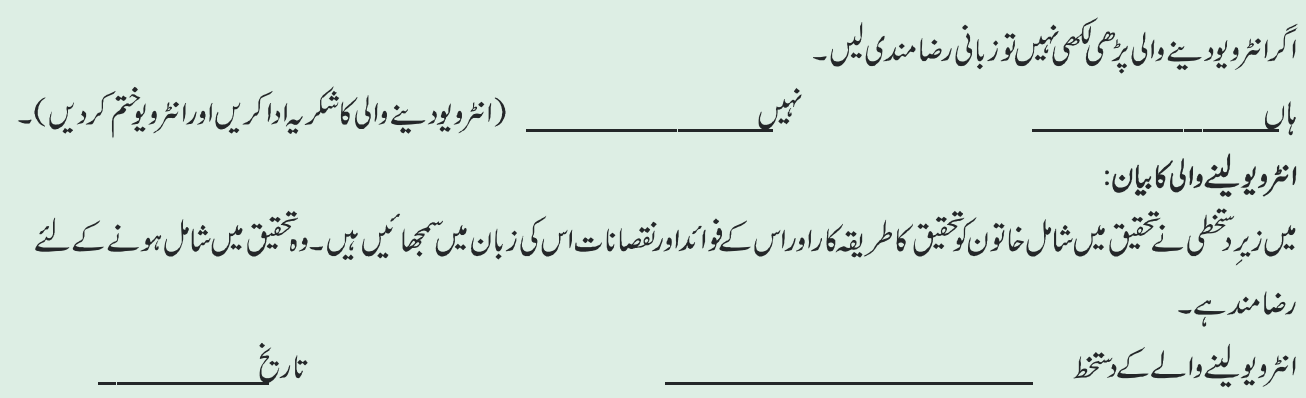


رضامندكنارمبرامشوالنام

(Comparison Area)

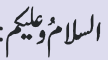

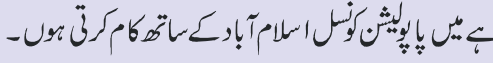

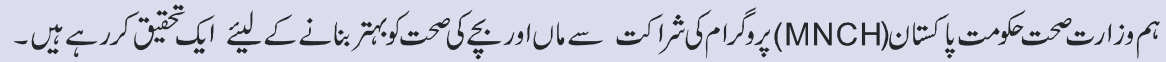

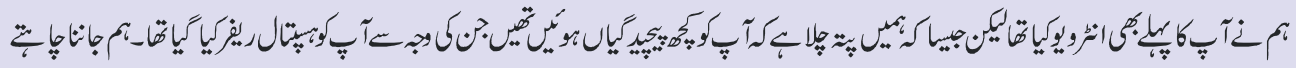

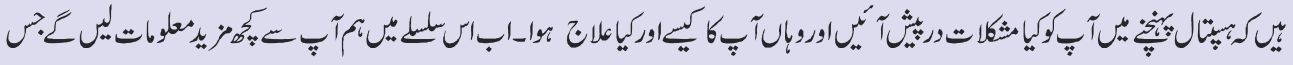

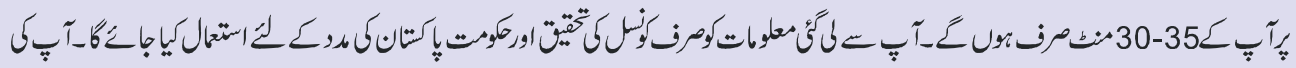

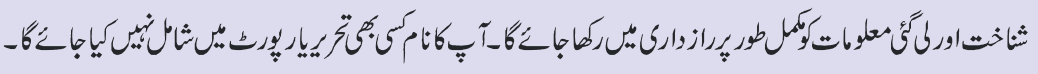
رضامنرى:

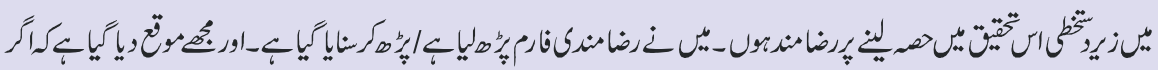

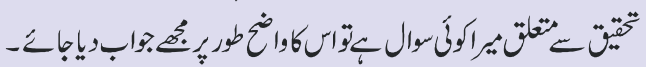

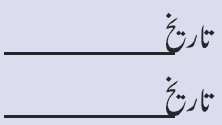

انمريويخوالك كرتخطي

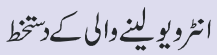

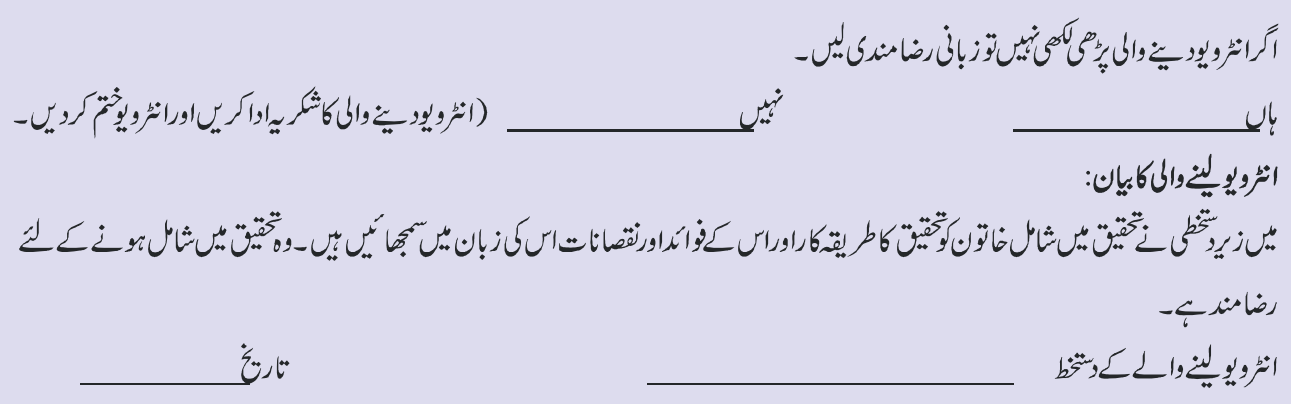




\section{Identification}

\begin{tabular}{|c|c|c|}
\hline \multirow[t]{6}{*}{$\mathrm{C}-1$} & Result of interview & Completed \\
\hline & & 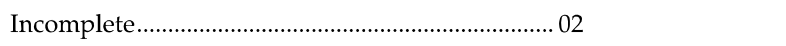 \\
\hline & & Refused \\
\hline & & Locked \\
\hline & & Eligible woman absent ………………………............. $05 \rightarrow$ Revisit \\
\hline & & Others (Specify) ............................................ \\
\hline $\mathrm{C}-2$ & Name and code of Interviewer & ${ }_{-}^{\prime}$ \\
\hline
\end{tabular}


History of last Labor \& Post partum period

\begin{tabular}{|c|c|c|c|}
\hline & Questions and Filters & Responses/codes & \\
\hline$C-3$ & $\begin{array}{l}\text { What was the reason for referral? } \\
\text { (Multiple responses are allowed) }\end{array}$ & 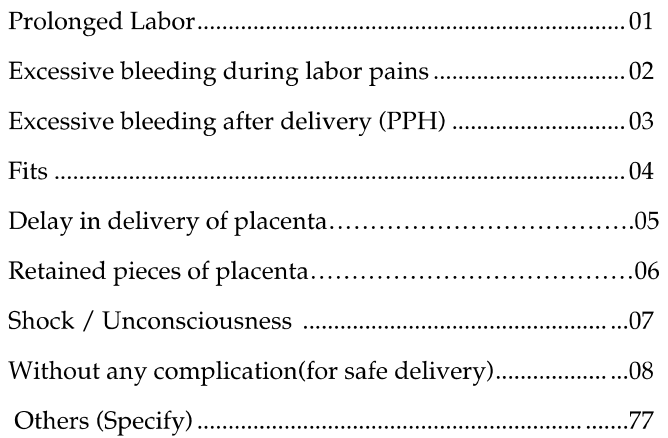 & $\rightarrow$ Go to C-7 \\
\hline $\mathrm{C}-4$ & 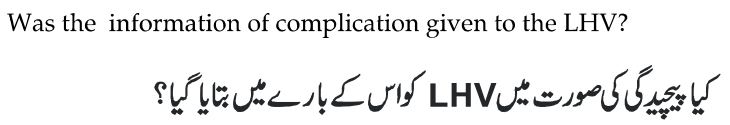 & Yes. & \\
\hline$C-5$ & 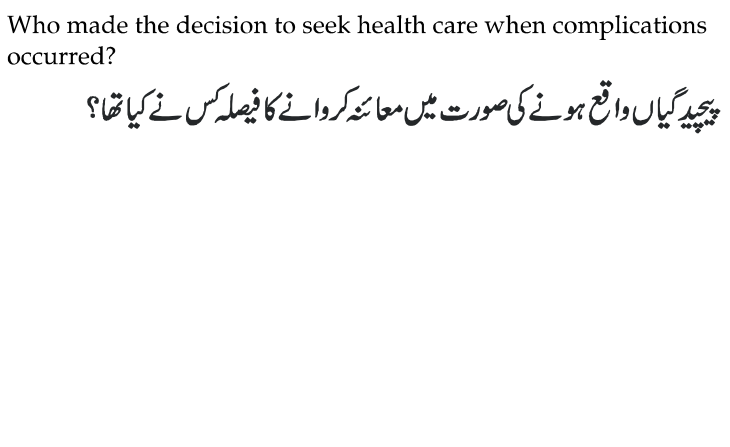 & Husband & \\
\hline C-6 & In case of complications which health facility you visited? & 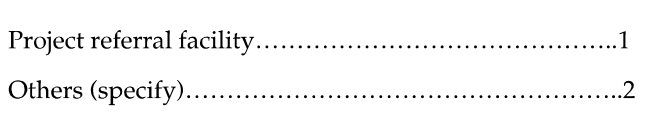 & \\
\hline $\mathrm{C}-7$ & 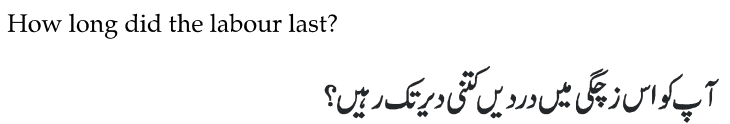 & 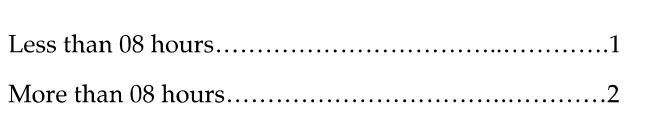 & \\
\hline C-8 & 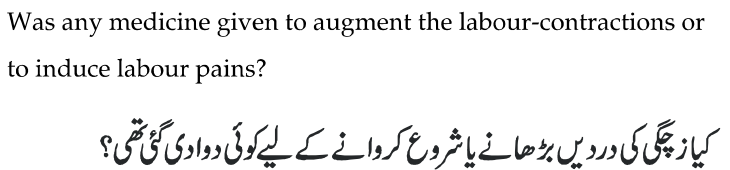 & 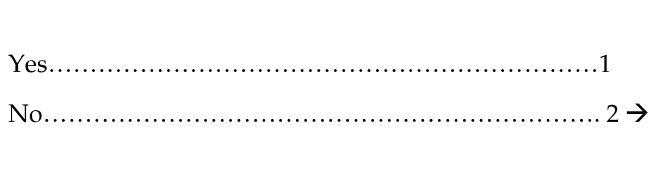 & Go to C-10 \\
\hline C-9 & $\begin{array}{l}\text { If yes, which medicine was given? } \\
\text { (Multiple responses are allowed) }\end{array}$ & Injection & \\
\hline
\end{tabular}




\begin{tabular}{|c|c|c|}
\hline C-10 & 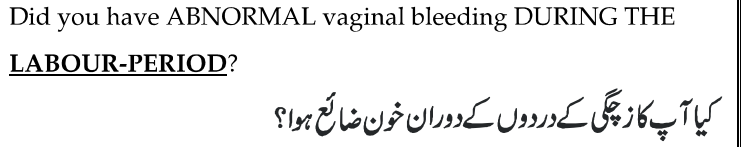 & 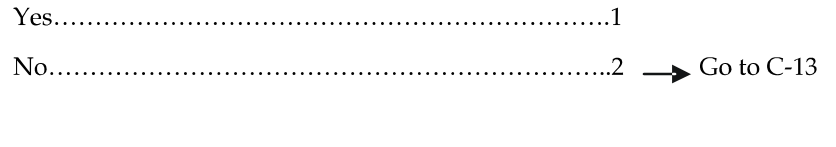 \\
\hline C-11 & If yes, duration of the bleeding? & 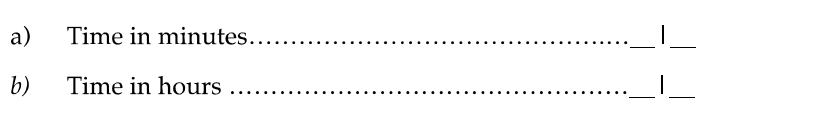 \\
\hline C-12 & Severity of the bleeding & 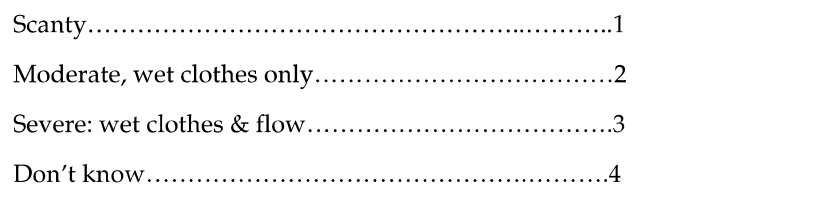 \\
\hline C-13 & $\begin{array}{l}\text { On getting the information about the commencement of your } \\
\text { labor pains after how much time you were visited by the birth } \\
\text { attendant? }\end{array}$ & 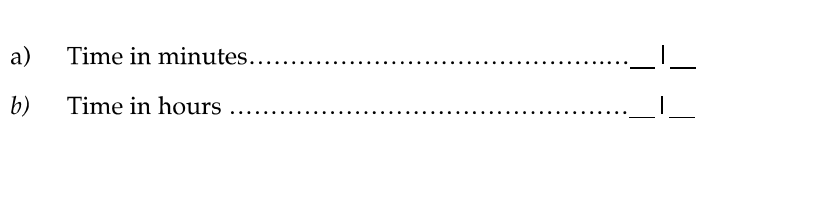 \\
\hline C-14 & What was the mode of delivery? & 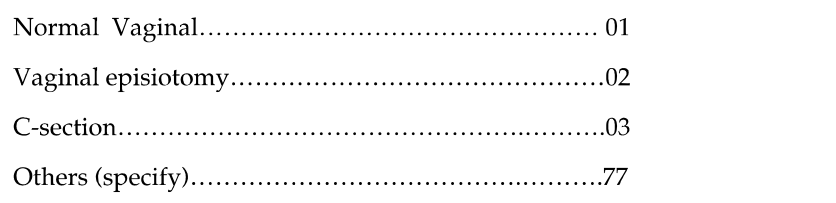 \\
\hline C-15 & Who delivered the baby? & MBBS doctor \\
\hline C-16 & 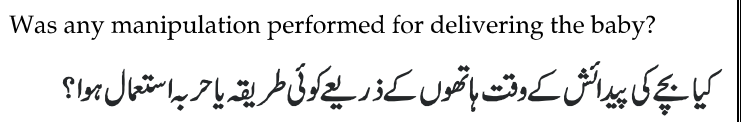 & 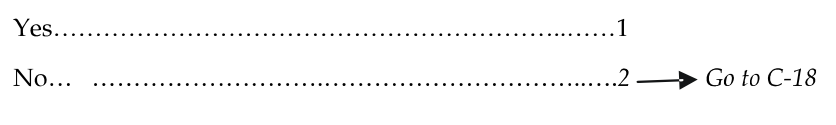 \\
\hline C-17 & 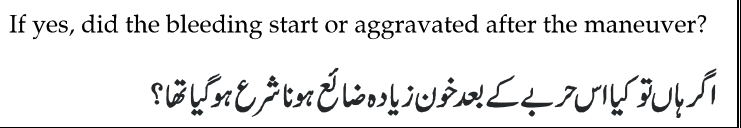 & 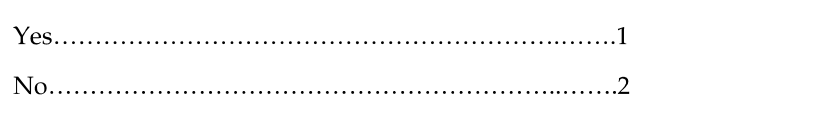 \\
\hline C-18 & 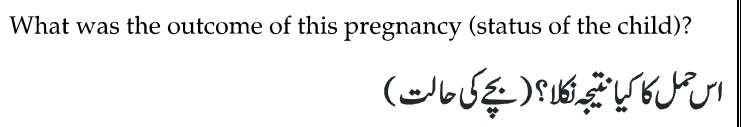 & a) Number of Live birth......................................... \\
\hline C-19 & 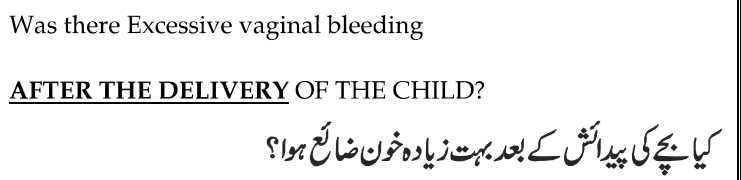 & 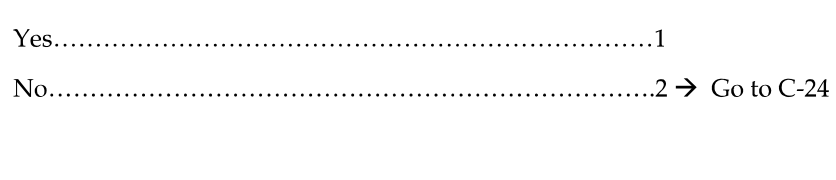 \\
\hline C-20 & 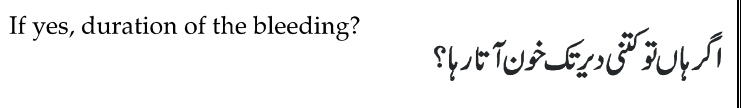 &  \\
\hline
\end{tabular}




\begin{tabular}{|c|c|c|}
\hline $\mathrm{C}-21$ & 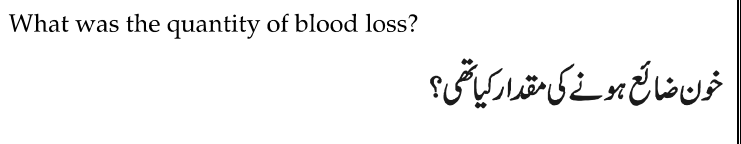 & 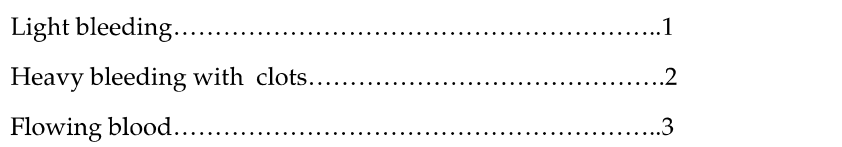 \\
\hline$C-22$ & $\begin{array}{l}\text { What was done to stop the bleeding at the household level? } \\
\text { (Multiple responses are allowed) }\end{array}$ & 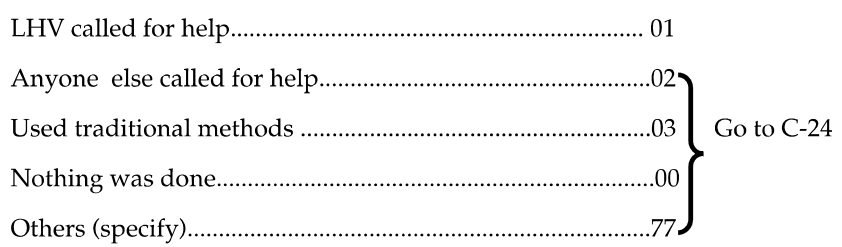 \\
\hline $\mathrm{C}-23$ & $\begin{array}{l}\text { What measures were taken by LHV? } \\
\text { (Multiple responses are allowed) }\end{array}$ & 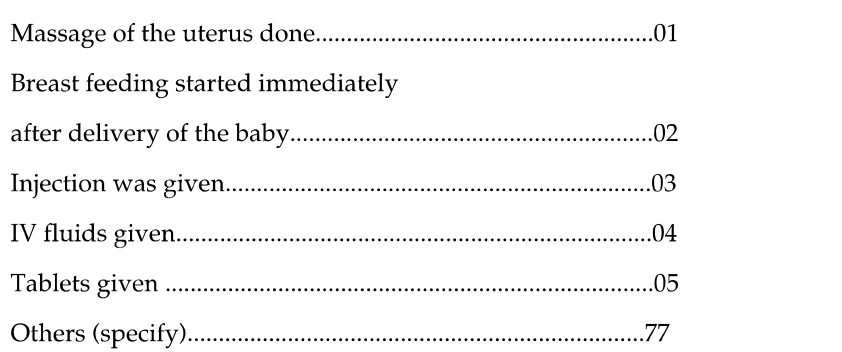 \\
\hline$C-24$ & 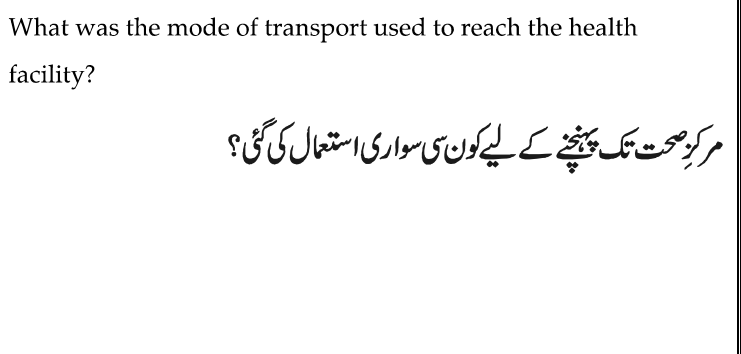 & 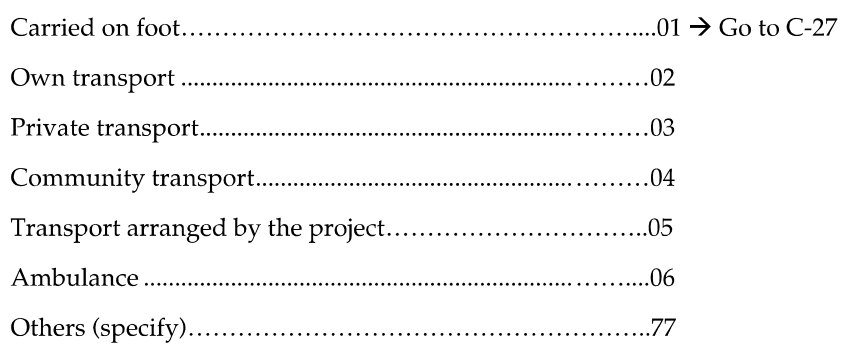 \\
\hline $\mathrm{C}-25$ & How much did it cost you? & 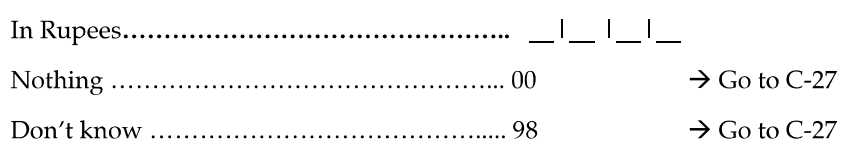 \\
\hline$C-26$ & 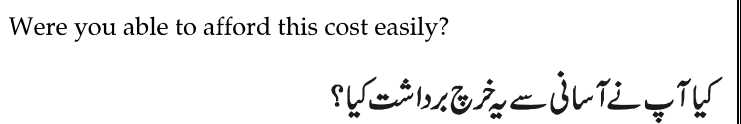 & 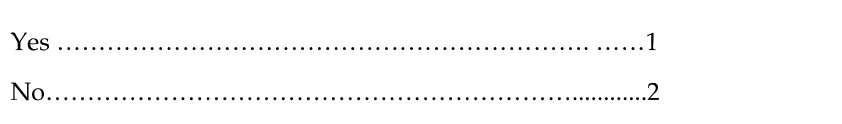 \\
\hline C-27 & How long did it take you to reach the health facility? & 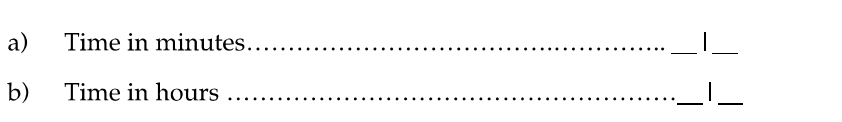 \\
\hline C- 28 & $\begin{array}{l}\text { How much time did it take to receive any treatment after } \\
\text { reaching at the health facility? }\end{array}$ & a) Time in minutes.................................................. \\
\hline C-29 & What was the duration of stay at the health facility? & a) Time in hours \\
\hline
\end{tabular}




\begin{tabular}{|c|c|c|}
\hline$C-30$ & Were you given any tablet for treatment at the health facility? & Yes \\
\hline C-31 & What was the name of tablet? & 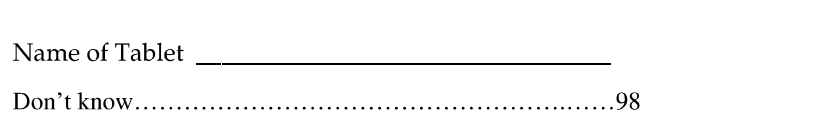 \\
\hline C-32 & What was the number of tablets? & Number of Tablets .......................................... I \\
\hline C-33 & What was the route of administration? & Oral \\
\hline C-34 & When were the tablet given? & 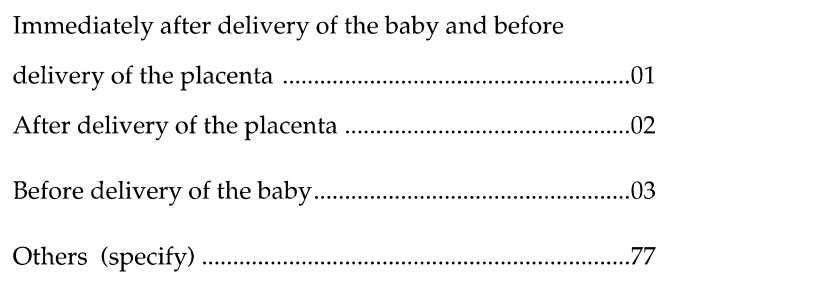 \\
\hline C-35 & $\begin{array}{l}\text { Where you given any injection for treatment at the health } \\
\text { facility? }\end{array}$ & Yes \\
\hline C-36 & What was the number of injections? & 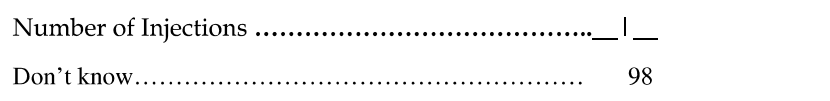 \\
\hline C-37 & $\begin{array}{l}\text { When they were given? } \\
\text { Multiple responses are allowed }\end{array}$ & 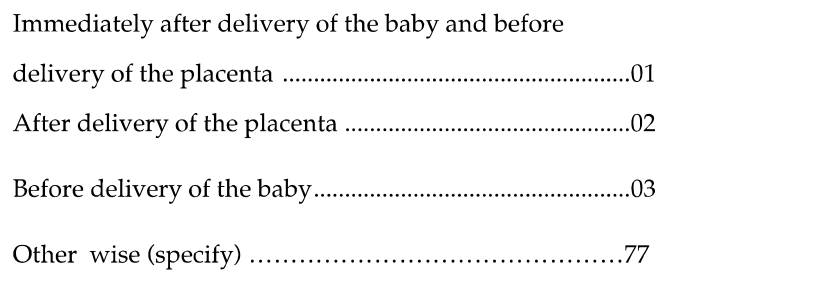 \\
\hline C-38 & $\begin{array}{l}\text { Does I v infusion s/drip used for the treatment at the health } \\
\text { facility? }\end{array}$ & Yes $\mathrm{N}$ \\
\hline C-39 & If yes, which infusion/drip was given? & 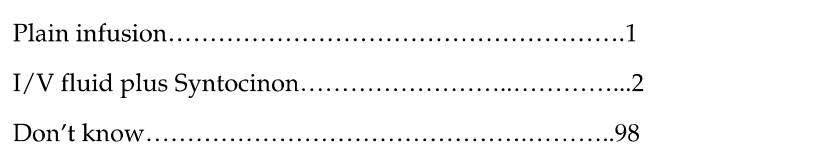 \\
\hline C- 40 & What was the number of infusions/drip given? & 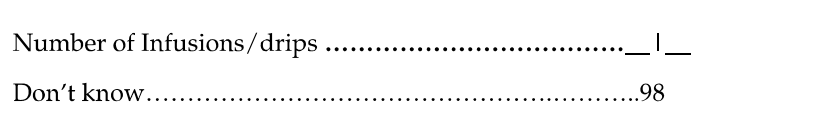 \\
\hline
\end{tabular}




\begin{tabular}{|c|c|c|}
\hline C-41 & Were you infused blood for the treatment at health facility? & 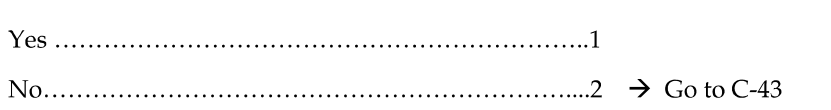 \\
\hline C-42 & If yes, how many pints (bottle) were infused? & Number of pints (bottles) \\
\hline C-43 & Was any surgery done for the treatment at health facility? & Yes \\
\hline C- 44 & What was the reason for surgery? & 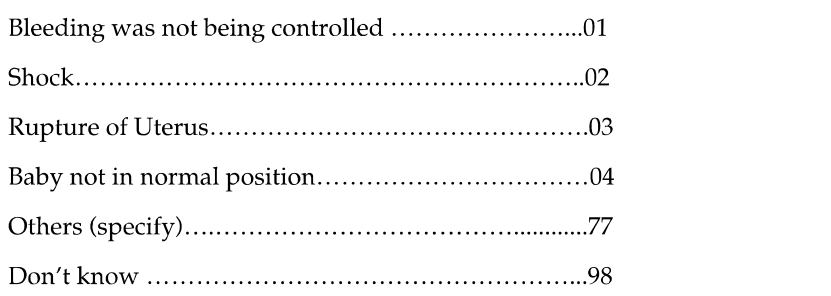 \\
\hline C-45 & Do you know which surgery was done? & 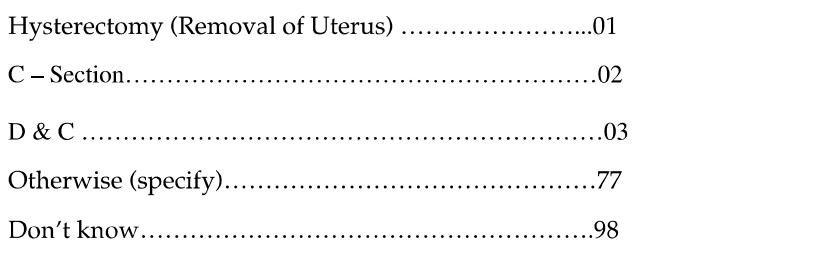 \\
\hline \multicolumn{3}{|c|}{ (End Interview in comparison area) } \\
\hline C-46 & 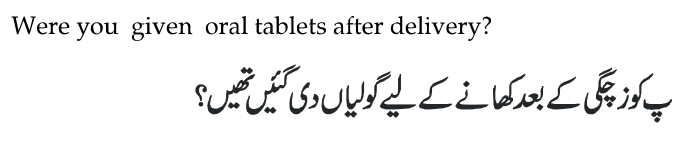 & 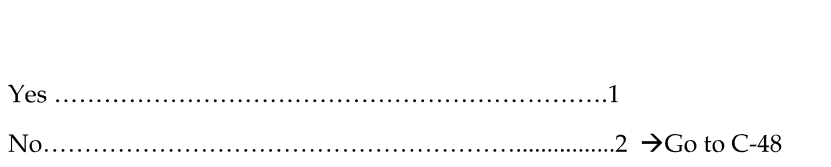 \\
\hline C-47 & If not given, what was the reason? & 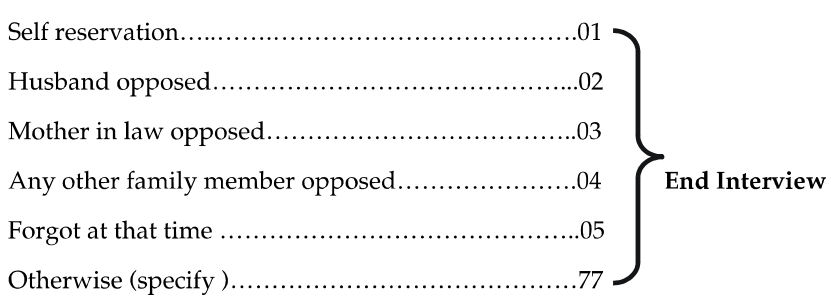 \\
\hline C- 48 & If tablets were given, what was the number of tablets? & 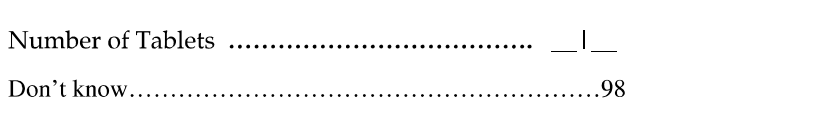 \\
\hline C- 49 & What was the name of tablets? & 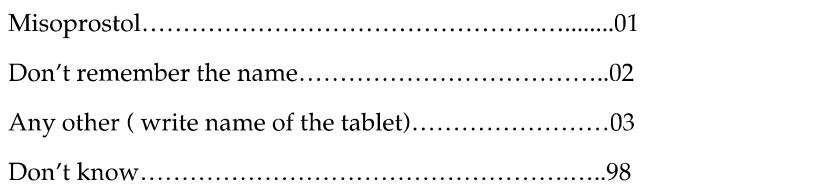 \\
\hline
\end{tabular}




\begin{tabular}{|c|c|c|}
\hline C-50 & At what time of labor they were given? & $\begin{array}{l}\text { Immediately after delivery of the baby and before } \\
\text { delivery of the placenta } \\
\text { After delivery of the placenta }\end{array}$ \\
\hline C-51 & Do you know why these tablets were given? & $\begin{array}{l}\text { For prevention of excessive bleeding } \\
\text { after delivery (PPH) } \\
\text { For Control of excessive bleeding } \\
\text { after delivery (PPH) }\end{array}$ \\
\hline C-52 & Who supplied these tablets? & 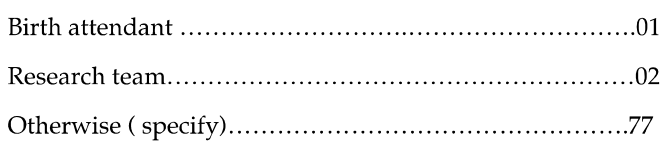 \\
\hline C-53 & 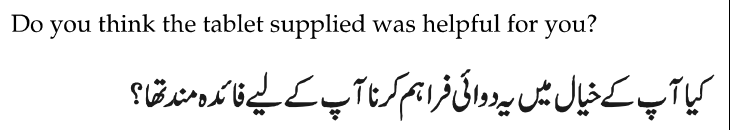 & Yes \\
\hline C-54 & 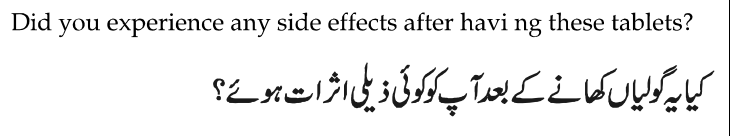 & Yes \\
\hline C-55 & $\begin{array}{l}\text { If yes, what were the side effects? } \\
\text { (Multiple responses are allowed) }\end{array}$ & Nausea \\
\hline C-56 & 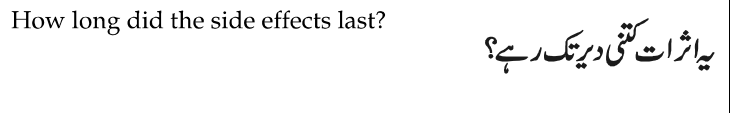 & 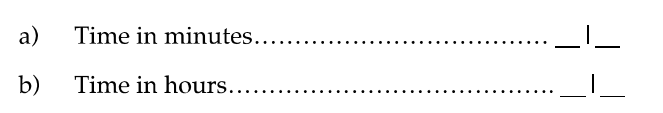 \\
\hline C-57 & 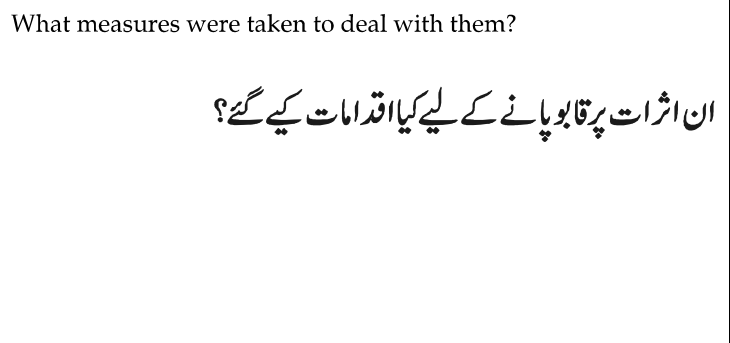 & 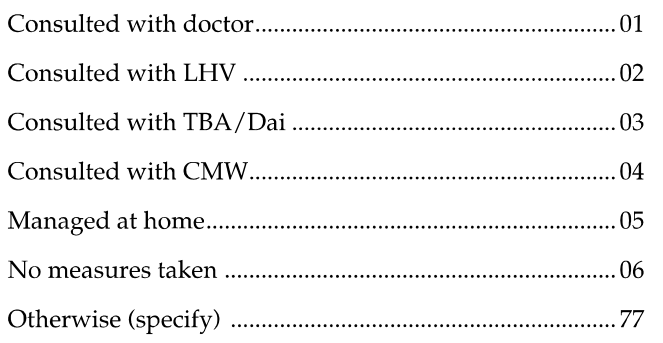 \\
\hline
\end{tabular}




\begin{tabular}{|c|c|c|}
\hline C-58 & 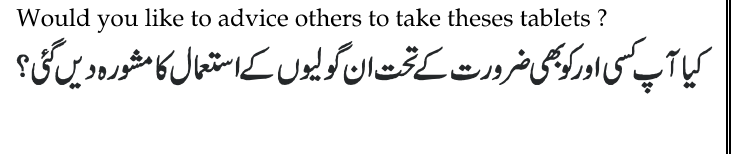 & Yes \\
\hline C-59 & Are you willing to pay to purchase these tablets in future? & Yes \\
\hline C-60 & Do you have any suggestions to improve its administration? & \\
\hline
\end{tabular}




\section{Processing Code

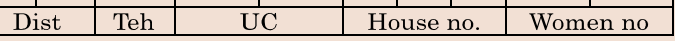

Pakistan Initiative for Mothers and Newborns (PAIMAN)

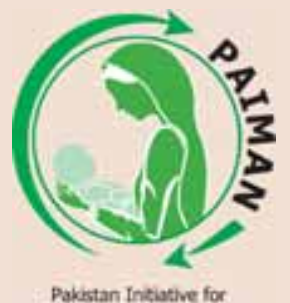

Mothers and Newborm

Assessing the feasibility of home administration of Misoprostol in the prevention of PPH in rural Pakistan An OR Study

\section{Post Partum Interview (D)}

(Birth Attendant)

(1) Population Council 


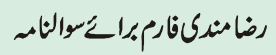

\section{(Intervention Area )}

\section{(Birth Attendant)}

السالم:

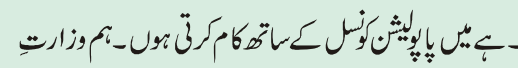

ميران

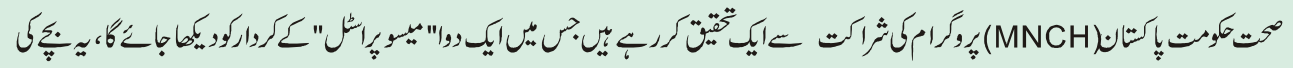

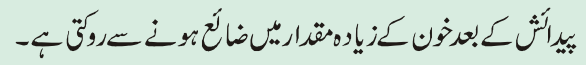

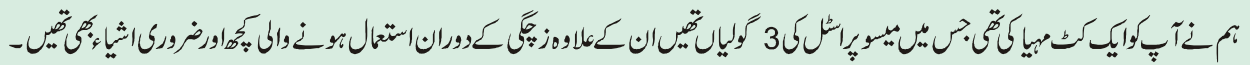

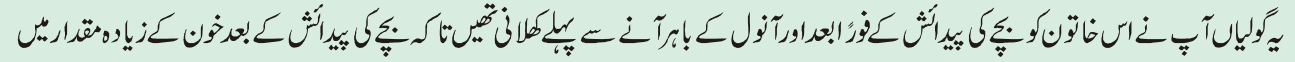

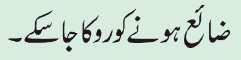

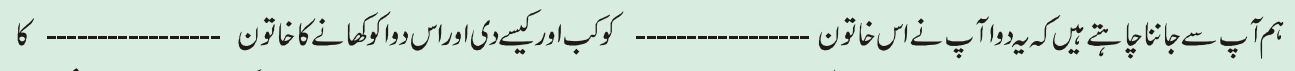

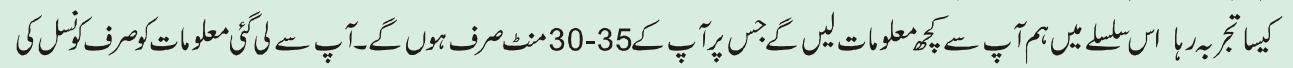

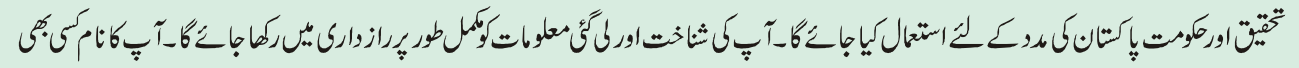

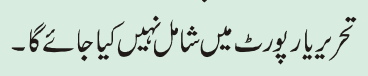
رضامنى:

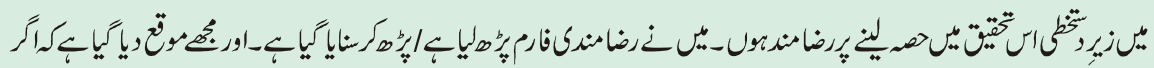

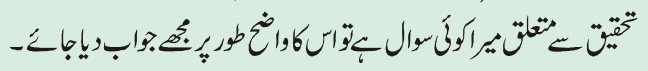

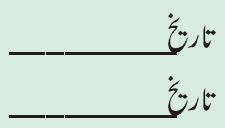

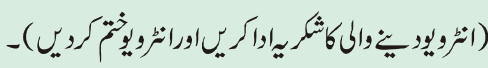

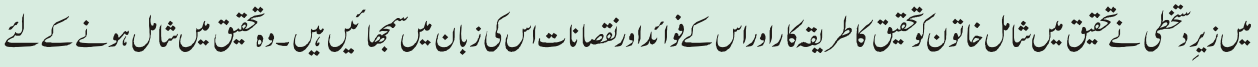
茾
انثرئيخ

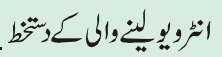

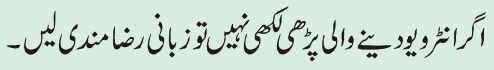

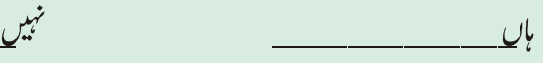

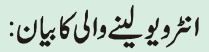
رضامنابك-

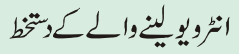


رضامندكفارم براحسوالثام

\section{(comparison Area)}

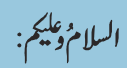

-

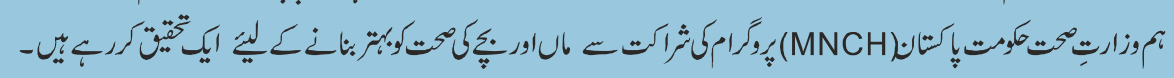

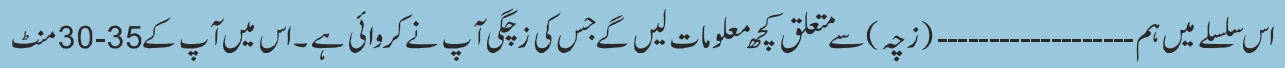

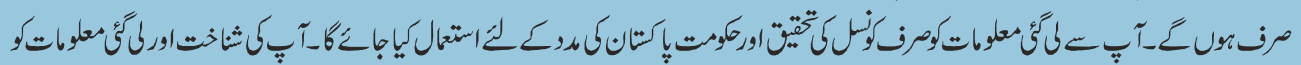

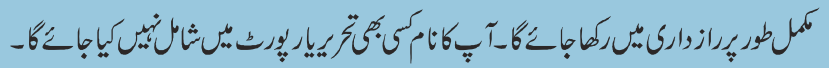
رضامنرى:

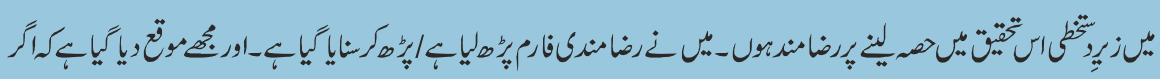

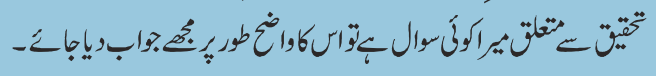

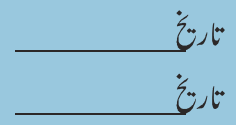

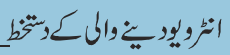

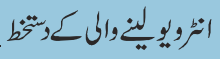

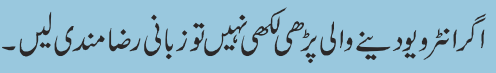

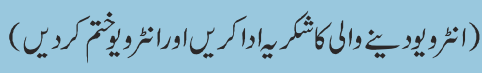
(n) 4 انمرويِ لِنوالكانيان:

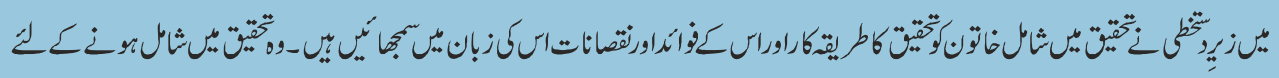

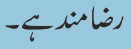
芒

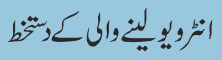




\section{Identification}

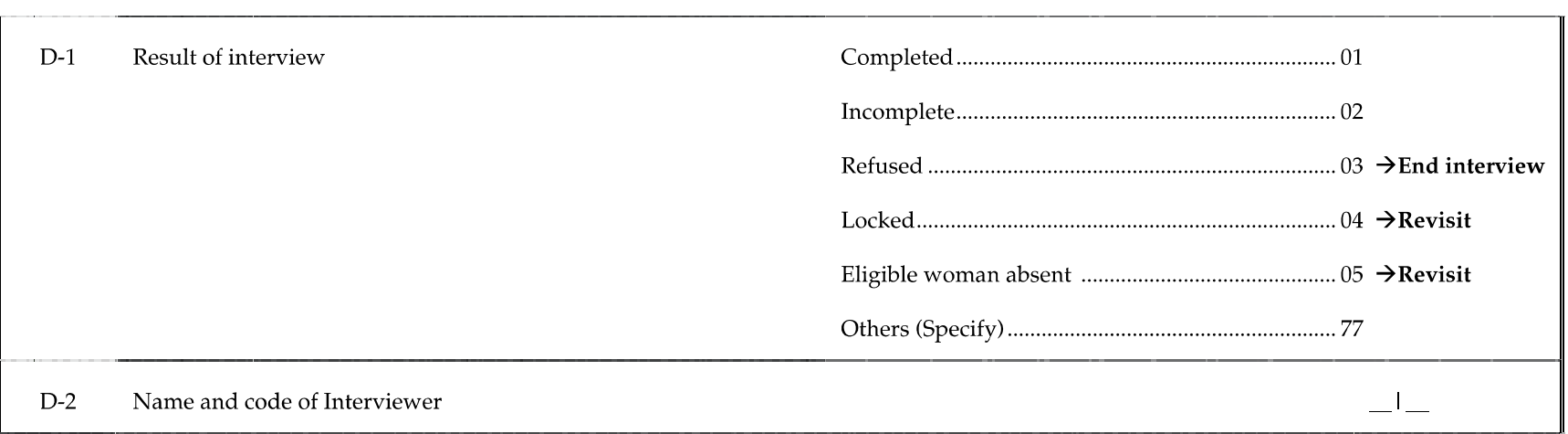




\section{Background Characteristics}

\begin{tabular}{|c|c|c|}
\hline & Questions and Filters & Responses and Codes \\
\hline D-3 & What is your date of birth? & 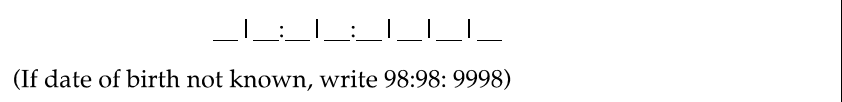 \\
\hline D-4 & What is your age? & Number of years ......................................................... \\
\hline D-5 & How many years of education have you completed? & 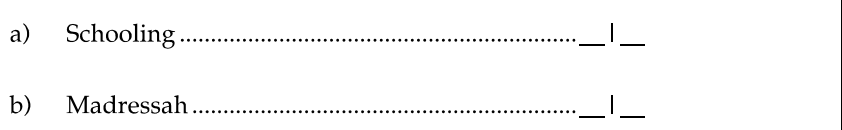 \\
\hline D-6 & What is your current marital status? & 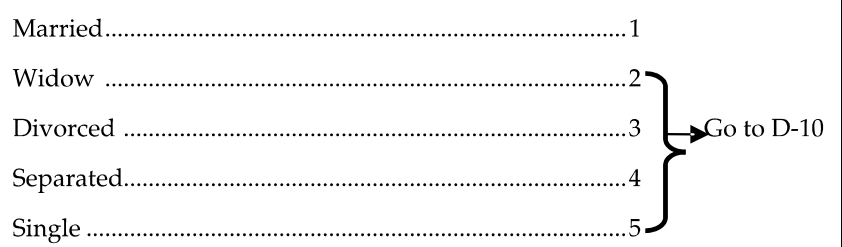 \\
\hline D-7 & $\begin{array}{l}\text { Did your husband ever attend school, madressah or studied at } \\
\text { home? }\end{array}$ & Yes \\
\hline D-8 & 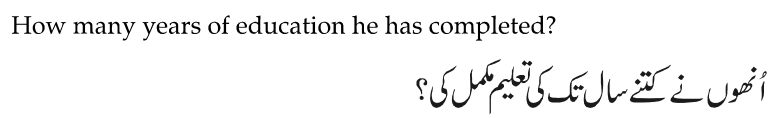 & 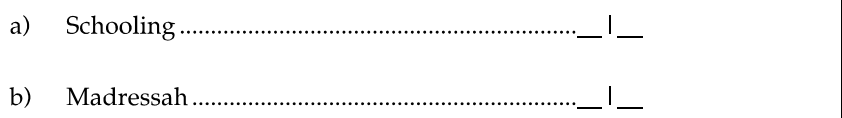 \\
\hline D-9 & What is your husband's main occupation? & Agriculture/Livestock/Poultry killed labor \\
\hline D-10 & What is the language spoken in your household? & Punjabi \\
\hline
\end{tabular}




\section{Professional Skills}

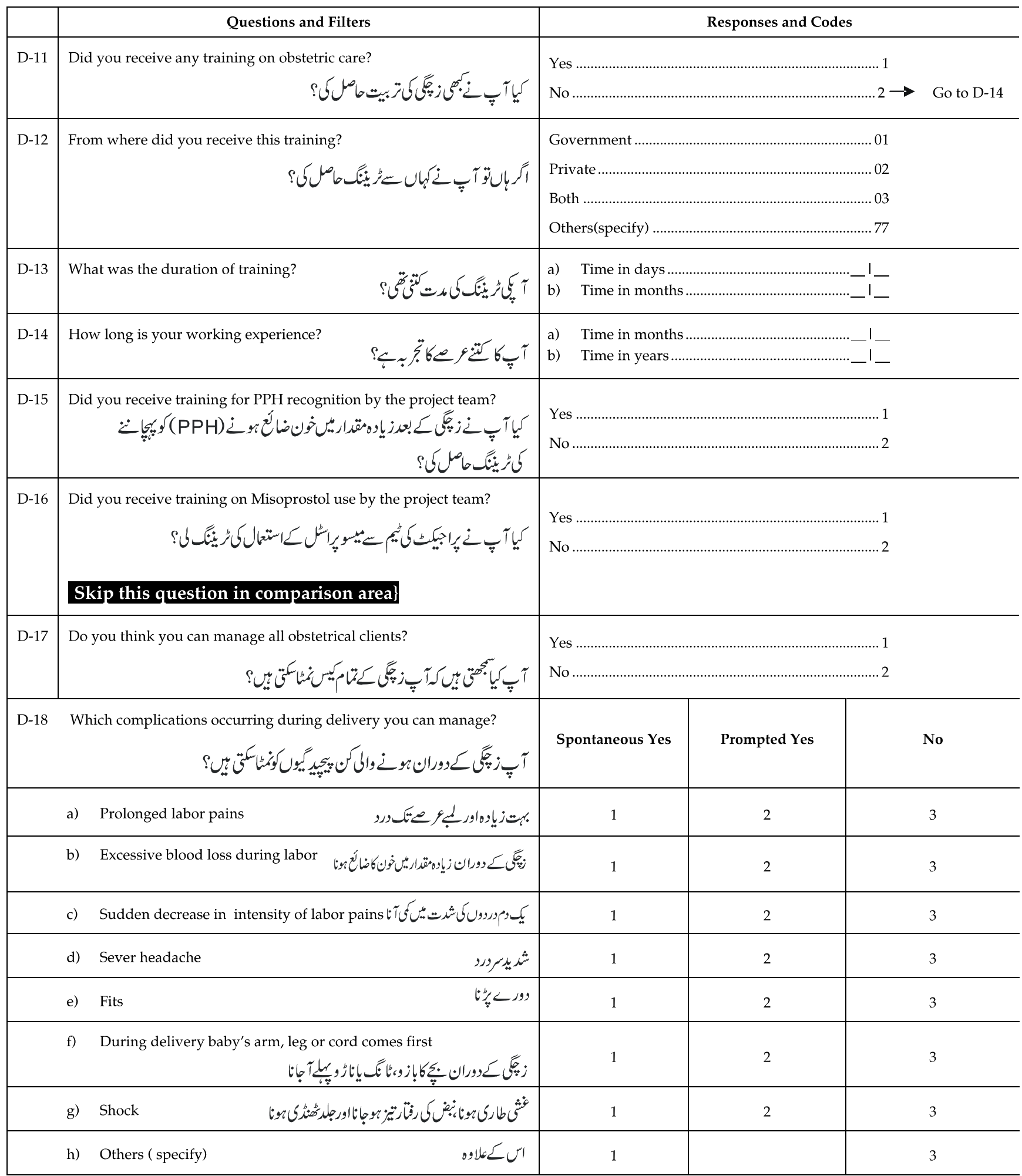




\begin{tabular}{|c|c|c|c|c|}
\hline D-19 & $\begin{array}{l}\text { Do you know what complications can occur during postpartum? } \\
\text { period? } \\
\text { (Multiple responses are allowed) }\end{array}$ & \multicolumn{3}{|c|}{ 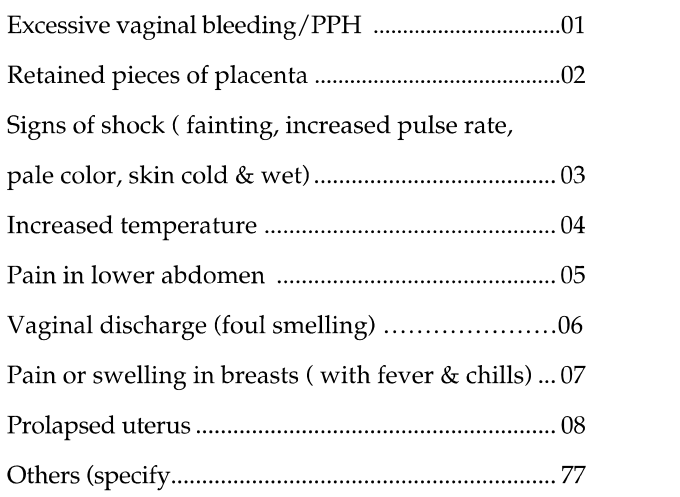 } \\
\hline D-20 & 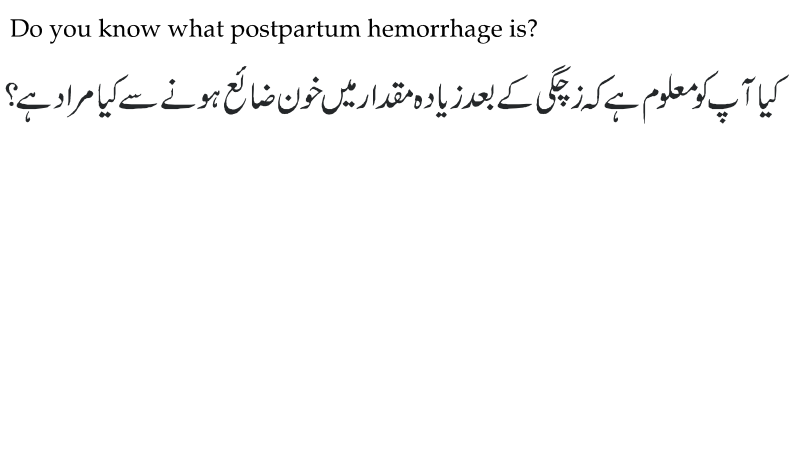 & \multicolumn{3}{|c|}{ 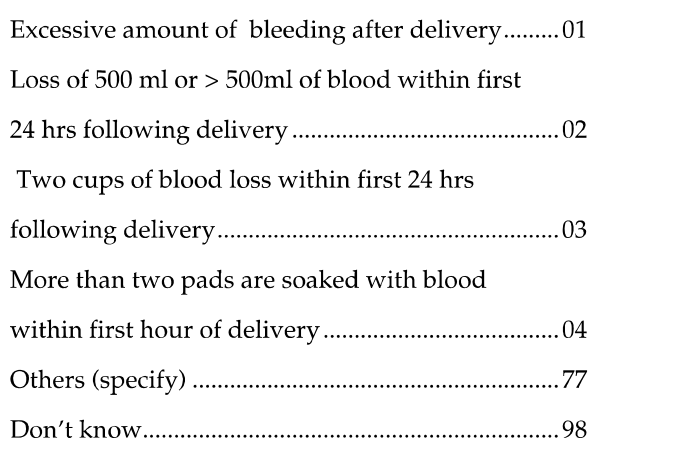 } \\
\hline $\mathrm{D}-21$ & $\begin{array}{l}\text { Which complications occuring during postpartum period you can } \\
\text { manage? }\end{array}$ & Spontaneous Yes & Prompted Yes & No \\
\hline & Excessive vaginal bleeding/PPH & 1 & 2 & 3 \\
\hline & Retained pieces of placenta & 1 & 2 & 3 \\
\hline & Signs of shock ( fainting, increased pulse rate & 1 & 2 & 3 \\
\hline & pale color, skin cold \& wet) & 1 & 2 & 3 \\
\hline & Increased temperature & 1 & 2 & 3 \\
\hline & Pain in lower abdomen & 1 & 2 & 3 \\
\hline & Vaginal discharge (foul smelling) & 1 & 2 & 3 \\
\hline & Pain or swelling in breasts ( with fever \& chills) & 1 & 2 & 3 \\
\hline & Prolapsed uterus & 1 & 2 & 3 \\
\hline & Others (specify77) & 1 & 2 & 3 \\
\hline
\end{tabular}




\begin{tabular}{|c|c|c|}
\hline D-22 & $\begin{array}{l}\text { Do you think there are any obstetrical complications which need } \\
\text { referral to health facility? }\end{array}$ & Yes \\
\hline D-23 & 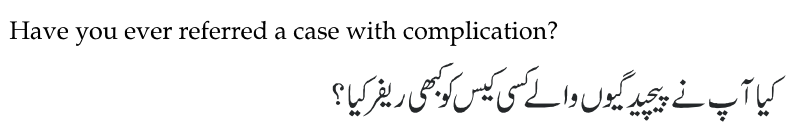 & No \\
\hline D-24 & $\begin{array}{l}\text { What was the reason for referral? } \\
\text { (Multiple responses are allowed) }\end{array}$ & 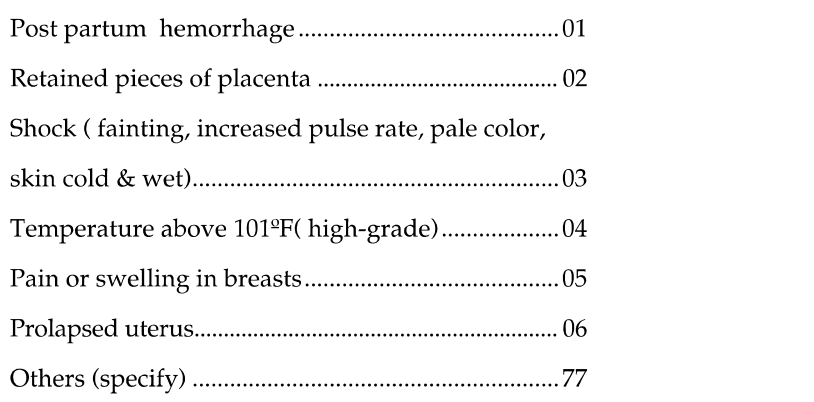 \\
\hline D-25 & Are you linked with any referral health facility? & Yes \\
\hline D-26 & $\begin{array}{l}\text { In case of complications, how women are taken to the health facility in } \\
\text { your area? }\end{array}$ & 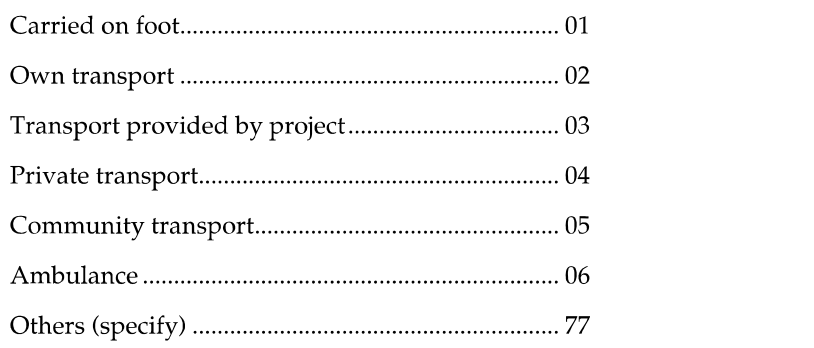 \\
\hline
\end{tabular}




\section{Knowledge and Feasibility regarding use of Misoprostol by Birth Attendant}

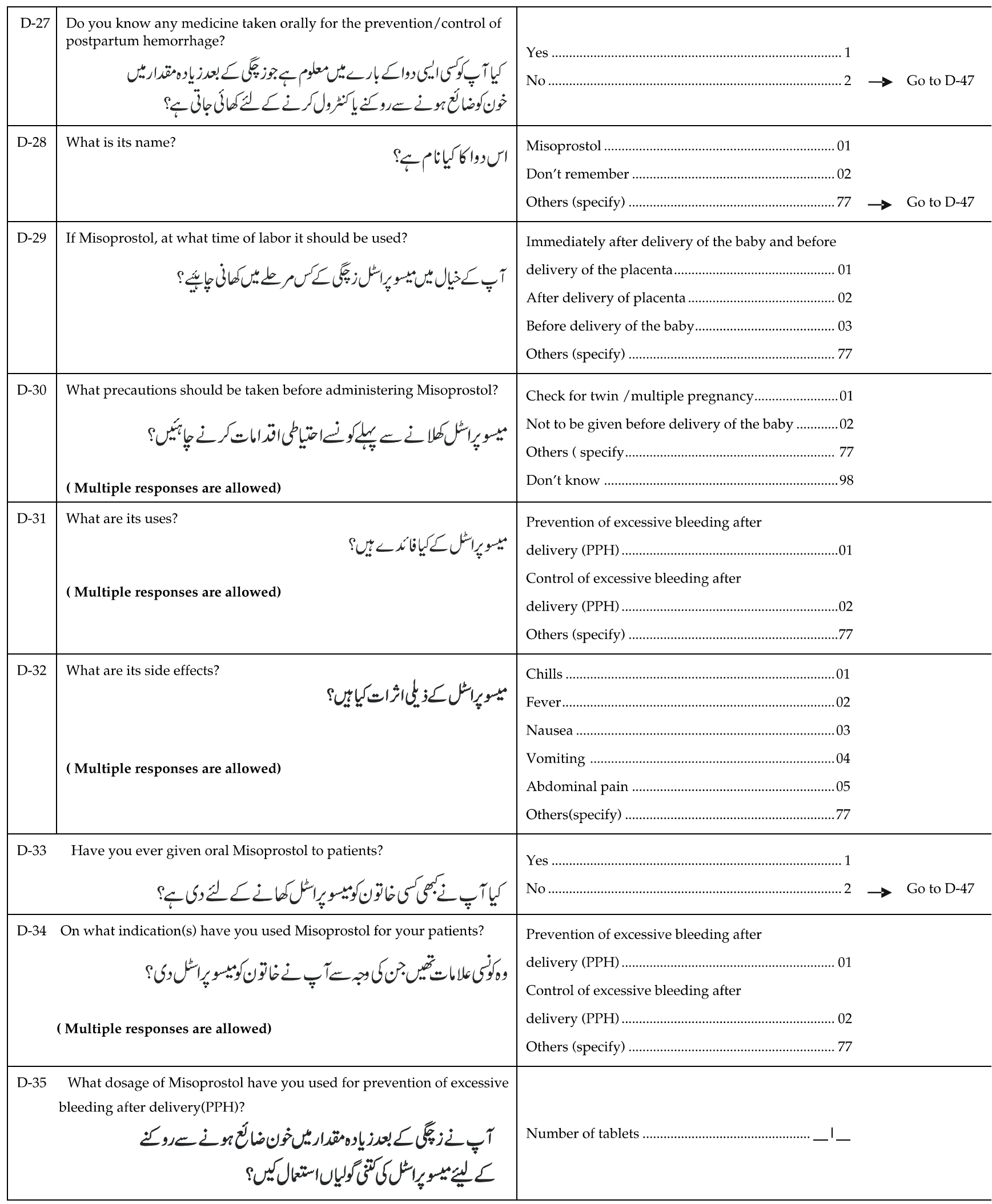




\begin{tabular}{|c|c|c|}
\hline D-36 & Do you think that the present availability of Misoprostol is sufficient? & Yes \\
\hline D-37 & What route of administration do you use for prevention of PPH? & Oral \\
\hline D-38 & Do all patients who need treatment with Misoprostol get it? & Yes \\
\hline D-39 & Where did you get the information you have on Misoprostol? & 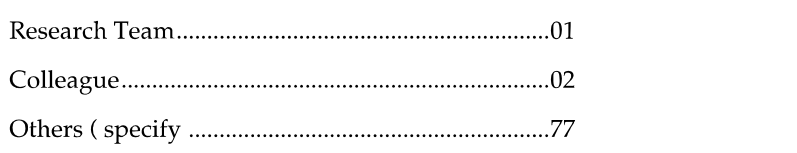 \\
\hline D-40 & Do you feel confident in using Misoprostol? & Yes \\
\hline D-41 & $\begin{array}{l}\text { What are the barriers in its administration? } \\
\text { (Multiple responses are allowed) }\end{array}$ & 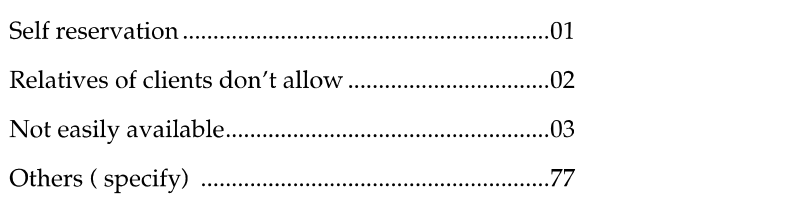 \\
\hline D-42 & $\begin{array}{l}\text { Have you experienced any side effects due to treatment with } \\
\text { Misoprostol? } \\
\qquad \text { S. }\end{array}$ & Yes $N$ No \\
\hline D-43 & $\begin{array}{l}\text { If yes, what were the side effects? } \\
\text { ( Multiple responses are allowed) }\end{array}$ & Fever \\
\hline D-44 & What is your over-all experience from using Misoprostol? & Very good \\
\hline D-45 & Would you like to advice others to take these tablets? & Yes No \\
\hline D-46 & Do you have any suggestions to improve its administration? & \\
\hline
\end{tabular}




\section{Experience of conducting last delivery of registered woman}

\begin{tabular}{|c|c|c|}
\hline D-47 & 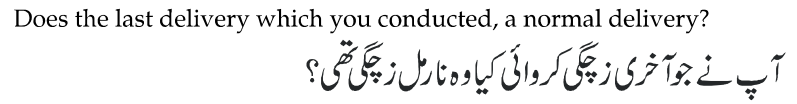 & No \\
\hline D-48 & $\begin{array}{l}\text { If no, what were the complications? } \\
\text { (Multiple responses are allowed) }\end{array}$ & 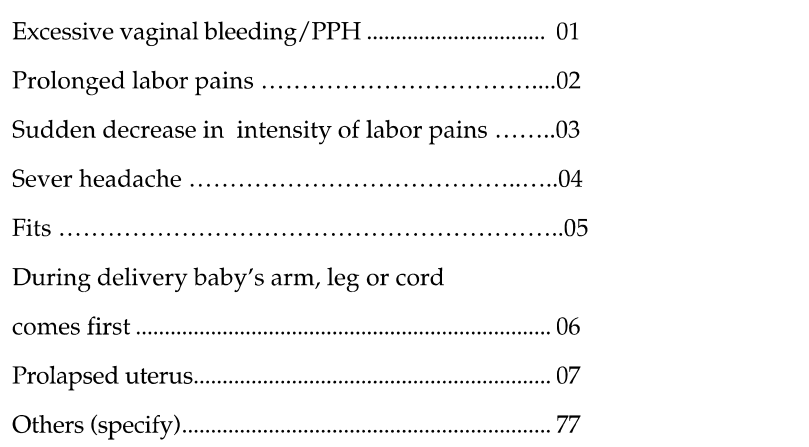 \\
\hline D-49 & Did you referred the woman for complications? & No \\
\hline D-50 & 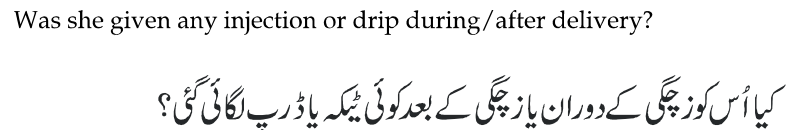 & No \\
\hline D-51 & If yes, at what time this was given? & 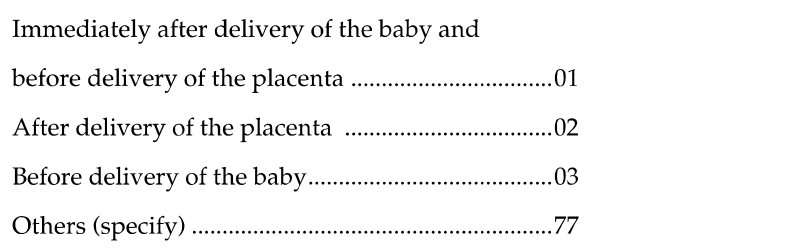 \\
\hline D-52 & What was the name of this injection? & $\begin{array}{l}\text { Synto/ oxytocin } \\
\text { Any other name } \\
\text { Others (specify) }\end{array}$ \\
\hline D-53 & Who gave the injection? & Herself \\
\hline D-54 & Why this injection or drip was given? & $\begin{array}{l}\text { For prevention of PPH } \\
\text { For Control of PPH } \\
\text { To augments labor pains } \\
\text { Others (specify) }\end{array}$ \\
\hline
\end{tabular}




\begin{tabular}{|c|c|c|}
\hline D-55 & If not referred, why? & 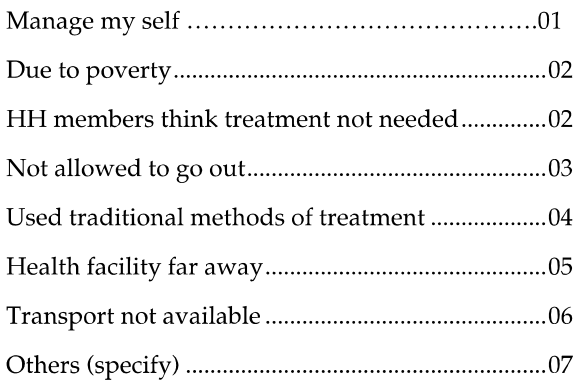 \\
\hline
\end{tabular}

(End Interview in comparison area) 


\section{Only for Intervention Area}

\begin{tabular}{|c|c|c|}
\hline D-56 & Was she given oral Misoprostol? & 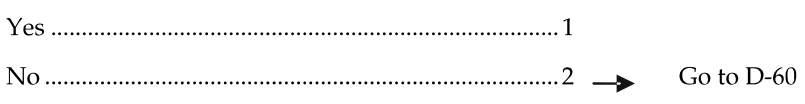 \\
\hline D-57 & At what time of labor it was given? & 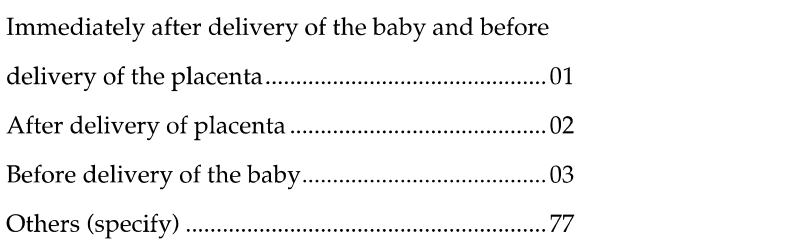 \\
\hline D-58 & 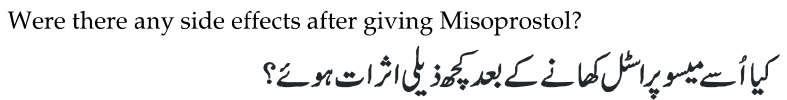 & 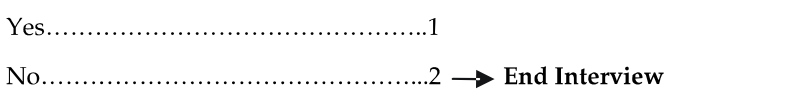 \\
\hline D-59 & $\begin{array}{l}\text { If yes, what were those? } \\
\text { (Multiple responses are allowed) }\end{array}$ & Fever \\
\hline D-60 & $\begin{array}{l}\text { If not given oral Misoprostol, why? } \\
\text { (Multiple responses are allowed) }\end{array}$ & 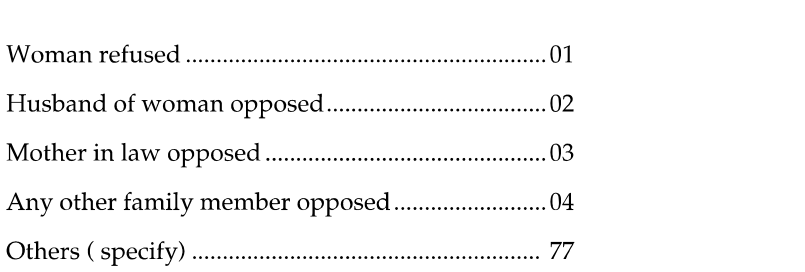 \\
\hline
\end{tabular}


Processing Code

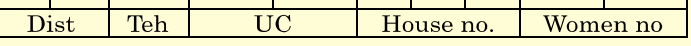

Pakistan Initiative for Mothers and Newborns (PAIMAN)

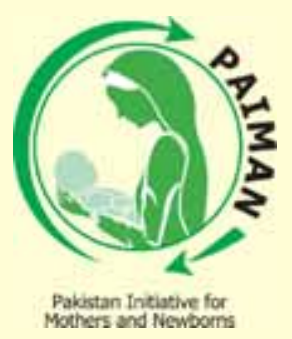

Assessing the feasibility of home administration of Misoprostol in the prevention of PPH in rural Pakistan An OR Study

\section{Post Partum Interview (E)}

(Relative / kin present at the time of delivery)

\section{Population Council}




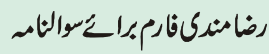

\section{(Intervention Area)}

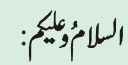

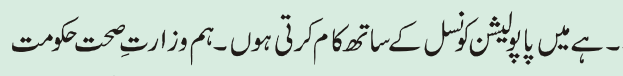

كيران

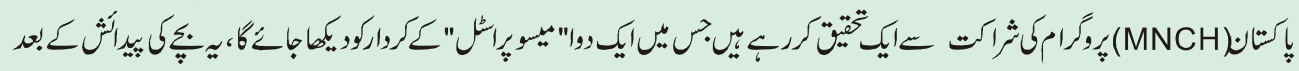

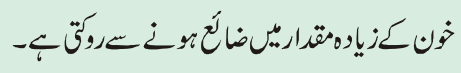

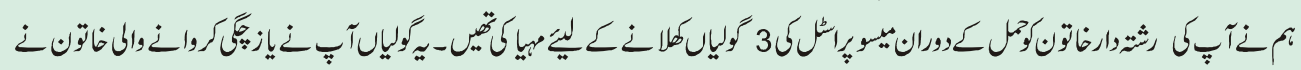

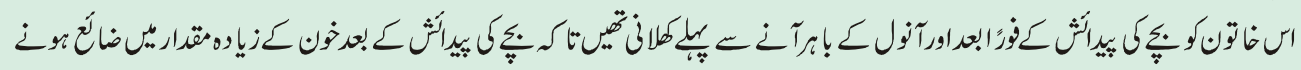
كورب6

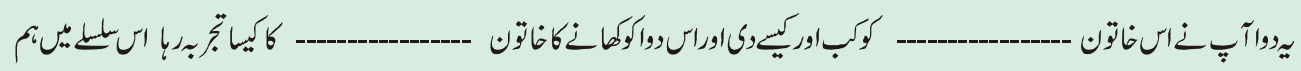

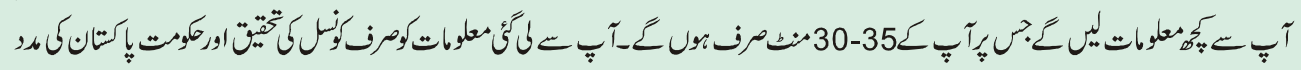

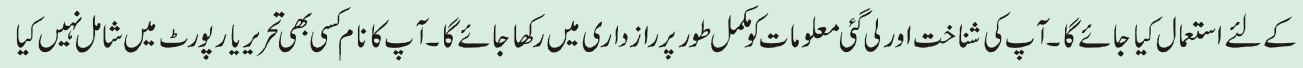
$-6<$ ?

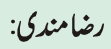

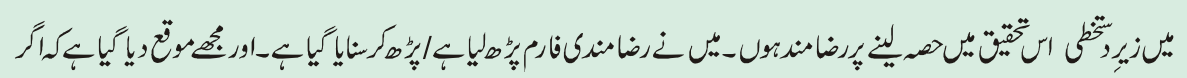



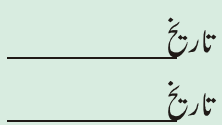

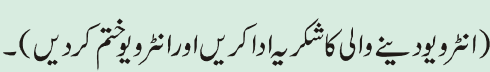

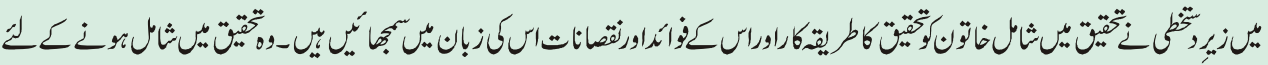
تارت

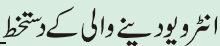

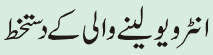

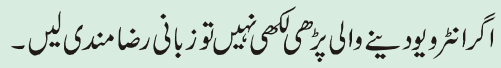
"in

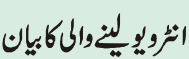

رضامندبك-

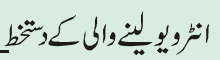




\section{Identification}

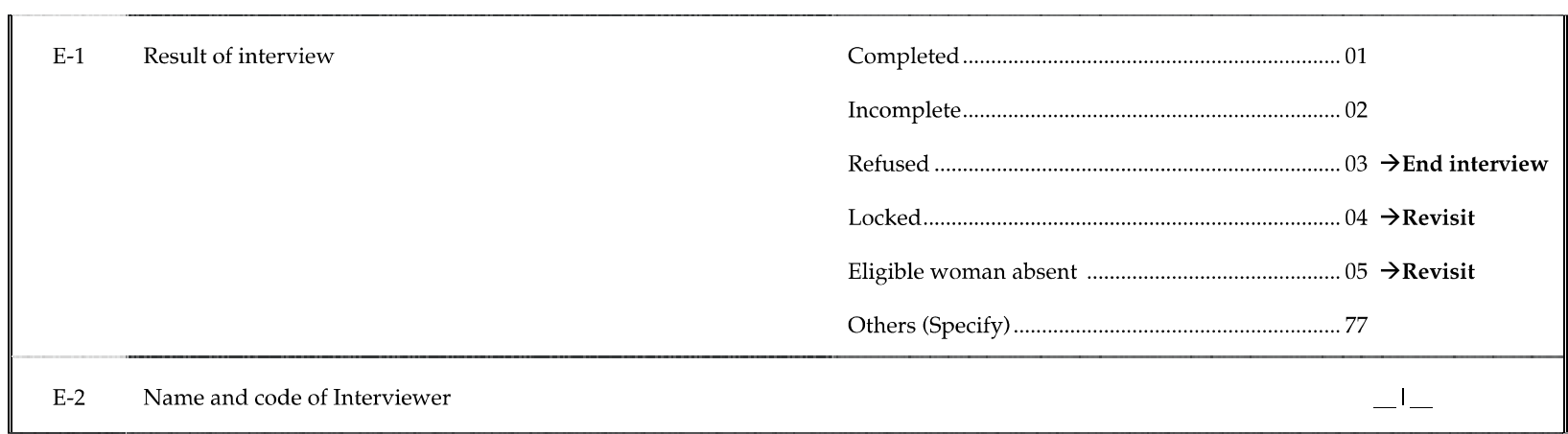




\section{History of last Pregnancy and Post partum period (from relative/kin)}

\begin{tabular}{|c|c|c|}
\hline & Questions and Filters & Responses/codes \\
\hline E-3 & Was she given any oral tablets during /after delivery? & 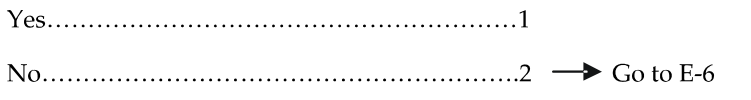 \\
\hline E-4 & If oral tablets given, what was the name of tablet? & 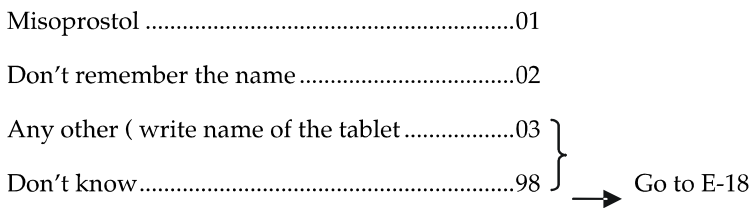 \\
\hline E-5 & How much tablets were given? & Number of tablets........................................... \\
\hline E-6 & If not given, why? & Woman was afraid to take it \\
\hline E-7 & At what time of labor they were given? & 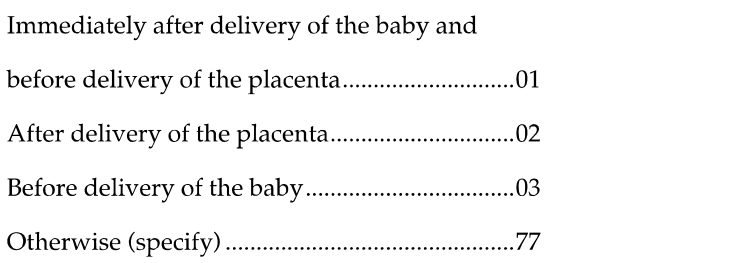 \\
\hline E-8 & Do you know why these tablets were given? & 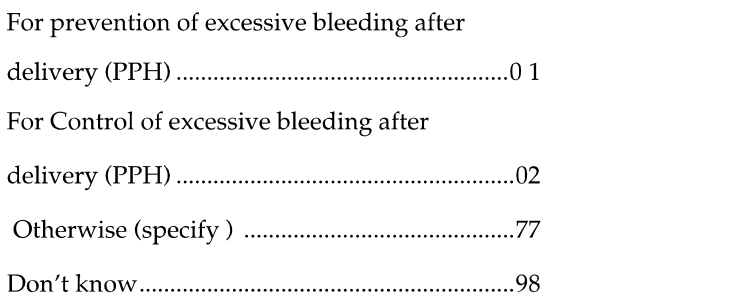 \\
\hline E-9 & Who supplied these tablets at her home? & Birth attendant \\
\hline E-10 & Who gave her the tablets to ingest? & Birth attendant \\
\hline
\end{tabular}




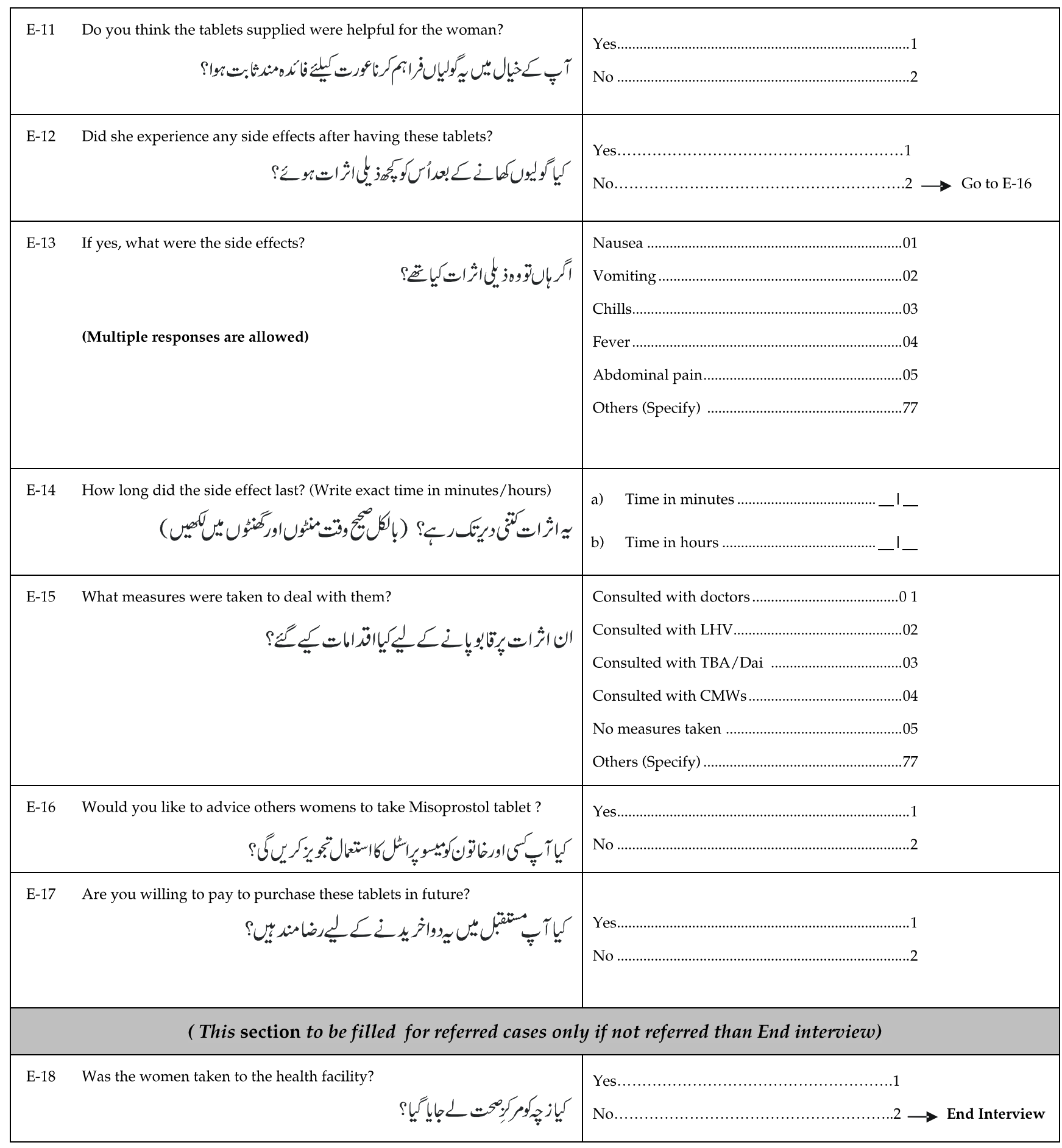




\begin{tabular}{|c|c|c|}
\hline E-19 & $\begin{array}{l}\text { If woman was referred, what was the reason for referral to the health } \\
\text { facility? } \\
\text { (Multiple responses are allowed) }\end{array}$ & 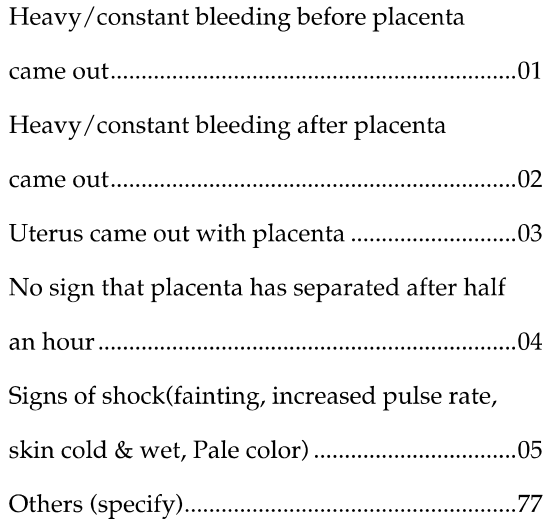 \\
\hline $\mathrm{E}-20$ & 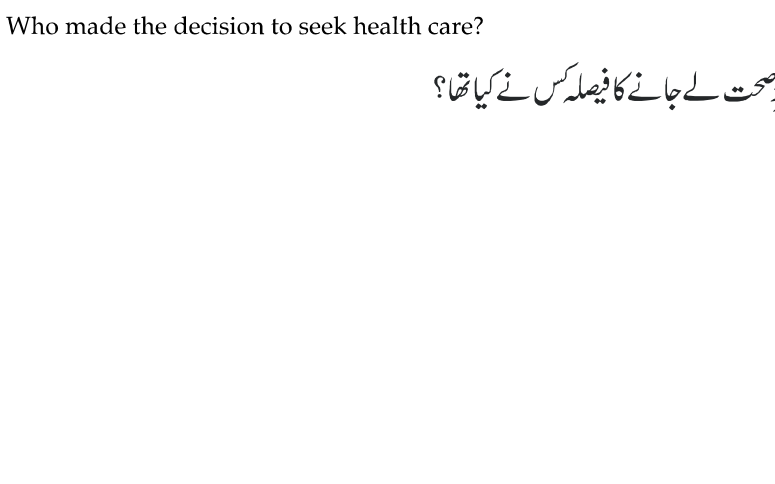 & Homan herself \\
\hline $\mathrm{E}-21$ & What was the mode of transport used to reach the health facility? & 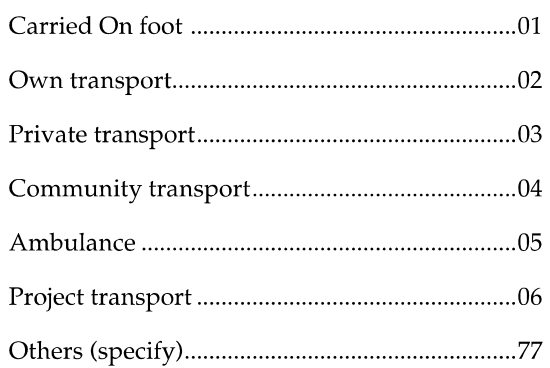 \\
\hline $\mathrm{E}-22$ & How long did it take her to reach health facility? & 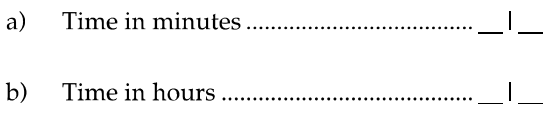 \\
\hline $\mathrm{E}-23$ & $\begin{array}{l}\text { How much time did it take to receive any treatment after reaching at } \\
\text { health facility? }\end{array}$ & 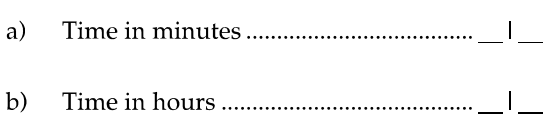 \\
\hline E-24 & What was the duration of her stay at the health facility? & a) Time in hours ..................................... \\
\hline E-25 & What was the result of this treatment? & 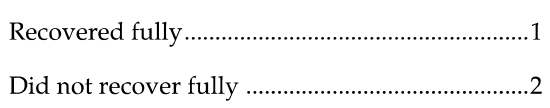 \\
\hline
\end{tabular}

